\title{
Spatial variation in brook trout (Salvelinus fontinalis ) population dynamics and juvenile recruitment potential in an Appalachian watershed
}

Zachary W. Liller

West Virginia University

Follow this and additional works at: https://researchrepository.wvu.edu/etd

\section{Recommended Citation}

Liller, Zachary W., "Spatial variation in brook trout (Salvelinus fontinalis ) population dynamics and juvenile recruitment potential in an Appalachian watershed" (2006). Graduate Theses, Dissertations, and Problem Reports. 2360.

https://researchrepository.wvu.edu/etd/2360

This Thesis is protected by copyright and/or related rights. It has been brought to you by the The Research Repository @ WVU with permission from the rights-holder(s). You are free to use this Thesis in any way that is permitted by the copyright and related rights legislation that applies to your use. For other uses you must obtain permission from the rights-holder(s) directly, unless additional rights are indicated by a Creative Commons license in the record and/ or on the work itself. This Thesis has been accepted for inclusion in WVU Graduate Theses, Dissertations, and Problem Reports collection by an authorized administrator of The Research Repository @ WVU. For more information, please contact researchrepository@mail.wvu.edu. 
Spatial Variation in Brook Trout (Salvelinus fontinalis) Population Dynamics and Juvenile Recruitment Potential in an Appalachian Watershed

\title{
Zachary W. Liller
}

\author{
A Thesis \\ Submitted to the \\ Davis College of Agriculture, Forestry, and Consumer Sciences \\ at West Virginia University \\ in partial fulfillment of the requirements \\ for the degree of \\ Masters of Science \\ In \\ Wildlife and Fisheries Resources
}

\author{
J. Todd Petty, Ph.D., Chair \\ Stuart A. Welsh, Ph.D. \\ Robert H. Hilderbrand, Ph. D \\ Wildlife and Fisheries Program of the Division of Forestry \\ Morgantown, West Virginia \\ 2006
}

Keywords: Brook Trout, Recruitment, Population Dynamics, Metapopulation, Distribution, Dispersal, Shavers Fork 


\begin{abstract}
Spatial Variation in Brook Trout (Salvelinus fontinalis) Population Dynamics and Juvenile Recruitment Potential in an Appalachian Watershed
\end{abstract}

\title{
Zachary W. Liller
}

I examined the spatial variation in brook trout population dynamics and juvenile recruitment potential in the upper Shavers Fork watershed, West Virginia. The objectives of my research were to (1) identify physico-chemical factors contributing to the spatial variation in the abundance of juvenile brook trout within small basin area stream reaches, (2) quantify patterns of brook trout distribution, movement, and post reproductive demographic parameters across multiple spatial scales, and (3) place the upper Shavers Fork watershed brook trout population along the continuum of watershed-scale metapopulation models. I sampled brook trout population size structure, physical habitat, and water chemistry at the reach- and watershedscale. The results of my research showed that (1) both water quality and physical habitat influenced the spatial variation in juvenile recruitment potential within small basin area stream reaches (2) small basin area tributary networks played an important role in structuring the upper Shavers Fork brook trout population, and (3) the brook trout population within the upper Shavers Fork watershed reflects a complex mosaic of elements found in metapopulation, source-sink and patchy population models. 


\section{Acknowledgments}

I would first like to thank the members of my graduate committee Dr. J. Todd Petty, Dr. Stuart Welsh, and Dr. Robert Hilderbrand for their contribution to this project. I would especially like to thank Todd Petty for the invaluable opportunities, guidance, encouragement, and enthusiasm he has provided during both my undergraduate and graduate careers. Thanks goes to Dr. Jason Freund, and David Thorne for help in the initial stages of this work. George Seidel, George Merovich, Roy Martin, and Jennifer Fulton provided valuable assistance with the analytical phases of this project. Special thanks goes out to all those who contributed in the collection of this data, day in and day out these people got up ate their donut and went to work. Specifically I want to thank: Jason Clingerman, Anthony Grubb, Mike Nicholas, Lora Tennant, Travis Bowman, Lee Haggarty, Logan Wamsley, Zachary Golightly, Seth Lemley, Jennifer Fulton, Ira Poplar-Jeffers, Zina Hense, George Merovich, Roy Martin, Sarah McClurg, Jason Freund, Brandon Keplinger, Todd Petty, and Heather Hildebrand. Extra special thanks goes to Heather Hildebrand for her support and encouragement during the final and most stressful phases of this project. Finally, I would like to thank my family, especially my grandparents Harold and Jean Hite, for their unending support. 


\section{Table of Contents}

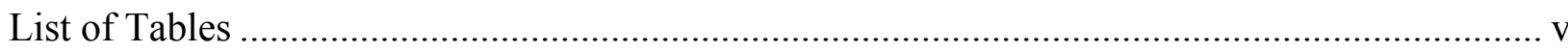

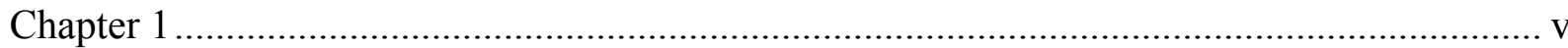

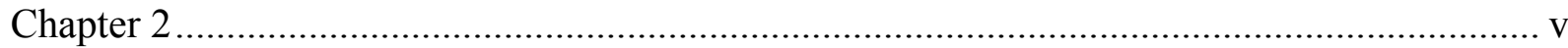

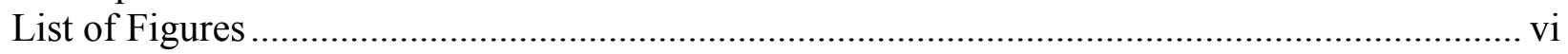

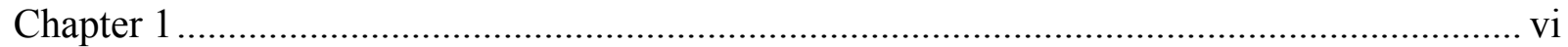

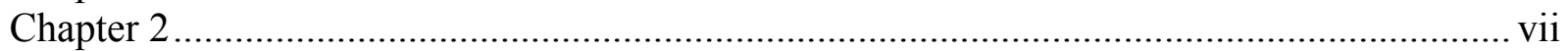

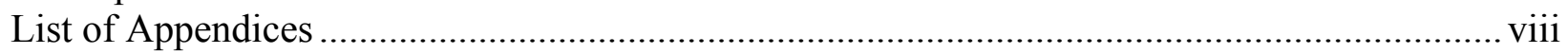

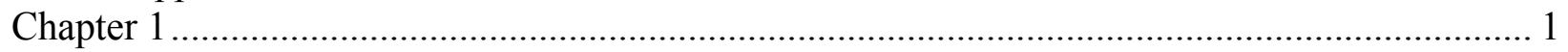

Physico-chemical Factors Influencing the Spatial Variation in Juvenile Brook Trout (Salvelinus fontinalis) Recruitment in an Appalachian Watershed ........................................ 1

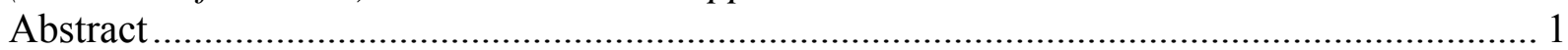

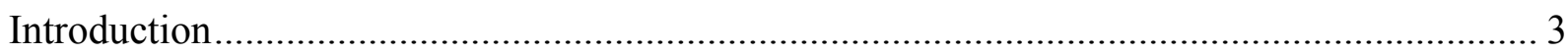

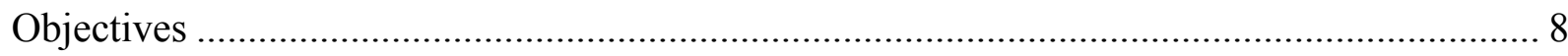

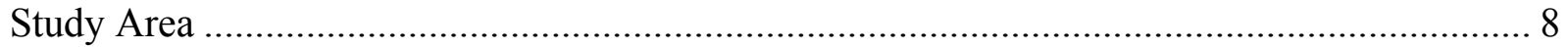

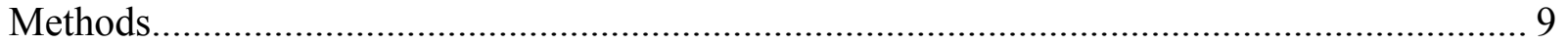

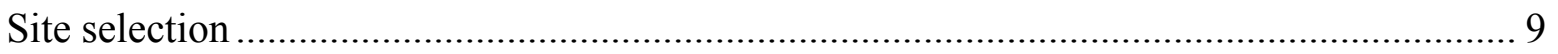

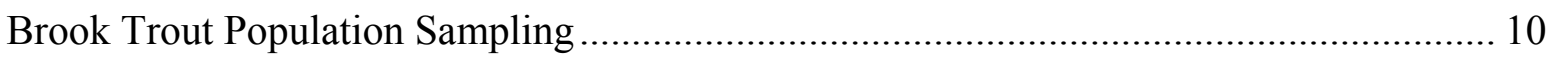

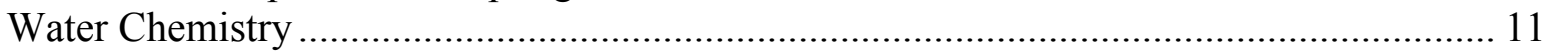

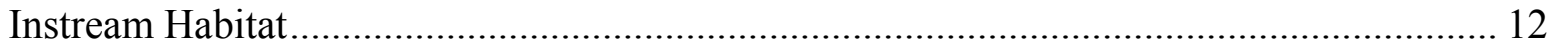

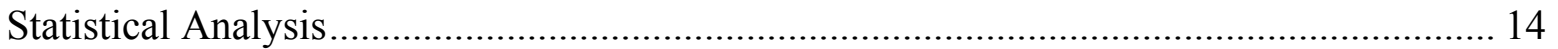

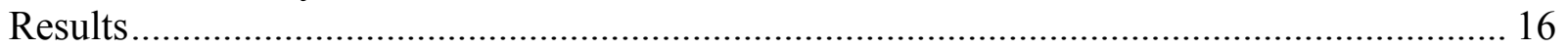

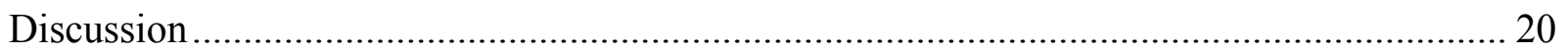

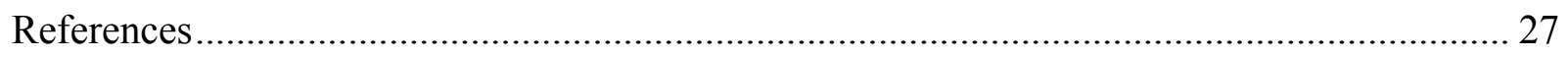

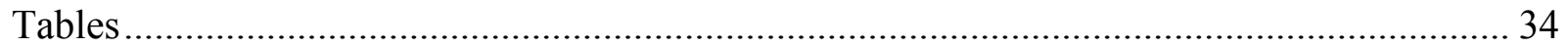

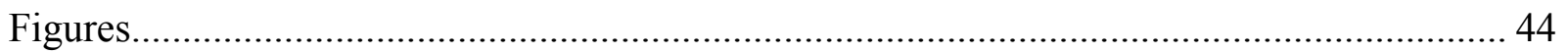

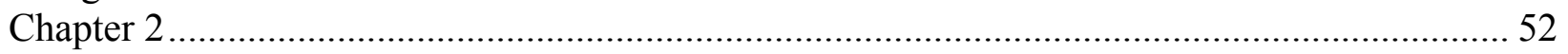

Spatial Variation in Brook Trout (Salvelinus fontinalis) Population Dynamics in an

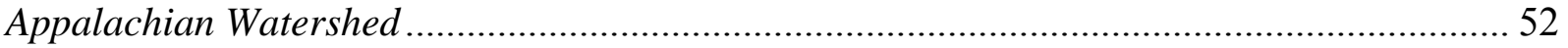

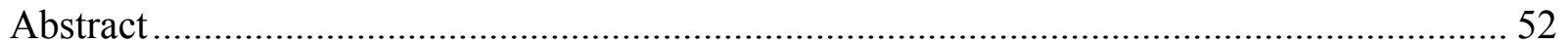

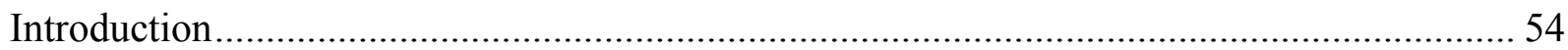

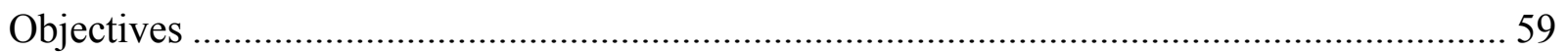

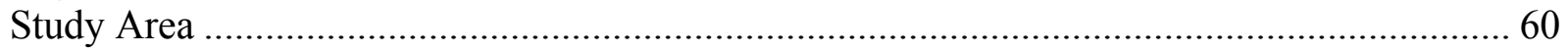

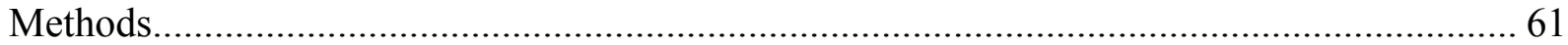

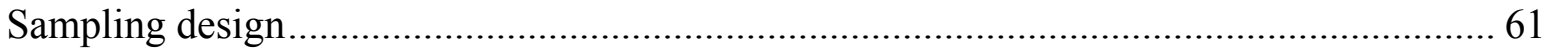

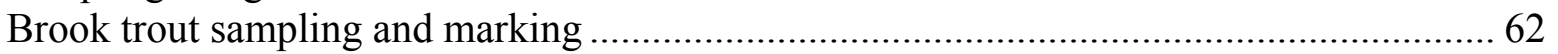

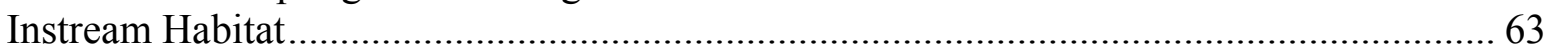

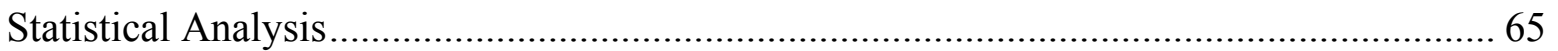

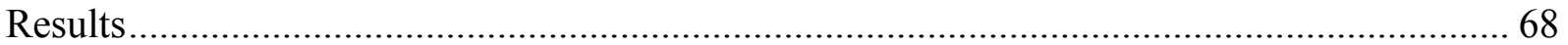

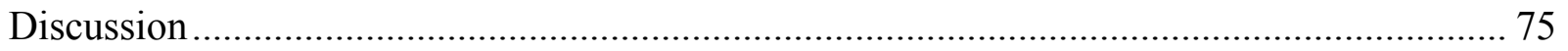

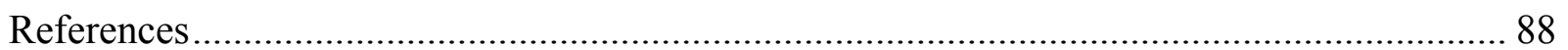

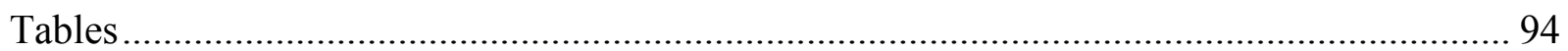

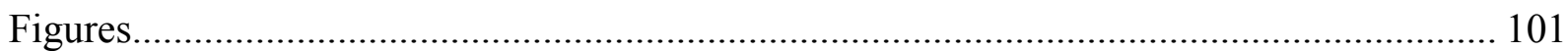

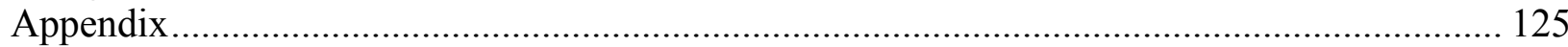

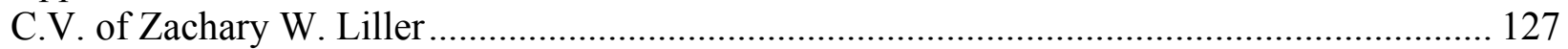




\section{List of Tables}

\section{Chapter 1}

Table 1. Summary characteristics of 34 sample sites within the upper Shavers Fork watershed.

Table 2. Factor loading scores for the dominant instream physical and chemical habitat gradients derived from 29 perennial study reaches within the upper Shavers Fork watershed.

Table 3. Summary results of the multiple regression analysis relating juvenile brook trout density to principle component scores, canopy cover, and adult brook trout density across 29 perennial study reaches.

Table 4. Summary results of the multiple regression analysis relating juvenile brook trout density to principle component scores, canopy cover, and adult brook trout density across 24 perennial study reaches with "good" water quality.

Table 5. Results of ANOVA on mean physical and chemical characteristics for the 4 relative juvenile density groups as identified by hierarchal classification.

Table 6. Juvenile brook trout summary statistics for each of the 4 relative juvenile density groups as identified by hierarchal classification.

Table 7. Summary results of the linear discriminant function analysis used to discriminate between the 4 relative juvenile density groups.

Table 8. Number of correctly classified sites from the linear discriminant function analysis used to discriminate between the 4 relative juvenile density groups.

Table 9. Summary results of the linear discriminant function analysis used to discriminate between the 3 relative juvenile density groups with "good" water quality.

Table 10. Number of correctly classified sites from the linear discriminant function analysis used to discriminate between the 3 relative juvenile density groups with "good" water quality.

\section{Chapter 2}

Table 1. Summary of brook trout mark-recapture data.

Table 2. Factor loading scores for the dominant instream physical habitat gradients derived from 86 perennial stream reaches within the upper Shavers Fork watershed.

Table 3. Summary results of the multiple regression analysis relating the proportional 
abundance of juveniles, small adults, and large adults to principle components of instream physical habitat, distance from main stem, and average $\mathrm{pH}$.

Table 4. Total number of juvenile, small adult and large adult brook trout originally marked in 1 of 15 small basin area stream networks and the percent that were found to have moved into and stayed within main stem habitat or moved into a different small basin area network.

Table 5. Seasonal mean, standard error, and ranges for small and large adult brook trout apparent survival, immigration rate, and population change across multiple spatial scales.

Table 6. Seasonal correlations between small and large adult brook trout apparent survival and dominant instream physical habitat gradients.

Table 7. Seasonal correlations between small and large adult brook trout immigration rates and dominant instream physical habitat gradients.

\section{List of Figures}

\section{Chapter 1}

Figure 1. Location of 34 study sites within the upper Shavers Fork watershed.

Figure 2. Brook trout length-frequency histogram used to classify all captured individuals into one of three size classes.

Figure 3. Relationship between the observed cumulative percent of juvenile brook trout density and the expected pattern based on the accumulation of available stream segments along a continuum of basin area.

Figure 4. Relationships between the major physical habitat gradients characterizing the perennial study reaches within the upper Shavers Fork watershed.

Figure 5. Relationships between the major chemical habitat gradients characterizing the perennial study reaches within the upper Shavers Fork watershed.

Figure 6. Relationships between $\mathrm{pH}$, alkalinity, monomeric $\mathrm{Al}^{+3}$, and juvenile brook trout density within 29 perennial stream reaches of the upper Shavers Fork watershed.

Figure 7. Mean canonical scores used to discriminate between the 4 relative juvenile density groups as identified by hierarchical clustering.

Figure 8. Mean canonical scores used to discriminate between the 3 relative juvenile density groups with "good" water quality as identified by hierarchical clustering. 


\section{Chapter 2}

Figure 1. Location of the dominant watershed-scale metapopulation models along a continuum of between patch variability in demographic rates and dispersal rates.

Figure 2. Representation of the current knowledge of the upper Shavers Fork brook trout population.

Figure 3. Location of the three study regions within the upper Shavers Fork watershed.

Figure 4. Seasonal brook trout length-frequency histograms used to classify all captured individuals into one of three size classes.

Figure 5. Season-to-season correlation of juvenile, small adult, and large adult proportional abundance across all sites.

Figure 6. Average proportional abundance of juvenile, small, and large adult brook trout across the available range of stream sizes.

Figure 7. Ratio of the average observed number of juvenile, small adult and large adult brook trout to that expected based on the total area of stream across a range of basin area.

Figure 8. Size-class-to-size-class correlations across all sites.

Figure 9. Average proportional abundance of brook trout within each size-class relative to reach specific physical habitat parameters.

Figure 10. Average proportional abundance of brook trout within each size-class relative to the dominant instream physical habitat gradients characterizing small basin area tributaries.

Figure 11. Temporal variation in the proportion of small adult recaptures relative to their direction and magnitude of movement within all small basin area stream networks.

Figure 12. Temporal variation in the proportion of large adult recaptures relative to their direction and magnitude of movement within all small basin area stream networks.

Figure 13. Percent of juvenile, small adult, and large adult brook trout originally marked in 1 of 15 small basin area stream networks that were found to have moved into and stayed within main stem habitat or moved into different small basin area network.

Figure 14. Season-to-season correlation of small and large adult apparent survival at the tributary network, tributary reach, and main stem reach scales. 
Figure 15. Seasonal relationships between small adult apparent survival and dominant instream physical habitat gradients.

Figure 16. Seasonal relationships between large adult apparent survival and dominant instream physical habitat gradients.

Figure 17. Season-to-season correlations of small and large adult immigration rates at the tributary network, tributary reach, and main stem reach scales.

Figure 18. Seasonal relationships between small adult immigration rates and dominant instream physical habitat gradients.

Figure 19. Seasonal relationships between large adult immigration rates and dominant instream physical habitat gradients.

Figure 20. Seasonal reach-to-reach variation in small adult population change.

Figure 21. Seasonal reach-to-reach variation in large adult population change.

Figure 22. Seasonal small adult brook trout population growth within 15 small basin area watersheds and 5 main stem reaches.

Figure 23. Seasonal large adult brook trout population growth within 15 small basin area watersheds and 5 main stem reaches.

Figure 24. Representation of the degree of connectivity between brook trout habitat patches within the upper Shavers Fork watershed.

\section{List of Appendices}

Appendix 1. Site names and northing and easting coordinates (NAD 83, UTM zone 17) for 34 sample sites located in the upper Shavers Fork watershed used to determine the role of physico-chemical habitat parameter on juvenile brook trout recruitment. 


\title{
Chapter 1
}

Physico-chemical Factors Influencing the Spatial Variation in Juvenile Brook Trout (Salvelinus fontinalis) Recruitment in an Appalachian Watershed

\begin{abstract}
Studies relating salmonid recruitment to physico-chemical stream characteristics are common, yet such studies are surprisingly rare in central Appalachian brook trout populations. Consequently our objectives were to quantify spatial variation in juvenile brook trout recruitment within the upper Shavers Fork watershed and relate this variability to local physico-chemical features. We focused on relatively small streams near mainstem habitat. The upper Shavers Fork is a $5^{\text {th }}$ order, high elevation watershed located in the Allegheny Plateau region of eastern West Virginia. Recent research within this watershed suggests that the brook trout population is currently limited at the watershed-scale by juvenile recruitment and access to high quality foraging habitat. Given that brook trout within this region have been shown to concentrate reproductive efforts within stream reaches with a basin area $<3 \mathrm{~km}^{2}$ our overriding objective was to identify physico-chemical factors contributing to the spatial variation in the abundance of juvenile brook trout within small basin area streams. Specifically we wanted to (1) further quantify the details of the relationship between juvenile brook trout recruitment and basin area within small basin area streams and (2) identify specific physical and chemical characteristics of small basin area tributaries that are related to juvenile brook trout recruitment success. Brook trout population size and age structure, water quality, and physical habitat where sampled within 34 small basin area $\left(<3 \mathrm{~km}^{2}\right)$ tributaries that drained within $1 \mathrm{~km}$ of the Shavers Fork main stem. Spatial variation in juvenile abundance was influenced by both physical and chemical characteristics. We determined that the most important streams to juvenile brook trout recruitment in this watershed were very small perennial systems $\left(<0.5 \mathrm{~km}^{2}\right)$ with spring $\mathrm{pH}$
\end{abstract}


exceeding 5.0, spring alkalinity exceeding $2.0 \mathrm{mg} / \mathrm{L} \mathrm{CaCO}_{3}$, a relatively homogenous depth profile, and a high availability of stream margin. Despite the importance of these local habitat factors to brook trout reproduction, a significant amount of variation in juvenile abundance could not be explained. This finding suggests that juvenile brook trout distributions may be influenced by local physico-chemical conditions as well as broader, watershed-scale processes. 


\section{Introduction}

The study of fish population ecology is largely centered on the identification of factors influencing the spatial and temporal patterns of individuals across the landscape. Populations are regulated by rates of additions (birth and immigration) and losses (death and emigration) that reflect the suite of biotic and abiotic factors that make up an organism's habitat (Pulliam 1988). The specific mechanisms (e.g. changes in survival, recruitment, and emigration) responsible for population regulation are often difficult to identify (Grossman et al. 2006). However, studies conducted over the last decade show that several processes influence the abundance of populations and these processes vary in complexity and context (Pulliam and Danielson 1991, Turchin and Hanski 2001, Hixon et at. 2002, Grossman et al. 2006).

Processes considered capable of influencing fish population abundances can be classified as either density-dependent or density-independent (Grossman et al. 2006). It is generally believed that density-dependent forces are required to generate regulated populations (Murdoch 1994, Turchin 1995) and recent studies suggest that density-dependent mechanisms regulate many stream fish populations (Grant and Kramer 1990, Elliot 1994, Milner et al. 2003, Grossman et al. 2006). Conversely, populations controlled by density-independent processes (e.g. acidic episodes, floods, droughts) statistically mirror random-walk populations (Murdoch 1994). It is generally believed that density-dependent mechanisms operate at all places and times (Sale and Tolimieri 2000). Although, the strength of density-dependence is related to environmental factors operating in a density-independent way (Einum 2005), and the relative importance of each process to population dynamics may be context specific (Grossman et al. 2006). 
It is generally believed that density-dependent processes are strongest within stable environments, whereas density-independent processes dominate within highly stochastic systems. Streams are longitudinal mosaics of patchy habitats that vary at functionally relevant spatial and temporal scales (Vannote 1980, Schlosser 1991, Schlosser and Angermier 1995, Lake 2000, Fausch et al. 2002). Populations inhabiting patchy environments experience different levels of fitness or reproductive success as a result of variation in resource abundance and predation (Lewin 1989). Stream fishes exist within linear systems that are subject to spatially and temporally variable patterns of disturbance (Lake 2000). Consequently, stream fish populations are likely influenced predominately by density-independent processes (Grossman et al. 1998, Lobón-Cerviá 2004, Lobón-Cerviá and Rincón 2004).

Recruitment limitation is a unique case of density independence where population size is controlled by the abundance of young entering the population (Danilowicz 1997). Populations influenced by factors limiting recruitment experience fluctuations similar to those of completely density-independent populations, except for the presence of strong serial correlations reflecting year-class strength (Danilowicz 1997). Recruitment, in the broadest sense, is the addition of new individuals to a population or successive life-cycles within a population (Caley et al. 1996). The process of recruitment provides a link between birth rates and the dynamics of juvenile and adult components of populations (Knapp et al. 1998). Patterns of recruitment are commonly reflected in the age structure and distribution of adults (marine fishes: Doherty and Fowler 1994, Caley et al. 1996, Armsworth 2002, Sandin and Pacala 2005; freshwater fishes: Freeman et al. 1988, Beard and Carline 1991, Knapp et al. 1998, Lóbon-Cerviá and Rincón 2004), suggesting that recruitment dynamics can theoretically limit or regulate adult populations (Doherty 1981, Caley 1996). 
Stream dwelling salmonids are ecologically and economically valuable fish common within coldwater systems throughout the world. Stream-dwelling salmonids are highly susceptible to environmental change (Hicks et al. 1991). Over the past century many watersheds that support salmonids have experienced considerable alterations due to land use practices (e.g. coal and timber extraction, grazing) and development resulting in the decline of wild trout populations (Hicks et al. 1991). Consequently, considerable attention has been directed towards identifying factors that limit salmonid populations and the internal feedback mechanisms that operate on their population dynamics (Lóbon-Cerviá and Rincón 2004).

A variety of processes have been shown to influence salmonid populations. Salmonid populations are influenced by density-dependent processes, which typically affect survival in the early life stages due to predation, parasitism, disease, and intraspecific competition (Elliot 1994, Milner et al. 2003). Although evidence of density-dependence in salmonid populations exists, it is generally believed that, due to the highly variable nature of stream systems, the strength of density-dependent processes is low and stream-dwelling salmonids are predominately influenced by density-independent forces. In fact, several studies have indicated that stream-dwelling salmonids are recruitment limited and populations are strongly influenced by the availability of suitable reproductive habitat (Beard and Carline 1991, Bozek and Rahel 1991, Knapp et al. 1998, Petty et al. 2005). These studies show that salmonid population persistence at the watershedscale may be dependent on critical spawning habitats as a source of juvenile recruitment (Petty et al. 2005). The degree of dispersal from reproductive areas can vary considerably and seasonal dependency suggests that the distribution of stream dwelling salmonids is in part influenced by the distribution of their spawning habitat. Consequently, a clear understanding of factors 
influencing salmonid reproduction and survival of early life stages is necessary to understanding their distribution and dynamics at the watershed-scale (Fausch et al. 2002).

Spawning habitat of stream-dwelling salmonids are non-substitutable areas, (Dunning et al. 1992) which vary spatially within stream networks and play a critical role in determining patterns of recruitment and ultimately juvenile and adult distribution and abundance (Beard and Carline 1991, Bozek and Rahel 1991, Knapp et al. 1998, Petty et al. 2005). Salmonids reproduce by constructing nests or redds in gravel sized substrate within well oxygenated alkaline waters. Consequently, factors such as substrate size (Beard and Carline 1991, Magee and McMahon 1996), groundwater inputs (Witzel and MacCrimmon 1983, Curry and Noakes 1995), water depth and velocity (Witzel and MacCrimmon 1983, Bernier-Bourgault and Magnan 2002), and water quality (Jordahl and Benson 1987, Mount et al. 1990, Fiss and Carline 1993) interact to determine patch-specific reproductive potential. Episodic high flows occurring at the time of egg development and emergence can limit recruitment through direct mortality and displacement (Montomery et al. 1999, Lóbon-Cerviá 2003, Lóbon-Cerviá 2004). Furthermore, proximity to low velocity margin habitat may influence the survival and recruitment of post-emergent young salmonids (Bozek and Rahel 1991). The relative importance of specific physico-chemical conditions required for successful reproduction of stream salmonids is variable and their mechanisms and consequences toward population dynamics is not well understood (LóbonCerviá and Rincón 2004).

The upper Shavers Fork watershed, located in the central Appalachian mountains of eastern West Virginia, provides a good example of the problems facing salmonid populations. Historically this watershed supported a rich native brook trout (Salvelinus fontinalis) fishery. Extensive timber harvesting and regionally high acid deposition combine to limit brook trout 
reproductive efforts to a few small basin area stream segments (Clayton et al. 1998, Petty et al. 2005). Recent research within the upper Shavers Fork watershed suggests that the brook trout population is currently limited at the watershed-scale by juvenile recruitment and access to high quality foraging habitat (Petty et al. 2005). Petty et al. (2005) found that nearly $80 \%$ of all spawning activity and juvenile recruitment within a $4^{\text {th }}$ order tributary basin of the upper Shavers Fork was concentrated within headwater stream segments draining less than $3 \mathrm{~km}^{2}$ with relatively good water quality (i.e. stream alkalinity $>10 \mathrm{mg} / \mathrm{L} \mathrm{CaCO}_{3}$ ) and ample instream cover. Furthermore, the spatial distribution of juvenile and small adult brook trout was temporally stable and significantly correlated with these high quality reproductive habitats. In contrast, large adult distribution was highly variable, but seasonally related to the spatial arrangement of reproductive habitat (Petty et al. 2005).

We know that reproductive success is an important determinant of brook trout distribution at the watershed-scale, and we know that brook trout reproduction within the upper Shavers Fork tends to be concentrated in small basin area tributaries. Approximately $46 \%$ of the total upper Shavers Fork watershed is drained by small basin area stream networks located within $1 \mathrm{~km}$ of the Shavers Fork main stem. Previous work within this drainage recognized the likely influence of these small tributary systems to the brook trout population (Goujot 2001, Bopp 2002, Thorne 2004, Hansbarger 2005, Petty et al. 2005). These small stream networks may provide critical reproductive habitat and a more immediate link between sources of juvenile recruitment and productive main stem habitat. If these small systems are important to the population dynamics of brook trout at the watershed-scale, then they could have serious implications for how managers allocate reclamation efforts in order to promote the recovery and persistence of the population. Unfortunately, we do not fully understand the range of recruitment 
potential or the specific characteristics of stream reaches that influence the degree of reproductive success within these small basin area tributaries.

\section{Objectives}

Given that brook trout have been shown to concentrate reproductive efforts in stream reaches with a basin area $<3 \mathrm{~km}^{2}$ our overriding objective was to identify physico-chemical factors contributing to the spatial variation in the abundance of juvenile brook trout. Specifically we wanted to (1) further quantify the details of the relationship between juvenile brook trout recruitment and basin area within small basin area streams and (2) identify specific physical and chemical characteristics of small basin area tributaries that are related to juvenile brook trout recruitment success.

\section{Study Area}

Our study area was located within a $30 \mathrm{~km}$ segment of the upper Shavers Fork watershed of the Cheat River, located in the Monongahela River basin. The upper Shavers Fork is a $5^{\text {th }}$ order $\left(139 \mathrm{~km}^{2}\right)$ high elevation $(>1000 \mathrm{~m})$ watershed located in Pocahontas and Randolph counties of West Virginia, on the eastern edge of the Appalachian Plateau physiographic province (Figure 1). The Shavers Fork main stem is a relatively low gradient $(<1 \%$ slope) system with a trellised drainage geometry consisting of a single main channel collecting numerous, high gradient, first and second-order tributaries. Additionally two third-order dendritic tributaries (First and Second Fork) comprising 26\% of the watershed drain into the main stem and effectively separate the watershed into 3 regions (below First Fork, between First and Second Fork, and above Second Fork) (Figure 1).

Our study was conducted within 34 first- and second-order tributaries draining into the upper Shavers Fork main stem (Figure 1). Each study site was located within $1 \mathrm{~km}$ of the 
Shavers Fork main stem and drained less than $3 \mathrm{~km}^{2}$. Consequently, study sites were characterized as having a high potential for brook trout reproduction and interaction with the larger main stem habitat. As a result of local variability in bedrock geology consisting of sandstone, shale, conglomerate, and coal (Waite et al. 2000) and regionally high acid precipitation (NADP 2000) studied reaches covered the full range of flow conditions, instream physical habitat, canopy cover, dissolved chemistry, slope, and basin area (Table 1). Brook trout were generally the only species present in studied streams; although, low numbers of mottled sculpin (Cottus bairdi), western blacknose dace (Rhinichthys obtusus), longnose dace (Rhinichthys cataractae), rosyside dace (Clinostomus funduloides), fantail darter (Etheostoma flabellare), creek chub (Semotilus atromaculatus), brown trout (Salmo trutta), and rainbow trout (Oncorhynchus mykiss) were observed in larger study reaches near the main stem of Shavers Fork.

\section{Methods}

\section{Site selection}

The locations of all potential study streams were determined using ArcGIS 9.1 spatial analysis software. All streams with a basin area $<3.0 \mathrm{~km}^{2}$ that drained within $1 \mathrm{~km}$ of main stem habitat (defined as any stream reach with a basin area $>15 \mathrm{~km}^{2}$ ) were identified from a flow accumulation grid, based on a West Virginia state 10 meter (re-sampled 30m) digital elevation model. Each stream was ground verified and presence / absence of anthropogenic barriers was noted during base flow conditions of fall 2003. Preliminary water quality (pH, alkalinity, and dissolved $\mathrm{Ca}^{+3}$ ) was determined from filtered water samples (filter size $0.45 \mu \mathrm{m}$; potentiometric titration to $\mathrm{pH} 4.5$ ). A calcium-hydrogen ion ratio was calculated to represent the water chemistry within each stream (Clayton et al. 1998). 
Within each of the three regions (i.e. below First Fork, between First and Second Fork, and above Second Fork), all identified streams were stratified by basin area $\left(<1 \mathrm{~km}^{2}, 1-2 \mathrm{~km}^{2}, 2-\right.$ $\left.3 \mathrm{~km}^{2}\right)$, Ca:H ion ratio $(<6,6-25,>25)$, and presence / absence of man-made barriers. All stream reaches with immediate downstream barriers to fish passage were not sampled. A minimum of one stream representing each available basin area / water quality combination was randomly selected from each of the three regions. Reach length was 40 times the mean wetted width; with a 150m minimum (Angermeier and Karr 1986, Yoder and Smith 1999). In order to avoid potential bias associated with confluences, sample reaches were located at least $50 \mathrm{~m}$ from the mouth of each study stream.

\section{Brook Trout Population Sampling}

We sampled brook trout populations within the 34 study reaches during base flow conditions in June 2004. Previous studies within the Upper Shavers Fork watershed indicate that June is the earliest time that juveniles can be effectively sampled (Petty et al. 2005). By sampling as early as possible, we attempted to minimize the effect of dispersal on juvenile distributions.

Two to three person teams, depending on stream size, sampled brook trout with backpack electrofishing units (Smith-Root, DC, $60 \mathrm{hz}, 400-600 \mathrm{~V}$ ), following single-pass procedures, and a combination of dip and seine nets. Brook trout capture probabilities within this watershed are equal among age-classes and seasons but not across a broad range of basin areas (Petty et al. 2005). In addition, a constant capture probability model was found to be the most appropriate model representing brook trout capture probabilities for 42 sites distributed throughout the Cheat River watershed (Petty et al. unpublished data). Even though data suggests that brook trout capture probabilities should be similar among study sites and the effective range of streams sizes 
considered in this study was small $\left(0.08-3 \mathrm{~km}^{2}\right)$, we conducted three-pass removal estimates on a subset of study reaches to assess the efficiency of our single-pass protocol. Capture probability was generally high (mean 0.717 , stdev 0.102 ) and displayed little variability (coefficient of variation $=14 \%$ ). More importantly, the number of brook trout captured from the first pass was strongly correlated with total population size estimated from three-pass depletion $(\mathrm{N}=18, \mathrm{r}=$ 0.97). These results indicate that the single-pass sampling procedure provided an unbiased measure of brook trout abundance in small basin area tributaries of this watershed. All trout captured were identified to species, anesthetized in clove oil (concentration $=40 \mathrm{mg} / \mathrm{L}$ ), and measured for standard length (SL) $( \pm 1 \mathrm{~mm})$ and weight $( \pm 0.1 \mathrm{~g})$.

Juvenile brook trout were distinguished from other size-classes based on frequency distributions of brook trout lengths pooled across all sites sampled within the Upper Shavers Fork during June 2004 (Figure 2). The juvenile cohort $(<60 \mathrm{~mm} \mathrm{SL})$ is a true representation of age and represents individuals known to have been spawned the previous fall. The small and large adult classes likely do not represent a true distinction in age. The term "adult" was simply used to represent individuals that were not in their first year of life and in the case of most small adults may not represent reproductive maturity. A stock size of $115 \mathrm{~mm}$ (SL) (Anderson and Neumann 1996) was used to differentiate between small and large adults.

\section{Water Chemistry}

Water chemistry data was collected at base flow conditions during April 2004. It has been shown that most streams in the Cheat River basin exhibit their worst chemical conditions during late winter and early spring (Petty and Barker 2005), and it is at this time that the survival of juvenile brook trout are most affected by episodic reduction in water quality (Jordahl and Benson 1987; Fiss and Carline 1993). Two whole water 250mL samples were collected from 
each stream reach. One sample was acidified with $2 \mathrm{~mL}$ sulfuric acid to maintain the dissolution of metals. All samples were filtered (filter size $0.45 \mu \mathrm{m}$ ) and processed at the West Virginia University Natural Resource Center for Coal and Energy. Samples were analyzed for $\mathrm{pH}$, alkalinity (mg/L $\left.\mathrm{CaCO}_{3}\right)$, and dissolved inorganic monomeric $\mathrm{Al}^{3+}(\mathrm{mg} / \mathrm{L})$ (henceforth, $\left.\mathrm{Al}\right)$.

\section{Instream Habitat}

Habitat surveys were conducted at base flow conditions during the summers of 2004 and 2005 and followed protocols similar to those described by Petty et al. (2005). Efforts combined visual estimation and transect based sampling to quantify a variety of physical habitat variables. All visual estimation was conducted by the same person in order to reduce sampling error. Thirteen habitat parameters were assessed at each site: basin area $\left(\mathrm{km}^{2}\right)$, channel slope $(\%)$, mean depth $(\mathrm{cm})$, depth variability, mean velocity $(\mathrm{cm} / \mathrm{s})$, distance to cover $(\mathrm{m})$, canopy cover $(\%)$, wetted channel width $(\mathrm{m})$, stream margin $(\%)$, spawning substrate $(\%)$, pool area $(\%)$, median substrate size $(\mathrm{mm})$, and large woody debris (LWD) $\left(\mathrm{m}^{2} / \mathrm{m}^{2}\right)$. This represents a list of previously suggested parameters important to salmonid redd site selection and juvenile habitat use (Witzel and MacCrimmon 1983, Bozek and Rahel 1991, Mclaughlin et al. 1994, Petty et al. 2005).

Basin area was mapped at the downstream end of each reach using a flow accumulation grid in Arc GIS 9.1 spatial analysis software. Mean channel slope was measured with a hand held clinometer $( \pm 1 \%)$ and survey rod. Working in an upstream direction, a thalweg profile was developed by measuring depth $( \pm 1 \mathrm{~cm})$, average current velocity $( \pm 1 \mathrm{~m} / \mathrm{s})$, and distance to cover $( \pm 0.1 \mathrm{~m})$ at 30 points spaced $5 \mathrm{~m}$ apart within the primary current seam. Spacing of sample points along the thalweg was slightly modified from the recommendations of Simonson et al. (1994). Depth variability was represented as the coefficient of variation ([standard deviation/mean]*100) of mean depth. Average velocity was measured with a Marsh McBirney 
digital flow meter at $60 \%$ of the water depth. Distance to cover was measured as the distance from the thalweg point to the nearest structural element with potential to provide refuge for a 200mm fish (Simonson et al. 1994). Transects were located every 50m at which canopy cover (spherical densitometer: 4 directional readings) and wetted width $( \pm 0.1 \mathrm{~m})$ were measured. The area $\left(\mathrm{m}^{2}\right)$ of stream margin and suitable spawning substrate was visually estimated at $10 \mathrm{~m}$ intervals and summed across the reach. Percentage of the reach represented by stream margin and suitable spawning substrate was calculated as the total area of each divided by the total wetted area of the reach. Stream margin was defined as any shallow $(<20 \mathrm{~cm})$ low velocity $(<0.04 \mathrm{~m} / \mathrm{s})$ area suitable for juvenile brook trout (Moore and Gregory 1988). Spawning substrate was defined as patches of small substrate $(4-30 \mathrm{~mm})$ in shallow, low velocity water (Hakala and Hartman 2004). Pool area $\left(\mathrm{m}^{2}\right)$ was obtained by multiplying the visually estimated total length (m) and width (m) of each pool and summing throughout the reach. Twenty percent of all pool dimensions were measured $( \pm 0.1 \mathrm{~m})$ and used to derive a correction factor for visual estimations (Dolloff et al. 1997). Percentage of the reach represented by pools was calculated as the total pool area divided by the total wetted area of the reach. Median substrate size $\left(\mathrm{D}_{50}\right)$ was determined by first classifying (Wentworth scale) 100 randomly selected pebbles along a zig-zag line that traversed the length of each reach (Bevenger and King 1995). Median substrate size was calculated as the antilogarithm of the summed proportion of bedrock, boulder, cobble, gravel, sand, and silt multiplied by their respective geometric mean size. LWD was assessed by categorizing all stems located within the active stream channel (includes root wads, spanners, and standing dead) into 1 of 12 categories based on visually estimated lengths (1-2m, 2-5m, 5$10 \mathrm{~m},>10 \mathrm{~m})$ and widths $(0.1-0.2 \mathrm{~m}, 0.2-0.3 \mathrm{~m},>0.3 \mathrm{~m})$. LWD density $\left(\mathrm{m}^{2} / \mathrm{m}^{2}\right)$ was calculated as 
the sum of the total area represented by each category (\# stems * median length * median width) divided by the wetted stream area.

\section{Statistical Analysis}

Basin area - juvenile brook trout relationship - Our first objective was to quantify the relationship between stream size and juvenile brook trout abundance within small basin area stream reaches draining $<3 \mathrm{~km}^{2}$. A Kolmogorov-Smirnov goodness-of-fit test was used to compare the observed cumulative juvenile density to the expected cumulative frequency of stream segments available along a range of basin area (sensu Petty et al. 2005). The analysis tested the null hypothesis that juvenile density was constant across the range of basin areas sampled.

Physico-chemical attributes and juvenile brook trout density - Our second objective was to quantify the local physical and chemical factors that influence the spatial variation in juvenile brook trout density among stream reaches draining $<3 \mathrm{~km}^{2}$. All study reaches that did not maintain surface flow during the study period (April 2004-June 2005) were not included in further statistical analysis procedures, regardless of their flow status in June 2004.

Stepwise multiple regression analysis was used to determine which physico-chemical variables were most important in explaining the spatial variation in juvenile brook trout density. Due to high correlations among local physical and chemical habitat parameters, principle component analysis (PCA) was used to reduce linear dependency and data redundancy, across all perennial sites, by generating new fully uncorrelated composite variates separately for both physical and chemical attributes (McGarigal et al. 2000). Physical and chemical component scores, percent canopy cover, and adult brook trout $(>60 \mathrm{~mm})$ density (\# / hectare) were selected for regression analysis. Variables were included in the regression model if $P<0.15$. The alpha- 
level used for acceptance of the overall model was 0.05. All statistical tests were judged at this level unless otherwise noted. Due to the likely importance of local water quality in regulating the spatial occurrence of juvenile brook trout, we also used simple linear regression to assess the relationship between juvenile density and each water quality parameter (i.e. $\mathrm{pH}$, alkalinity, Al).

The Ward's method of hierarchical cluster analysis was used to assign each study reach into one of three groups (high, low, absent) based on observed juvenile density. We further separated the sites where juveniles were absent into absent with "good" water quality and absent with "poor" water quality based on observed water quality thresholds $(\mathrm{pH}<5.0$, alkalinity $<2$ $\mathrm{mg} / \mathrm{L} \mathrm{CaCO}_{3}$ - see Results), giving a total of 4 categories. One-way analysis of variance (ANOVA) was used to test for significant differences among groups based on individual physical and chemical parameters as well as dominant instream physical and chemical gradients described by PCA. Backward stepwise linear discriminant analysis was used to determine which physical and chemical parameters best discriminated among predefined groups. Backward selection occurred until all modeled parameters were significant at $P \leq 0.15$ level. Correlation analysis was used to quantify the strength of the relationship between each modeled parameter and the site specific canonical scores associated with each discriminant axis. Parameters with significant correlations were considered key variables that distinguished among groups along each axis. We used the proportional chance criterion $\left(\mathrm{C}_{\mathrm{pro}}\right)$ (Morrison 1969) to assess classification accuracy. The premise of $\mathrm{C}_{\text {pro }}$ is that classification based on the discriminating variables should exceed that obtained by randomly assigning samples to groups in proportion to group sizes. $\mathrm{C}_{\text {pro }}$ was computed by summing the squared proportional contribution of each group (Morrison 1969). In order to more clearly assess the role of the physical habitat in determining the relative abundance of juveniles in good water sites we removed all sites with poor water 
quality and conducted a similar discriminant analysis including only physical habitat parameters.

\section{Results}

A total of 733 brook trout were captured, from single-pass electrofishing, across the 34 study reaches, and considerable reach-to-reach variability in the number of brook trout was observed (range: $0-64)$. Small adult brook trout $(60-115 \mathrm{~mm}$ standard length) were numerically dominant making up $60 \%$ of the total catch, whereas juveniles $(<60 \mathrm{~mm}$ SL) and large adults ( $>115 \mathrm{~mm}$ SL) made up 22 and $18 \%$ respectively.

Basin area - juvenile brook trout relationship- Juvenile brook trout were observed across the entire sampled range of basin area $\left(0.08-3 \mathrm{~km}^{2}\right)$ and were found to occur most often within the smallest study reaches (Figure 3). Juvenile brook trout density was significantly higher in small basin area stream reaches than expected by chance alone (Kolmogrov-Smirnov; $D_{\max }=$ $0.30, \mathrm{~N}=34, P=0.004)$. In fact, nearly $90 \%$ of the cumulative density occurred in stream reaches draining less than $0.5 \mathrm{~km}^{2}, 30 \%$ more than would be expected by chance (Figure 3 ). These results suggest that brook trout reproduction is concentrated within the smallest perennial streams available.

Of the 34 stream reaches sampled, 5 (15\%) did not maintain surface water flow for the duration of study (Table 1). Reach drying was not restricted to the smallest basin area streams segments (range $0.08-0.36 \mathrm{~km}^{2}$ ), suggesting that stream size alone was not a sufficient measure of critical habitat for brook trout reproduction. In general juvenile brook trout were not observed in any stream reach that went dry, with the exception of site 20 . Site 20 began at the confluence of the stream network and the Shavers Fork main stem and supported a single juvenile, however; the individual was found less than 5 meters from the Shavers Fork main stem. 
Physico-chemical attributes and juvenile brook trout density- We identified three ecological gradients from correlated physical habitat variables (henceforth, PPC) within perennial study sites (Table 2, Figure 4). The analyses suggest a substrate size - stream margin gradient (PPC 1), a stream size gradient (PPC 2), and a complexity gradient (PPC 3). Two ecological gradients were identified from the correlated water quality variables (henceforth CPC): an acidity gradient (CPC 1) and an Al gradient (CPC 2) (Table 2, Figure 5).

Using stepwise multiple regression, we produced a highly significant model relating physico-chemical parameters to juvenile brook trout density across all perennial sites (Full model: $\left.F=18.08, \mathrm{df}=28, P=<0.0001, \mathrm{R}^{2}=0.58\right)$. PPC 1 and $\mathrm{CPC} 1$ were found to be the most important predictor variables (Table 3). This model was strongly influenced by five chronically acidic sites; consequently, CPC 1 alone explained $51 \%$ of the variation in juvenile density among sites. Simple linear regression of each water quality parameter and juvenile density illustrated that no juveniles were observed in stream reaches with a spring $\mathrm{pH}<5.0$ and a spring alkalinity $<2.0 \mathrm{mg} / \mathrm{L} \mathrm{CaCO}_{3}$ (Figure 6). The lack of juvenile brook trout below these values suggests critical water quality thresholds exist below which stream reaches were incapable of supporting juvenile brook trout. No critical threshold was identified for $\mathrm{Al}$; however, high juvenile density was only observed in streams with no Al present in spring (Figure 4). No significant relationship was observed between $\mathrm{pH}\left(\mathrm{R}^{2} 0.06, P=0.25\right)$ or alkalinity $\left(\mathrm{R}^{2}\right.$ $0.06, P=0.27)$ and juvenile brook trout density once water quality exceeded the observed critical threshold (Figure 6). Within sites that maintained a spring $\mathrm{pH}>5.0$ and a spring alkalinity $>2.0$ $\mathrm{mg} / \mathrm{L} \mathrm{CaCO}_{3}$, we produced a significant model relating physico-chemical parameters to juvenile brook trout density (Full model: $F=8.41, \mathrm{df}=23, P=0.008, \mathrm{R}^{2}=0.28$ ), where PPC 1 was the only selected predictor variable (Table 4). 
When similarity among perennial sites was defined in terms of juvenile density, three groups (high $\mathrm{N}=11$, low $\mathrm{N}=10$, and absent $\mathrm{N}=8$ ) were identified by hierarchical classification. The absent group was further separated into sites with good water quality (henceforth Absent-1; $\mathrm{N}=3, \mathrm{pH}>5.0$ and alkalinity $>2.0 \mathrm{mg} / \mathrm{L} \mathrm{CaCO}_{3}$ ) and sites with poor water quality (henceforth Absent-2; $\mathrm{N}=5, \mathrm{pH}<5.0$ and alkalinity $<2.0 \mathrm{mg} / \mathrm{L} \mathrm{CaCO}_{3}$ ) (Table 5 and 6). Significant differences between groups were identified in relation to basin area, wetted stream width, percent stream margin, median substrate size, spring $\mathrm{pH}$, spring alkalinity, PPC 1, and CPC 1 (Table 5). In general, the high density group had a smaller mean basin area, wetted width, and substrate size and a higher mean percent stream margin compared to low density or absent groups (Table 5). Streams with good water quality but no juveniles (i.e. Absent-1), possessed less stream margin and slightly larger substrate than high density streams (Table 5).

Using two canonical functions identified using discriminant analysis, we were able to distinguish between the four groups (High, Low, Absent-1, and Absent-2) based on the physicochemical parameters. The stepwise selection process indicated that the linear combination of basin area, depth CV, \% stream margin, LWD density, and spring $\mathrm{pH}$ was the best model with respect to simultaneously maximizing among group separation and within group cohesiveness. Both canonical functions were significantly different from zero (Wilks-Lambda $<0.0001$; Canon $1: \mathrm{R}_{\mathrm{c}}{ }^{2}=0.86$; Canon $2: \mathrm{R}_{\mathrm{c}}{ }^{2}=0.58$ ), indicating that the five physico-chemical variables successfully discriminated between groups (Table 7). This model correctly classified $86 \%$ of sites (Table 8$), 56 \%$ more than would be expected by chance alone $\left(\mathrm{C}_{\mathrm{pro}}=0.30\right)$.

In general, sites supporting juvenile brook trout had a higher spring $\mathrm{pH}$ than those that did not, whereas sites with a high relative density occurred in smaller basin area stream reaches with higher $\%$ stream margin than sites with a low relative density. Spring $\mathrm{pH}$ and $\%$ stream 
margin were key discriminating variables along canonical axis 1 and significantly separated stream reaches with the ability to support juvenile brook trout from those that did not. As indicated by a high correlation coefficient $(\mathrm{r}=0.98)$, spring $\mathrm{pH}$ was the dominant attribute responsible for group separation along canonical axis 1. Basin area and percent stream margin were key discriminating variables along canonical axis 2 and significantly separated high density sites from low density sites. This linear combination of variables was not able to significantly separate study reaches with no juvenile brook trout but good water quality from other reaches that did support juveniles (Figure 7).

When only good water sites were considered, we used two canonical functions identified by discriminant analysis to distinguish between the three groups (High, Low, and Absent-1) with good water quality (i.e. $\mathrm{pH}>5.0$ and alkalinity $>2.0 \mathrm{mg} / \mathrm{L} \mathrm{CaCO}_{3}$ ) based solely on physical attributes. The linear combination of basin area, depth CV, \% pool area, \% stream margin, and LWD, was found to be the most effective model at distinguishing among groups. Both canonical functions were significantly different from zero (Wilks-Lambda $=0.0001$; Canon $1: \mathrm{R}_{\mathrm{c}}{ }^{2}=0.66$; Canon 2: $\mathrm{R}_{\mathrm{c}}{ }^{2}=0.56$ ), indicating that the five physical variables successfully discriminated between groups (Table 9). This model correctly classified $92 \%$ of sites (Table 10), 52\% more than would be expected by chance alone $\left(\mathrm{C}_{\mathrm{pro}}=0.40\right)$.

In general, sites supporting juvenile brook trout had a more homogenous depth / flow regime than those that did not, whereas sites with a high relative density occurred in smaller basin area stream reaches with a higher percent stream margin than sites with a low relative density. Basin area and percent stream margin were the key discriminating variables along canonical axis 1 and significantly separated high density sites from low density sites. Depth CV 
was the key discriminating variable along canonical axis 2 and significantly separated sites that supported juvenile brook trout from those that did not (Figure 8).

\section{Discussion}

Results of this study suggest that within the upper Shavers Fork watershed small basin area streams located near the main stem do provide critical reproductive habitats for brook trout. Juvenile brook trout were observed throughout the range of stream sizes between 0.08 and 3.0 $\mathrm{km}^{2}$. However, sites displayed considerable variation in local physical and chemical conditions resulting in variable recruitment of juvenile brook trout. Juvenile brook trout were only observed within study reaches with perennial flow, spring $\mathrm{pH}$ above 5.0, and spring alkalinity levels above $2.0 \mathrm{mg} / \mathrm{L} \mathrm{CaCO}_{3}$. Within these "suitable" systems juvenile density was influenced by the local physical habitat; although, a considerable amount of variation was unexplained. In general, juvenile density was highest within the smallest stream reaches, providing no evidence that a critical basin area exists below which brook trout reproduction does not occur. Furthermore, high juvenile density was at least in part a function of the availability of shallow, low velocity, marginal habitat.

This study suggests that droughts may be an important mechanism in structuring brook trout populations within the upper Shavers Fork. This conclusion is based on the absence of juvenile brook trout within stream reaches that went dry during the study period. Reach drying is common in many small headwater systems due to drainage basin geometry (Lake 2000, 2003), and hydrologic variability is an important factor in structuring fish assemblages (Grossman et al. 1982, Schlosser 1985, Poff and Allen 1995, Dodds et al. 2004). Droughts affect population abundance by reducing the quality and availability of local pool and riffle habitat (Lake 2000, Lake 2003, Hakala and Hartman 2004). Hakala and Hartman (2004) observed a 67\% decrease in 
juvenile brook trout abundance across several Appalachian streams following a severe drought. The literature is full of examples relating flow dynamics (especially floods) to juvenile recruitment and population dynamics of stream-dwelling salmonids (Spina 2001, Cattanéo et al. 2002, Lóbon-Cerviá 2003, Lóbon-Cerviá 2004, Hakala and Hartman 2004). Unfortunately, there is a lack of literature addressing minimum stream size and flow requirements for brook trout reproduction and juvenile recruitment.

Spring water quality was the limiting factor defining a reach's ability to support juvenile brook trout within perennial stream reaches. This conclusion is based on (1) the importance of the acidity gradient as a predictor of juvenile density (2) the observed critical water quality threshold for spring $\mathrm{pH}(>5.0)$ and alkalinity $\left(>2.0 \mathrm{mg} / \mathrm{L} \mathrm{CaCO}_{3}\right)$. Our findings are consistent with the results of several other studies within the northeastern United States (Johnson and Webster 1977, Baker et al. 1996; Van Sickle et al. 1996; Wigington et al. 1996; Welsh and Perry 1997, Petty et al. 2005). Johnson and Webster (1977) found that brook trout avoided reproducing in areas with $\mathrm{pH}$ levels below 5.0, but above this level they did not discriminate based on water quality. Welsh and Perry (1997) showed that systems like Shavers Fork dominated by poorly buffered geologic groups (e.g. Pottsville sandstone and Mauch Chunk shale) are prone to acidic episodes that exceed critical thresholds for many fishes. Petty et al. (2005) showed complete recruitment failure within stream reaches with alkalinity below $7 \mathrm{mg} / \mathrm{L}$ $\mathrm{CaCO}_{3}$. Numerous physiological mechanisms can cause mortality in acidified streams and affect reproductive success through increased larval mortality (Jordahl and Benson 1987; Fiss and Carline 1993) or failure of females to produce mature eggs (Frenette and Dodson 1984).

Although $\mathrm{pH}$ and alkalinity are important determinants of water quality, the critical factor is believed to be increased mobilization of monomeric aluminum during acidic episodes (Mount 
et al. 1990; Ingersoll et al. 1990, Parkhurst et al. 1990). Baker et al. (1996) indicated that inorganic monomeric aluminum levels above $0.06 \mathrm{mg} / \mathrm{L}$ were unsuitable for the survival and reproduction of many stream fishes. We observed juvenile brook trout across a wide range of spring Al levels (0-0.4 mg/L). Within sites that had elevated Al levels in spring, juvenile brook trout density was always low but not always absent. Juvenile brook trout response to Al toxicity is reduced in early developmental stages (Ingersoll et al. 1990) and it is possible that this increased resistance was sufficient to prevent complete recruitment failure in stream reaches with high spring $\mathrm{Al}$ concentrations. More likely, however, is that moderate levels of $\mathrm{pH}$ and $\mathrm{Ca}^{+2}$ resulted in a calcium-hydrogen ion ratio $>10$, which has been shown to be sufficient to allow for successful brook trout reproduction in acid impaired streams (Clayton et al. 1998).

Our observation that juvenile brook trout occurred within stream reaches with low buffering capacity suggests that successful juvenile recruitment may be prone to temporal fluctuations due to acidic episodes. During extended low-flow periods many small streams appear as attractive reproductive habitat due to relatively high $\mathrm{pH}$ levels (Lamothe 2002, Petty et al. 2005). However, during acidic episodes, $\mathrm{pH}$ levels in low-alkalinity streams may drop to below 4.0 (Wigington et al. 1996, Lamothe 2002) resulting in complete recruitment failure. Acidic episodes throughout Appalachia typically occur during spring snowmelt or fall thunderstorms coinciding with various reproductive activities (e.g. redd site selection, emergence). The importance of duration of acidic episodes is likely contingent on preexisting conditions; however, both long-term acidic episodes ( $>24 \mathrm{~h})$ (Van Sickle et al. 1996) and shortterm pulses (Mount et al. 1990) have been shown to reduce survival of early brook trout life stages. Clearly, the timing, duration, frequency, and magnitude of acidic episodes must be 
considered to determine the susceptibility of brook trout populations to acidification (Ingersoll et al. 1990).

Within perennial sites chemically capable of supporting juveniles, basin area, was a critical factor influencing the relative abundance of juvenile brook trout. This conclusion is supported by (1) the disproportionate distribution of juvenile brook trout within stream reaches draining $<0.5 \mathrm{~km}^{2}$ and (2) the role of basin area as a key factor discriminating between stream reaches with high and low relative abundance of juveniles. Our findings are consistent with the work of Petty et al. (2005) who provided overwhelming support for the role of small basin area stream reaches in structuring the reproductive effort and spatial distribution of brook trout within a $4^{\text {th }}$ order tributary basin of the upper Shavers Fork.

The importance of small basin area stream reaches to brook trout spawning and rearing may be related to a variety of factors such as groundwater inputs, flow regime, and predation. Groundwater influences the distribution, reproductive success, biomass, productivity, behavior, and movement of fishes (Power et al. 1999), by influencing temperature, flow, and chemical regimes (Witzel and MacCrimmon 1983). Consequently, many studies of stream-dwelling brook trout reproductive strategies suggest groundwater influxes within low-order stream reaches partially regulate the spatial variation in reproductive effort (Witzel and MacCrimmon 1983, Curry and Noakes 1995, Sorenson et al. 1995, Essington et al. 1998). Sorenson et al. (1995) showed that brook trout in Minnesota streams selected spawning sites with groundwater upwellings and low current velocities. Curry and Noakes (1995) indicate that increases in the contribution of groundwater to base flow draws brook trout to centralized spawning areas but does not influence redd site selection within these areas. Although they observed this pattern throughout the northeastern range of brook trout, there was a relative lack of support in central 
Appalachia where substrate size and water quality dominated redd site selection. In addition to the likely influence of groundwater, bed-scouring flows that damage eggs, increase mortality of emerging fry, and displace developing juveniles are rare in small streams (Harvey 1987, Sun et al. 2002). However, the small size of these watersheds makes them highly susceptible to droughts and drying (Lake 2000, Lake 2003). Fortunately, the low flows characterizing these small systems may actually protect larvae and juveniles from predators and potential competitors (Petty et al. 2005). The majority of the study reaches were too shallow to support large predatory fishes throughout most of the year.

The distribution of juvenile brook trout was also related to the availability of shallow, low velocity habitat. This conclusion is supported by the role of stream margin and depth CV as critical habitat features influencing the relative abundance of juveniles. Margin habitat is characterized by low water velocity, heterogeneous substrate, abundant detritus, and structural protection from high flows (Moore and Gregory 1988). Stream margin is typically abundant within low gradient stream reaches and / or those with structural elements (i.e. boulders and LWD) that slow current and increase bed roughness (Moore and Gregory 1988). When stream margin is defined by flow characteristics and not position within the channel, many small basin area systems are dominated by margin habitat. Margin habitat provides profitable conditions for newly emerged and developing salmonids by reducing energy expenditure, increasing consumption rates, reducing predation risks, and reducing risk of downstream displacement (Grant and Noakes 1987; Moore and Gregory 1988; McLaughlin et al 1994; McLaughlin and Noakes 1998; Hubert and Joyce 2005). McLaughlin and Noakes (1998) suggest that low velocity habitats significantly reduce energetic costs of young brook trout while not affecting consumption rates of food types. Hubert and Joyce (2005) showed that stream margin provided 
critical refuge from larger predatory fishes for juvenile cutthroat trout (Oncorhynchus clarki). In addition, the shallow low flows characteristic of margin dominated small basin systems rarely experience flow conditions required to displace young fishes (Harvey 1987). Finally, reduced flows within margin habitat allows for the accumulation of detritus which may increase invertebrate biomass and provide an increased food base for developing brook trout.

This study was successful in identifying local physical and chemical attributes that influence the spatial distribution and abundance of juvenile brook trout. Unfortunately, there was a considerable amount of unexplained variance within the small basin area reaches with good water quality. Some of this observed variation is likely explained as error in sampling the brook trout populations and physico-chemical conditions within each site. However, the brook trout capture probabilities reported for this study were very similar to those previously assessed for this region (Petty et al. unpublished data). Akaike's Information Criterion was used to show that brook trout throughout the Cheat River watershed are best represented by a constant capture probability model (Petty et al. unpublished data). Additionally, standardized habitat and water quality sampling methods were used to reduce sampling error. Consequently, we feel that sampling did not influence the conclusions presented in this study. There are numerous factors that likely influenced reproductive success and juvenile density outside the scope of this study including: condition of spawning adults and viability of gametes, physical and chemical conditions affecting survival of all immature life stages from fertilization through emergence, food availability, predation, geographic position, and localized stochasticity. In addition, it is possible that broad-scale habitat factors rather than local features are more influential in determining the spatial allocation of reproductive effort and consequently juvenile brook trout distribution within the upper Shavers Fork watershed. Consequently, a major source of error 
may be that habitat measurements were not assessed at the appropriate spatial scale (Feist et al. 2003).

This study combined with the work of Petty et al. (2005) provides valuable insight into factors influencing brook trout reproduction and patterns of brook trout population dynamics within the upper Shavers Fork watershed. We know that brook trout reproductive effort is concentrated within stream reaches draining $<3 \mathrm{~km}^{2}$. Within this critical range no basin area exists below which juvenile recruitment does not occur. In fact, stream segments draining $<0.5$ $\mathrm{km}^{2}$ were found to be most important to brook trout reproduction. We recognize that water quality is the critical attribute that determines successful brook trout reproduction within this watershed. Much of the reproductive effort is concentrated within stream segments that are prone to acidic episodes and are likely temporally unstable. We further recognize that local physical features such as availability of nursery habitat, in the form of stream margin, likely influence the recruitment of juvenile brook trout. Finally, we know that all brook trout are at least seasonally dependent on access to high quality reproductive habitat. We understand that reproductive habitat is critical to the persistence of the Shavers Fork brook trout population at the watershed-scale. However, the productivity of the population is likely dependent on access to high quality foraging habitat within the main stem of Shavers Fork (Thorne 2004, Petty et al. 2005). Unfortunately, we do not fully understand to what degree reproductive habitats and foraging habitats are connected and how this level of connection influences brook trout populations at the watershed-scale. Consequently, watershed-scale approaches are needed to assess the linkages between large water bodies used as supplementary feeding habitats and small, alkaline streams that act as sources of juvenile brook trout recruitment. 


\section{References}

Anderson, R. O. and R. M. Neumann. 1996. Length, weight, and associated structural indices. Pages 447-482 in B. R. Murphy and D. W. Willis, editors: Fisheries Techniques, 2nd edition. American Fisheries Society, Bethesda, MD.

Angermier, P. L. and J. R. Karr. 1986. Applying an index of biotic integrity based on streamfish communities: considerations in sampling and interpretation, North American Journal of Fisheries Management 6:418-427.

Armsworth, P. R. 2002. Recruitment limitation, population regulation, and larval connectivity in reef fish metapopulations. Ecology 83:1092-1104.

Baker, J. P. J. Van Sickle, C. J. Gagen, D. R. DeWalle, W. E. Sharpe, R. F. Carline, B. P. Baldigo, P. S. Murdoch, D. W. Bath, W. A. Kretser, H. A. Simonin, and P. J. Wigington Jr. 1996. Episodic acidification of small streams in the northeastern United States: effects on fish populations. Ecological Applications 6:422-437.

Beard, T.D., and R.F. Carline. 1991. Influence of spawning and other stream habitat features on spatial variability of wild brown trout. Transactions of the American Fisheries Society 120:711722.

Bernier-Bourgault, I., and P. Magnan. 2002. Factors affecting redd site selection, hatching, and emergence of brook charr, Salvelinus fontinalis, in an artificially enhanced site. Environmental Biology of Fishes 64: 333-341.

Bevenger, G. S., and R. M. King. 1995. A pebble count procedure for assessing watershed cumulative effects. Research Paper RM-RP-319. Fort Collins, CO: USDA Forest Service, Rocky Mountain Forest and Range Experiment Station. 17 pp.

Bopp, J. 2002. The combined effects of water chemistry, canopy cover, and basin area on benthic macroinvertebrates along a central Appalachian stream continuum. Thesis submitted to the Davis College of Agriculture, Forestry, and Consumer Sciences, West Virginia University.

Bozek, M. A., and R. J. Rahel. 1991. Assessing habitat requirements of young Colorado River cutthroat trout by use of macro and microhabitat analyses. Transaction of the American Fisheries Society 120:571-581.

Caley, M. J., M. H. Carr, M. A. Hixon, T. P. Hughes, G. P. Jones, and B. A. Menge. 1996. Recruitment and the local dynamics of open marine populations. Annual Review of Ecology and Systematics 27:477-500.

Cattanéo, F., N. Lamouroux, P. Breil, and H. Capra. 2002. The influence of hydrological and biotic processes on brown trout (Salmo trutta) population dynamics. 
Canadian Journal of Fisheries and Aquatic Sciences 59:12-22.

Clayton, J. L., E. S. Dannaway, R. Menendez, H. W. Rauch, J. J. Renton, S. M. Sherlock, and P. E. Zurbuch. 1998. Application of limestone to restore fish communities in acidified streams. North American Journal of Fisheries Management 18:347-360.

Curry, R. A., and D. L. G. Noakes. 1995. Groundwater and the selection of spawning sites by brook trout (Salvelinus fontinalis). Canadian Journal of Fisheries and Aquatic Sciences 52:1733-1740.

Danilowicz, B. S. 1997. A potential mechanism for episodic recruitment of coral reef fish. Ecology 78: 1415-1423.

Doherty, P. J. 1981. Coral reef fishes: recruitment-limited assemblage? Proceedings of the $4^{\text {th }}$ International Coral Reef Symposium. 2:465-70.

Doherty, P. J., and T. Fowler. 1994. An empirical test of recruitment limitation in a coral reef fish. Science 263: 935-939.

Dolloff, A. C., H. E. Jennings, and M. D. Owens. 1997. A comparison of basin-wide and representative reach habitat survey techniques in three southern Appalachian watersheds. North American Journal of Fisheries Management 17:339-347.

Dunning, J. B., B. J. Danielson, and H. R. Pulliam. 1992. Ecological processes that affect populations in complex landscapes. Oikos 65:169-175

Einum, S. 2005. Salmonid population dynamics: stability under weak density dependence?

Oikos 110:3.

Elliott, J. M. 1994. Quantitative ecology and the brown trout. Oxford University Press, Oxford, England.

Essington, T. E., P. W. Sorenson, and D. G. Paron. 1998. High rate of redd superimposition by brook trout (Salvelinus fontinalis) and brown trout (Salmo trutta) in a Minnesota stream cannot be explained by habitat availability alone. Canadian Journal of Fisheries and Aquatic Sciences 55:2310-2316.

Fausch, K. D., C. E. Torgersen, C. V. Baxter, and H. W. Li. 2002. Landscapes to riverscapes: bridging the gap between research and conservation of stream fishes. Bioscience 52:483-497.

Fiest, B. E., E. A. Steel, G. R. Pess, and R. E. Bilby. 2003. The influence of scale on salmon habitat restoration priorities. Animal Conservation 6:271-282.

Fiss, F. C., and R.F. Carline. 1993. Survival of brook trout embryos in three episodically acidified streams. Transactions of the American Fisheries Society 122:268-278. 
Flebbe, P. A. 1994. A regional view of the margin: salmonid abundance and distribution in the southern Appalachian Mountains of North Carolina and Virginia. Transactions of the American Fisheries Society 123:657-667.

Freeman, M. C., M. K. Crawford, J. C. Barret, D. E. Facey, M. G. Flood, J. Hill, D. J. Stouder, and G. D. Grossman. 1988. Fish assemblage stability in a southern Appalachian stream. Canadian Journal of Fisheries and Aquatic Sciences 45:1949-1958.

Frenette J. J., and J. J. Dodson. 1984. Brook trout (Salvelinus fontinalis) population structure in acidified Lac Tantare, Quebec. Canadian Journal of Fisheries and Aquatic Sciences 41:865-877.

Goujot, R. C. 2002. Geology, Surface Hydrology, and Fish Habitat Relationships in the upper Shavers Fork Drainage Basin, West Virginia. Thesis submitted to the Eberly College of Arts and Sciences, Department of Geology and Geography, West Virginia University.

Galbreath, F. F. 2001. Persistence of native southern Appalachian brook trout populations in the Pigeon River system, N.C. North American Journal of Fisheries Management 21:927-934.

Grant, J. W. A., and D. L. Kramer. 1990. Territory size as a predictor of the upper limit to population density of juvenile salmonids in streams. Canadian Journal of Fisheries and Aquatic Sciences 47:1724-1737.

Grant, J. W. A., and D. L. G. Noakes. 1987. Movers and stayers: foraging tactics of young-ofthe-year brook charr, Salvelinus fontinalis. Journal of Animal Ecology 56:1001-1013.

Grossman, G. D., P. B. Moyle, and J. O. Whitaker, Jr. 1982. Stochasticity in structural and functional characteristics of an Indiana stream fish assemblage: a test of community theory. The American Naturalist 120:423-445.

Grossman, G. D., R. E. Ratajczak Jr., M. K. Crawford, and M. C. Freeman. 1998. Assemblage organization in stream fishes: Effects of environmental variation and interspecific interactions. Ecological Monographs 68:395-420.

Grossman, G. D., R. E. Ratajczak Jr., J. T. Petty, M. D. Hunter, J. T. Peterson, and G. Grenouillet. In press. Population dynamics of mottled sculpin (pices: Cottidae) in a variable environment: an information theoretic approach.

Hansbarger, J. L. 2005. Trout movement and habitat use in the upper Cheat River, watershed. Thesis submitted to the Davis College of Agriculture, Forestry, and Consumer Sciences, West Virginia University.

Hakala, J. P., and K. J. Hartman. 2004. Drought effect on stream morphology on brook trout (Salvelinus fontinalis) populations in forested headwater streams. Hydrobiologia 515:203-213. 
Hicks, B. J., J. D. Hall, P. A. Disson, and J. R. Sedell. 1991. Responses of salmonids to habitat changes. American Fisheries Society Special Publication. 19:559-585.

Hixon, M. A., S. W. Pascala, and S. A. Sandin. 2002. Population regulation: historical context and contemporary challenges of open vs. closed systems. Ecology 83; 1490-1508.

Hubert, W. A., and M. P. Joyce. 2005. Habitat associations of age-0 cutthroat trout in a spring stream improved for adult salmonids. Journal of Freshwater Ecology 20 (2):277-286.

Ingersoll, C. G., D. R. Mount, D. D. Gulley, T. W. LaPoint, and H. L. Bergman. 1990. Effects of $\mathrm{pH}$, aluminum, and calcium on survival and growth of eggs and fry of brook trout (Salvelinus fontinalis). Canadian Journal of Fisheries and Aquatic Sciences 47:1580-1592.

Johnson, D. W., and D. A. Webster. 1977. Avoidance of low pH in selection of spawning sites by brook trout (Salvelinus fontinalis). Journal of Fisheries Research Board of Canada 34:2215 2218.

Jordahl, D. M., and A. Benson. 1987. Effect of low pH on survival of brook trout embryos and yolk-sac larvae in West Virginia streams. Transactions of the American Fisheries Society 116:807-816.

Knapp, R. A., V. T. Vredenburg, and K. R. Matthews. 1998. Effects of stream channel morphology on golden trout spawning habitat and recruitment. Ecological Applications 8:1104-1117.

Larson, G. L., and S. E. Moore. 1985. Encroachment of exotic rainbow trout into stream populations of native brook trout in the southern Appalachian mountains. Transactions of the American Fisheries Society 114:195-203.

Lake, P. S. 2000. Disturbance, patchiness, and diversity in streams. Journal of the North American Benthological Society19:573-592.

Lake, P. S. 2003. Ecological effects of perturbation by drought in flowing waters. Freshwater Biology 48:1161-1172.

Lamothe, P. J. 2002. Spatial population dynamics of brook trout (Salvelinus fontinalis) in a central Appalachian watershed. Thesis Submitted to The College of Agriculture, Forestry, and Consumer Sciences, Department of Forestry, West Virginia University.

Lewin, R. 1989. Sources and sinks complicate ecology. Science 234:477-478.

Lóbon-Cerviá, J. 2003. Spatiotemporal dynamics of brown trout production in a Cantabrian stream: effects of density and habitat quality. Transactions of the American Fisheries Society 132:621-637. 
Lóbon-Cerviá, J. 2004. Discharge-dependent covariation patterns in the population dynamics of brown trout (Salmo trutta) within a Cantabrian river drainage. Candian Journal of Aquatic Science 61:1929-1939.

Lóbon-Cerviá, J., and P. A. Rincón. 2004. Environmental determinants of recruitment and their influence on the population dynamics of stream-living brown trout Salmo trutta. Oikos 105:641646.

Magee, J. P., T. E. McMahon, and R. F. Thurow. 1996. Spatial variation in spawning habitat of cutthroat trout in a sediment-rich stream basin. Transactions of the American Fisheries Society 125:768-779.

McGarigal, K., S. Cushman, and S. Stafford. 2000. Multivariate statistics for wildlife and ecology research. Springer, New York.

McLaughlin, R. L., J. W. A. Grant, and D. L. Kramer. 1994. Foraging movements in relation to morphology, water-column use, and diet for recently emerged brook trout (Salvelinus fontinalis) in still-water pools. Canadian Journal of Fisheries and Aquatic Sciences 51:268-279.

McLaughlin, R. L., and D. L. G. Noakes. 1998. Going against the flow: an examination of the propulsive movements made by young-of-year brook trout in streams. Canadian Journal of Fisheries and Aquatic Sciences 55:853-860.

Milner, N. J., Elliot, J. M., Armstrong, J. D. Gardiner R., Welton, J. S., and Ladle M. 2003. The natural control of salmon and trout populations in streams. Fisheries Research. 62:111-125.

Montgomery, D. R., E. M. Beamer, G. R. Pess, and T. P. Quinn. 1999. Channel type and salmonid distribution and abundance. Canadian Journal of Aquatic Science 56:377-387.

Moore, K. M. S. and S. V. Gregory. 1988. Summer habitat utilization and ecology of cutthroat trout fry (Salmo clarki) in Cascade Mountain streams. Canadian Journal of Fisheries and Aquatic Sciences 45:1921-1930.

Mount, D. R., M. J. Swanson, J. E. Breck, A. M. Farag, and H. L. Bergman. 1990. Responses of brook trout (Salvelinus fontinalis) fry to fluctuating acid, aluminum, and low calcium exposure. Canadian Journal of Fisheries and Aquatic Sciences 47:1623-1630.

Murdoch, W. W. 1994. Population regulation in theory and practice. Ecology 75:271-287.

NADP. 2000. http://nadp.sws.uiuc.edu. National Atmospheric and Deposition Program.

Parkhurst, B. R., H. L. Bergman, J. Fernandez, D. D. Gulley, J. r. Hockett, and D. A. Sanchez. 1990. Inorganic monomeric aluminum and $\mathrm{pH}$ as predictors of acidic water toxicity to brook trout (Salvelinus fontinalis). Canadian Journal of Fisheries and Aquatic Sciences 47:1631-1640. 
Petty, J. T. and J. Barker. 2004. Water quality variability in tributaries of the Cheat river, a mined Appalachian watershed. 2004 National Meeting of the American Society of Mining and Reclaimation and the 25th West Virginia Surface Mining Drainage Task Force.

Petty, J. T., P. J. Lamothe, and P. M. Mazik. 2005. Spatial and seasonal dynamics of brook trout populations in a central Appalachian watershed.Transactions of the American Fisheries Society. 134:572-587.

Poff, N. L., and Allan, J. D. 1995. Functional organization of stream fish assemblages in relation to hydrologic variability. Ecology 76:606-627.

Power, G., R. S. Brown, and J. G. Imhof. 1999. Groundwater and fish - insights from northern North America. Hydrological Processes 13:401-422.

Pulliam, H. R. 1988. Sources, sinks and population regulation. American Naturalist 132:652661.

Pulliam, H. R., and B. J. Danielson. 1991. Sources, sinks, and habitat selection: a landscape perspective on population dynamics. American Naturalist 137:S51-S66.

Sale, P. F., and N. Tolimieri. 2000. Density dependence at some time and place? Oecologia 124: $166-171$.

Sandin, S. A., and S. W. Pacala. 2005. Demographic theory of coral reef fish populations with stochastic recruitment: comparing sources of population regulation. The American Naturalist 165:107-119.

Schlosser, I. J. 1985. Flow regime, juvenile abundance, and the assemblage structure of stream fishes. Ecology 66:1484-1490.

Schlosser, I. J. 1991. Stream fish ecology: a landscape perspective. Bioscience 41:704-712.

Schlosser, I. J., and P. L. Angermeier. 1995. Spatial variation in demographic processes of lotic fishes: Conceptual models, empirical evidence, and implications for conservation. American Fisheries Society Symposium 17:392-401.

Simonson, T. D., J. Lyons, and P. D. Kanehl. 1994. Quantifying fish habitat in streams: transect spacing, sample size, and a proposed framework. North American Journal of Fisheries Management 14:607-615.

Sorensen, P. W., J. R. Cardwell, T. Essington, and D. E. Weigel. 1995. Reproductive interactions between sympatric brook and brown trout in a small Minnesota stream. Canadian Journal of Fisheries and Aquatic Sciences 52:1958-1965.

Spina, A.P. 2001. Incubation discharge and aspects of brown trout population dynamics. Transactions of the American Fisheries Society 130:322-327. 
Sun, G., S. G. McNulty, D. M. Amatya, R. W. Skaggs, L. W. Swift Jr., J. P. Shepard, and H. Riekerk. 2002. A comparison of the watershed hydrology of coastal forested Wetlands and the mountainous uplands in the Southern US. Journal of Hydrology 263:92-104.

Thorne, D. W. 2004. Spatial and seasonal variation in brook trout diet, growth, and consumption in a complex Appalachian watershed. Thesis submitted to the Davis College of Agriculture, Forestry, and Consumer Sciences, West Virginia University.

Turchin, P. 1995. Population regulation: old arguments and a new synthesis. In: Cappuccino, N., and Price, P. (eds) Population dynamics: new approaches and synthesis. Academic Press, San Diego.

Turchin, P. and I. Hanski. 2001. Contrasting alternative hypothesis about rodent cycles by translating them into parameterized models. Ecology Letters, 4:267-276.

Vannote, R. L., G. W. Minshall, K. W. Cummins, J. R. Sedell, and C. E. Cushing. 1980. The river continuum concept. The Canadian Journal of Fisheries and Aquatic Sciences. 37:130-137.

Van Sickle, J., J.P. Baker, H.A. Simonin, B.P. Baldigo, W.A. Kretser, W.E. Sharpe. 1996. Episodic acidification of small streams in the northeast United States: fish mortality in field bioassays. Ecological Applications 6:408-421.

Waite, I. R., A. T. Herlihy, D. P. Larsen, and D. J. Klemm. 2000. Comparing strengths of geographic and non-geographic classifications of stream benthic macroinvertebrates in the MidAtlantic Highlands, USA. Journal of the North American Benthological Society 19:429-441.

Welsh, S. A. and S. A. Perry. 1997. Acidification and fish occurrence in the upper Cheat River drainage, West Virginia. Journal of the American Water Resources Association 33:423-429.

Wigington, P. J. Jr., J. P. Baker, D. R. DeWalle, W. A. Kretser, P. S. Murdoch, H. A. Simonin, J. Van Sickle, M. K. McDowell, D. V. Peck, and W. R. Barchet. 1996. Episodic acidification of small streams in the northeast United States: episodic response project. Ecological Applications 6:374-388.

Witzel, L. D. and H. R. MacCrimmon. 1983. Redd-site selection by brook trout and brown trout in southwestern Ontario streams. Transactions of the American Fisheries Society 112:760-771.

Yoder, C. O., and M. S. Smith. 1999. Using fish assemblages in a state biological assessment and criteria program: essential concepts and considerations. In Simon, T. P. Editor. 1999. Assessing the sustainability and biological integrity of water resources using fish communities. CRC press. New York, USA. 671p. 
Table 1. Summary characteristics of 34 sample sites draining within $1 \mathrm{~km}$ of the Upper Shavers Fork main stem. Sites represent a broad range of stream size $\left(0.08-3 \mathrm{~km}^{2}\right)$, instream physical characteristics, canopy cover, and water quality. Site numbers increase with increasing spatial position in the watershed (see Figure 1).

\begin{tabular}{|c|c|c|c|c|c|c|c|c|c|c|c|c|c|c|c|}
\hline $\begin{array}{c}\text { Site } \\
\#\end{array}$ & $\begin{array}{l}\text { Basin } \\
\text { Area } \\
\left(\mathrm{km}^{2}\right)\end{array}$ & $\begin{array}{l}\text { Wetted } \\
\text { Width } \\
(\mathrm{m})\end{array}$ & $\begin{array}{l}\text { Slope } \\
(\%)\end{array}$ & $\begin{array}{l}\text { Mean } \\
\text { Depth } \\
(\mathrm{cm})\end{array}$ & $\begin{array}{c}\text { Mean } \\
\text { Velocity } \\
\text { (m/sec) }\end{array}$ & $\begin{array}{c}\text { Mean } \\
\text { Distance to } \\
\text { Cover }(m)\end{array}$ & $\begin{array}{c}\text { Pool } \\
\text { Area } \\
(\%)\end{array}$ & $\begin{array}{c}\text { Stream } \\
\text { Margin } \\
(\%)\end{array}$ & $\begin{array}{c}\text { Spawning } \\
\text { Substrate } \\
(\%)\end{array}$ & $\begin{array}{c}\text { Canopy } \\
\text { Cover } \\
(\%)\end{array}$ & $\begin{array}{c}\text { LWD } \\
\left(\mathrm{m}^{2}\right)\end{array}$ & $\begin{array}{c}\text { Median } \\
\text { Substrate } \\
\text { Size } \\
(\mathrm{mm})\end{array}$ & $\begin{array}{c}\text { Spring } \\
\text { pH }\end{array}$ & $\begin{array}{c}\text { Spring } \\
\text { Alkalinity } \\
(\mathrm{mg} / \mathrm{L} \\
\left.\mathrm{CaCO}_{3}\right)\end{array}$ & $\begin{array}{c}\text { Spring } \\
\text { Monomeric } \\
\mathrm{Al}^{+3} \\
(\mathrm{mg} / \mathrm{L})\end{array}$ \\
\hline 1 & 2.43 & 3.2 & 7.2 & 19 & 0.29 & 0.6 & 30 & 24 & 7 & 82 & 72 & 71 & 6.2 & 8.6 & 0.00 \\
\hline 2 & 1.53 & 2.2 & 14.1 & 21 & 0.30 & 0.4 & 48 & 30 & 6 & 75 & 117 & 84 & 6.3 & 8.5 & 0.24 \\
\hline 3 & 2.17 & 4.2 & 7.2 & 19 & 0.34 & 0.5 & 13 & 17 & 6 & 87 & 67 & 102 & 5.0 & 1.6 & 0.34 \\
\hline 4 & 2.64 & 3.7 & 5.0 & 17 & 0.24 & 0.5 & 17 & 14 & 4 & 81 & 62 & 55 & 5.8 & 2.5 & 0.19 \\
\hline 5 & 1.49 & 3.3 & 9.1 & 14 & 0.19 & 0.7 & 15 & 17 & 6 & 87 & 65 & 73 & 4.6 & 0.4 & 0.23 \\
\hline 6 & 0.88 & 3.2 & 12.1 & 21 & 0.36 & 0.5 & 44 & 16 & 8 & 87 & 85 & 70 & 4.7 & 1.3 & 0.39 \\
\hline 7 & 0.62 & 2.5 & 13.5 & 18 & 0.19 & 0.5 & 23 & 14 & 6 & 84 & 92 & 63 & 4.7 & 0.9 & 0.22 \\
\hline 8 & 2.79 & 2.9 & 6.6 & 19 & 0.29 & 0.6 & 28 & 25 & 6 & 78 & 71 & 82 & 5.4 & 2.0 & 0.23 \\
\hline 9 & 3.00 & 2.6 & 2.6 & 15 & 0.22 & 0.8 & 71 & 46 & 18 & 75 & 91 & 32 & 6.2 & 6.6 & 0.40 \\
\hline 10 & 0.21 & 1.4 & 6.3 & 8 & 0.13 & 0.7 & 39 & 44 & 19 & 88 & 102 & 20 & 6.0 & 4.3 & 0.00 \\
\hline 11 & 0.35 & 3.3 & 8.8 & 16 & 0.14 & 0.3 & 17 & 18 & 8 & 82 & 118 & 63 & 5.4 & 2.5 & 0.00 \\
\hline 12 & 0.24 & 1.6 & 17.2 & 11 & 0.07 & 0.4 & 23 & 26 & 12 & 91 & 163 & 30 & 5.9 & 2.7 & 0.00 \\
\hline 13 & 1.12 & 3.1 & 9.8 & 19 & 0.12 & 0.3 & 33 & 24 & 9 & 79 & 118 & 71 & 6.2 & 4.6 & 0.00 \\
\hline 14 & 1.34 & 2.9 & 9.6 & 23 & 0.11 & 0.5 & 47 & 34 & 7 & 82 & 91 & 107 & 6.1 & 3.0 & 0.00 \\
\hline 15 & 0.08 & 0.8 & 4.8 & 7 & 0.04 & 0.4 & 53 & 67 & 8 & 84 & 144 & 3 & 6.0 & 2.7 & 0.00 \\
\hline 16 & 0.49 & 1.5 & 8.5 & 10 & 0.06 & 0.5 & 24 & 28 & 6 & 78 & 86 & 18 & 6.3 & 7.7 & 0.00 \\
\hline 17 & 0.13 & 0.9 & 7.2 & 8 & 0.08 & 0.6 & 27 & 34 & 16 & 78 & 60 & 8 & 6.2 & 8.9 & 0.00 \\
\hline 18 & 0.35 & 2.0 & 7.6 & 13 & 0.09 & 0.8 & 23 & 41 & 5 & 79 & 95 & 28 & 5.8 & 2.3 & 0.00 \\
\hline 19 & 0.20 & Dry & Dry & Dry & Dry & Dry & Dry & Dry & Dry & Dry & Dry & Dry & Dry & Dry & Dry \\
\hline 20 & 0.21 & Dry & Dry & Dry & Dry & Dry & Dry & Dry & Dry & Dry & Dry & Dry & Dry & Dry & Dry \\
\hline 21 & 0.08 & Dry & Dry & Dry & Dry & Dry & Dry & Dry & Dry & Dry & Dry & Dry & Dry & Dry & Dry \\
\hline 22 & 0.39 & 1.0 & 2.2 & 13 & 0.16 & 0.2 & 49 & 67 & 25 & 52 & 22.53 & 7 & 6.2 & 4.8 & 0.00 \\
\hline 23 & 0.08 & Dry & Dry & Dry & Dry & Dry & Dry & Dry & Dry & Dry & Dry & Dry & Dry & Dry & Dry \\
\hline 24 & 0.36 & Dry & Dry & Dry & Dry & Dry & Dry & Dry & Dry & Dry & Dry & Dry & Dry & Dry & Dry \\
\hline 25 & 0.27 & 2.2 & 4.7 & 9 & 0.14 & 0.5 & 9 & 28 & 4 & 82 & 46 & 25 & 6.3 & 6.5 & 0.34 \\
\hline 26 & 0.08 & 1.2 & 7.4 & 8 & 0.19 & 0.8 & 32 & 51 & 15 & 89 & 76 & 4 & 6.3 & 7.4 & 0.00 \\
\hline 27 & 0.30 & 1.4 & 4.6 & 11 & 0.22 & 0.5 & 24 & 48 & 22 & 78 & 45 & 28 & 6.3 & 11.6 & 0.00 \\
\hline 28 & 0.14 & 0.7 & 1.5 & 18 & 0.13 & 0.7 & 78 & 86 & 23 & 42 & 30 & 1 & 6.4 & 9.4 & 0.00 \\
\hline 29 & 0.13 & 2.0 & 22.9 & 10 & 0.29 & 0.5 & 14 & 22 & 6 & 87 & 110 & 33 & 6.5 & 18.2 & 0.25 \\
\hline 30 & 2.26 & 3.8 & 3.0 & 19 & 0.22 & 0.4 & 25 & 24 & 3 & 75 & 64 & 68 & 6.6 & 12.7 & 0.00 \\
\hline 31 & 1.42 & 3.3 & 6.6 & 30 & 0.25 & 0.4 & 28 & 19 & 4 & 79 & 58 & 63 & 6.1 & 0.0 & 0.00 \\
\hline 32 & 0.48 & 2.4 & 10.5 & 17 & 0.12 & 0.5 & 21 & 22 & 4 & 84 & 89 & 65 & 6.3 & 2.9 & 0.00 \\
\hline 33 & 0.33 & 1.6 & 10.6 & 11 & 0.03 & 0.5 & 33 & 37 & 5 & 91 & 128 & 66 & 4.4 & 0.0 & 0.00 \\
\hline 34 & 0.08 & 1.3 & 11.1 & 7 & 0.06 & 0.5 & 24 & 48 & 7 & 89 & 41 & 16 & 6.7 & 39.9 & 0.00 \\
\hline
\end{tabular}


Table 2. Factor loading scores for the dominant instream physical and chemical habitat gradients derived from 29 perennial study reaches within the upper Shavers Fork watershed. Only factor loading $>|0.4|$ are presented.

\begin{tabular}{|c|c|c|c|c|c|}
\hline & \multicolumn{3}{|c|}{ Physical } & \multicolumn{2}{|c|}{ Chemical } \\
\hline & $\mathrm{PC} 1$ & PC 2 & PC 3 & PC 1 & PC 2 \\
\hline Eigenvalue & 4.00 & 2.41 & 1.30 & 1.94 & 0.89 \\
\hline$\%$ Contribution & 36.35 & 21.89 & 11.81 & 64.59 & 29.59 \\
\hline Basin Area $\left(\mathrm{km}^{2}\right)$ & ---- & 0.41 & ---- & & 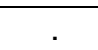 \\
\hline Slope (\%) & ---- & -0.45 & ---- & . & . \\
\hline Mean Depth $(\mathrm{cm})$ & ---- & ---- & ---- & . & . \\
\hline Depth CV & ---- & ---- & 0.58 & . & . \\
\hline Mean Velocity (m/s) & ---- & ---- & --- & . & . \\
\hline Mean Distance to Cover & ---- & ---- & ---- & . & . \\
\hline Pool Area (\%) & ---- & --- & 0.52 & . & . \\
\hline Stream Margin (\%) & -0.46 & ---- & ---- & . & . \\
\hline Spawning Substrate (\%) & ---- & ---- & --- & . & . \\
\hline $\operatorname{LWD}\left(\mathrm{m}^{2}\right)$ & --- & -0.40 & 0.45 & & \\
\hline Median Substrate Size $(\mathrm{mm})$ & 0.46 & ---- & ---- & & . \\
\hline Spring pH & . & & . & 0.68 & ---- \\
\hline Spring Alkalinity $\left(\mathrm{mg} / \mathrm{L} \mathrm{CaCO}_{3}\right)$ & . & & . & 0.62 & 0.42 \\
\hline Spring Monomeric $\mathrm{Al}^{+3}$ & & & & ---- & 0.90 \\
\hline
\end{tabular}


Table 3. Summary results of the multiple regression analysis relating juvenile brook trout density (\#/hectare) to principle component scores along the dominant instream physical and chemical habitat gradients, canopy cover, and adult brook trout (> $60 \mathrm{~mm} \mathrm{SL}$ ) density (\#/hectare) across 29 perennial study reaches located within the upper Shavers Fork watershed.

\begin{tabular}{lccccc}
\hline \multicolumn{1}{c}{ Habitat Variable } & F-Value & D.F. & Partial R & $\begin{array}{c}\text { Direction of } \\
\text { Effect }\end{array}$ & $P$-value \\
\hline $\begin{array}{l}\text { Acidity Gradient } \\
\text { (CPC 1) }\end{array}$ & 14.15 & 1 & 0.51 & Positive & 0.0009 \\
$\begin{array}{l}\text { Substrate Size Gradient } \\
\text { (PPC 1) }\end{array}$ & 4.48 & 1 & 0.07 & Negative & 0.04 \\
Full Model & 18.08 & 28 & 0.58 & & $<0.0001$ \\
\hline
\end{tabular}


Table 4. Summary results of the multiple regression analysis relating juvenile brook trout density (\#/hectare) to principle component scores along dominant instream physical and chemical habitat gradients, canopy cover, and adult brook trout (> $60 \mathrm{~mm} \mathrm{SL}$ ) density (\#/hectare) across 24 perennial study reaches with "good" water quality (spring $\mathrm{pH}>5.0$ and spring alkalinity $>2.0 \mathrm{mg} / \mathrm{L} \mathrm{CaCO}_{3}$ ) located within the upper Shavers Fork watershed.

\begin{tabular}{cccccc}
\hline Habitat Variable & F-Value & D.F. & Partial R & $\begin{array}{c}\text { Direction of } \\
\text { Effect }\end{array}$ & $P$-value \\
\hline $\begin{array}{c}\text { Substrate Size Gradient } \\
\text { (PPC 1) }\end{array}$ & 8.41 & 1 & 0.28 & Negative & 0.008 \\
Full Model & 8.41 & 23 & 0.28 & & 0.008 \\
\hline
\end{tabular}


Table 5. Results of ANOVA on mean $( \pm \mathrm{SE})$ physical and chemical characteristics for the 4 relative juvenile density groups (high $\mathrm{N}=11$, low $\mathrm{N}=10$, absent-1 $\mathrm{N}=3$, absent-2 $\mathrm{N}=5$ ) as identified by hierarchal classification. The absent-1 group represents sites with no juveniles and "good" water quality $\left(\mathrm{pH}>5.0\right.$, alkalinity $\left.>2 \mathrm{mg} / \mathrm{L} \mathrm{CaCO}_{3}\right)$. The absent-2 group represents sites with no juveniles and "poor" water quality $\left(\mathrm{pH}<5.0\right.$, alkalinity $<2 \mathrm{mg} / \mathrm{L} \mathrm{CaCO}_{3}$ ).

Significant differences $(P<0.05)$ are listed in bold. Letters indicate differences in group means.

\begin{tabular}{|c|c|c|c|c|c|c|}
\hline Parameter & High & Low & Absent-1 & Absent-2 & $\boldsymbol{F}$ & $\boldsymbol{P}$ \\
\hline Basin Area $\left(\mathrm{km}^{2}\right)$ & $0.33(0.12)^{\mathrm{A}}$ & $1.67(0.34)^{\mathrm{B}}$ & $0.63(0.40)^{\mathrm{AB}}$ & $1.10(0.33)^{\mathrm{AB}}$ & 5.9 & 0.003 \\
\hline Wetted Width $( \pm 0.1 \mathrm{~m})$ & $1.4(0.2)^{\mathrm{A}}$ & $2.8(0.2)^{\mathrm{B}}$ & $2.5(0.8)^{\mathrm{AB}}$ & $3.0(0.4)^{\mathrm{B}}$ & 7.3 & 0.001 \\
\hline Slope $( \pm 0.1 \%)$ & $7.4(1.5)$ & $8.6(1.8)$ & $7.5(0.6)$ & $10.5(1.1)$ & 0.7 & 0.557 \\
\hline Mean Depth $( \pm 1 \mathrm{~cm})$ & $11(1)$ & $16(1)$ & $16(7)$ & $16(2)$ & 2.6 & 0.074 \\
\hline Mean Velocity $(\mathrm{m} / \mathrm{sec})$ & $0.14(0.02)$ & $0.20(0.03)$ & $0.16(0.05)$ & $0.22(0.06)$ & 0.9 & 0.443 \\
\hline Mean Dist. to Cover $( \pm 0.1 \mathrm{~m})$ & $0.5(0.1)$ & $0.5(0.0)$ & $0.4(0.1)$ & $0.6(0.0)$ & 0.6 & 0.591 \\
\hline Pool Area $( \pm 1 \%)$ & $37(6)$ & $31(5)$ & $24(4)$ & $26(6)$ & 0.8 & 0.532 \\
\hline Stream Margin $( \pm 1 \%)$ & $49(6)^{\mathrm{A}}$ & $26(3)^{\mathrm{B}}$ & $23(5)^{\mathrm{B}}$ & $20(4)^{\mathrm{B}}$ & 7.8 & 0.001 \\
\hline Spawning Substrate $( \pm 1 \%)$ & $13(2)$ & $7(1)$ & $9(4)$ & $6(1)$ & 2.6 & 0.076 \\
\hline Canopy Cover $( \pm 1 \%)$ & $77(5)$ & $80(1)$ & $80(1)$ & $87(1)$ & 1.0 & 0.400 \\
\hline $\operatorname{LWD}\left( \pm 1 \mathrm{~m}^{2}\right)$ & $80(14)$ & $86(6)$ & $78(20)$ & $88(12)$ & 0.3 & 0.863 \\
\hline Median Substrate Size $( \pm 1 \mathrm{~mm})$ & $22(7)^{\mathrm{A}}$ & $60(8)^{\mathrm{B}}$ & $45(18)^{\mathrm{AB}}$ & $75(7)^{\mathrm{B}}$ & 7.4 & 0.001 \\
\hline Spring $\mathrm{pH}$ & $6.2(0.1)^{\mathrm{A}}$ & $6.1(0.1)^{\mathrm{A}}$ & $5.9(0.2)^{\mathrm{A}}$ & $4.6(0.1)^{\mathrm{B}}$ & 39.4 & 0.001 \\
\hline Spring Alk. $\left( \pm 0.1 \mathrm{mg} / \mathrm{L} \mathrm{CaCO}_{3}\right)$ & $9.1(3.2)^{\mathrm{A}}$ & $6.9(1.7)^{\mathrm{A}}$ & $3.8(2.6)^{\mathrm{AB}}$ & $0.8(0.3)^{\mathrm{B}}$ & 6.1 & 0.003 \\
\hline Spring Mon. $\mathrm{Al}^{+3}(\mathrm{mg} / \mathrm{L})$ & $0.05(0.04)$ & $0.11(0.05)$ & $0.00(0.00)$ & $0.24(0.07)$ & 2.9 & 0.055 \\
\hline Physical PC 1 & $-1.71(0.57)^{\mathrm{A}}$ & $0.93(0.32)^{\mathrm{B}}$ & $0.59(1.38)^{\mathrm{AB}}$ & $1.54(0.42)^{\mathrm{B}}$ & 7.5 & 0.001 \\
\hline Physical PC 2 & $-0.19(0.51)$ & $0.39(0.51)$ & $-0.28(0.84)$ & $-0.19(0.58)$ & 0.3 & 0.817 \\
\hline Physical PC 3 & $-0.04(0.39)$ & $-0.15(0.39)$ & $0.64(0.39)$ & $0.00(0.52)$ & 0.4 & 0.793 \\
\hline Chemical PC 1 & $0.73(0.24)^{\mathrm{A}}$ & $0.44(0.28)^{\mathrm{A}}$ & $-0.02(0.58)^{\mathrm{A}}$ & $-2.47(0.12)^{\mathrm{B}}$ & 20.2 & 0.001 \\
\hline Chemical PC 2 & $-0.04(0.26)$ & $0.23(0.31)$ & $-0.84(0.34)$ & $0.13(0.51)$ & 1.0 & 0.397 \\
\hline
\end{tabular}


Table 6. Juvenile brook trout summary statistics for each of the 4 relative juvenile density groups (high $\mathrm{N}=11$, low $\mathrm{N}=10$, absent- $\mathrm{N}=3$, absent- $\mathrm{N}=5$ ) as identified by hierarchal classification. The absent-1 group represents sites with no juveniles and "good" water quality $\left(\mathrm{pH}>5.0\right.$, alkalinity $\left.>2 \mathrm{mg} / \mathrm{L} \mathrm{CaCO}_{3}\right)$. The absent-2 group represents sites with no juveniles and "poor" water quality $\left(\mathrm{pH}<5.0\right.$, alkalinity $\left.<2 \mathrm{mg} / \mathrm{L} \mathrm{CaCO}_{3}\right)$.

\begin{tabular}{lccc}
\hline & \# Streams & $\begin{array}{c}\text { Mean Density } \\
(\# / \text { ha })\end{array}$ & $\begin{array}{c}\text { Range } \\
(\text { \#/ha })\end{array}$ \\
\cline { 2 - 4 } High & 11 & 593 & $212-1,238$ \\
Low & 10 & 88 & $63-167$ \\
Absent 1 & 3 & 0 & ---- \\
Absent 2 & 5 & 0 & --- \\
\hline
\end{tabular}


Table 7. Summary results of the linear discriminate function analysis used to discriminate between the 4 relative juvenile density groups (high $\mathrm{N}=11$, low $\mathrm{N}=10$, absent- $\mathrm{N}=3$, absent$2 \mathrm{~N}=5$ ) as identified by hierarchal classification. The absent-1 group represents sites with no juveniles and "good" water quality $(\mathrm{pH}>5.0 \text {, alkalinity }>2 \mathrm{mg} / \mathrm{L} \mathrm{CaCO})_{3}$. The absent-2 group represents sites with no juveniles and "poor" water quality $(\mathrm{pH}<5.0$, alkalinity $<2 \mathrm{mg} / \mathrm{L}$ $\mathrm{CaCO}_{3}$ ). Modeled parameters were correlated to canonical axis 1 and 2. Significant correlations are shown in bold and were considered key discriminating variable along each axis. Model is significant at the alpha $<0.05$ level, Wilks-Lambda $<0.0001$.

\begin{tabular}{|c|c|c|c|c|}
\hline & \multicolumn{2}{|c|}{ Canonical Function 1} & \multicolumn{2}{|c|}{ Canonical Function 2} \\
\hline Eigenvalue & \multicolumn{2}{|c|}{6.25} & \multicolumn{2}{|c|}{1.36} \\
\hline$\%$ Contribution & \multicolumn{2}{|c|}{76.6} & \multicolumn{2}{|c|}{16.69} \\
\hline $\mathrm{R}_{\mathrm{c}}^{2}$ & \multicolumn{2}{|c|}{0.86} & \multicolumn{2}{|c|}{0.58} \\
\hline Variable & Correlation & $P$-Value & Correlation & $P$-Value. \\
\hline Basin Area $\left(\mathrm{km}^{2}\right)$ & -0.15 & 0.42 & 0.81 & $<0.001$ \\
\hline Depth CV & -0.29 & 0.12 & -0.27 & 0.16 \\
\hline Stream Margin (\%) & 0.44 & 0.02 & -0.57 & $<0.001$ \\
\hline LWD & -0.09 & 0.63 & 0.19 & 0.32 \\
\hline Spring $\mathrm{pH}$ & 0.98 & $<0.001$ & -0.01 & 0.96 \\
\hline
\end{tabular}


Table 8. Number of correctly classified sites (\%) from the linear discriminate function analysis used to discriminate between the 4 relative juvenile density groups $(\mathrm{N}=29)$. Model is significant at the alpha $<0.05$ level, Wilks-Lambda $<0.0001$.

\begin{tabular}{ccccc}
\hline & Absent 1 & Absent 2 & High & Low \\
\hline Absent 1 & $3(100)$ & 0 & 0 & 0 \\
Absent 2 & 0 & $5(100)$ & 0 & 0 \\
High & 0 & $1(9)$ & $8(73)$ & $2(18)$ \\
Low & $1(10)$ & 0 & 0 & $9(90)$ \\
\hline
\end{tabular}


Table 9. Summary results of the linear discriminate function analysis used to discriminate between the 3 relative juvenile density groups with "good" water quality (high $\mathrm{N}=11$, low $\mathrm{N}=$ 10 , absent-1 $\mathrm{N}=3$ ) as identified by hierarchal classification. The absent-1 group represents sites with no juveniles and "good" water quality $\left(\mathrm{pH}>5.0\right.$, alkalinity $\left.>2 \mathrm{mg} / \mathrm{L} \mathrm{CaCO}_{3}\right)$. Modeled parameters were correlated to canonical axis 1 and 2. Significant correlations are shown in bold and were considered key discriminating variable along each axis. Model is significant at the alpha $<0.05$ level, Wilks-Lambda $=0.0001$.

\begin{tabular}{|c|c|c|c|c|}
\hline & \multicolumn{2}{|c|}{ Canonical 1} & \multicolumn{2}{|c|}{ Canonical 2} \\
\hline Eigenvalue & \multicolumn{2}{|c|}{1.92} & \multicolumn{2}{|c|}{1.26} \\
\hline$\%$ Contribution & \multicolumn{2}{|c|}{60.41} & \multicolumn{2}{|c|}{39.59} \\
\hline $\mathrm{R}_{\mathrm{c}}^{2}$ & \multicolumn{2}{|c|}{0.66} & \multicolumn{2}{|c|}{0.56} \\
\hline Variable & Correlation & $P$-Value & Correlation & $P$-Value \\
\hline Basin Area $\left(\mathrm{km}^{2}\right)$ & -0.80 & $<0.001$ & 0.20 & 0.35 \\
\hline Depth CV & -0.01 & 0.98 & -0.69 & $<0.001$ \\
\hline Pool Area (\%) & 0.22 & 0.31 & 0.24 & 0.27 \\
\hline Stream Margin (\%) & 0.76 & $<0.001$ & 0.30 & 0.16 \\
\hline LWD & -0.18 & 0.40 & 0.05 & 0.81 \\
\hline
\end{tabular}


Table 10. Number of correctly classified sites (\%) from the linear discriminate function analysis used to discriminate between the 3 relative juvenile density group with "good" water quality (N $=24$ ). Model is significant at the alpha $<0.05$ level, Wilks-Lambda $=0.0001$.

\begin{tabular}{cccc}
\hline & Absent & High & Low \\
\hline Absent & $3(100)$ & 0 & 0 \\
High & 0 & $10(91)$ & $1(9)$ \\
Low & $1(10)$ & 0 & $9(90)$ \\
\hline
\end{tabular}




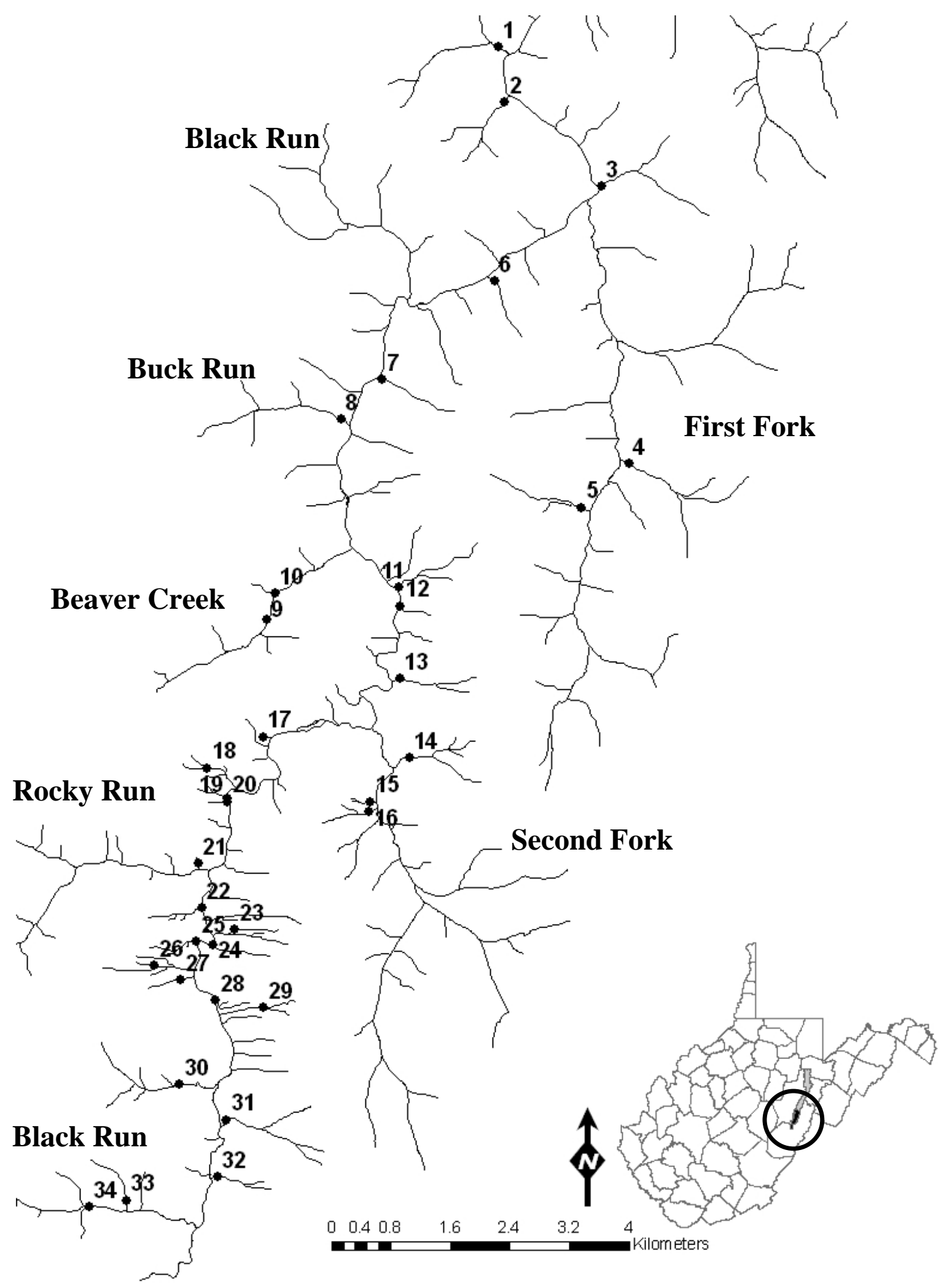

Figure 1. Location of 34 study sites (closed circles) within the upper Shavers Fork watershed of Pocahontas and Randolph counties, West Virginia (insert). 


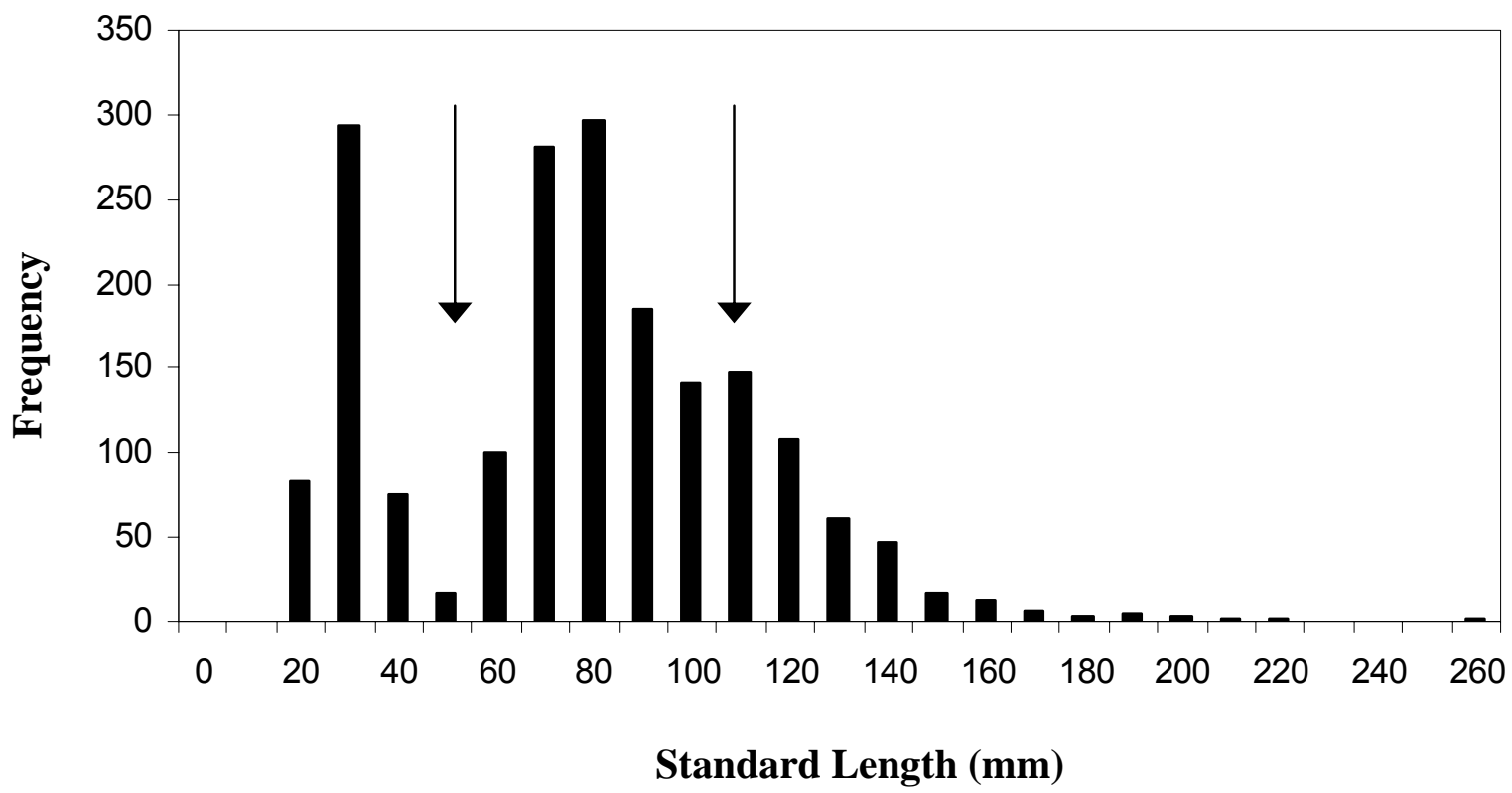

Figure 2. Brook trout length-frequency histogram used to classify all captured individuals into one of three size classes: juveniles ( $\mathrm{SL}<60 \mathrm{~mm}$ ), small adults $(60 \mathrm{~mm}<\mathrm{SL}<115 \mathrm{~mm}$ ), and large adults $(\mathrm{SL}>115)$. Data was pooled from all sites sampled within the upper Shavers Fork watershed during June 2004. 


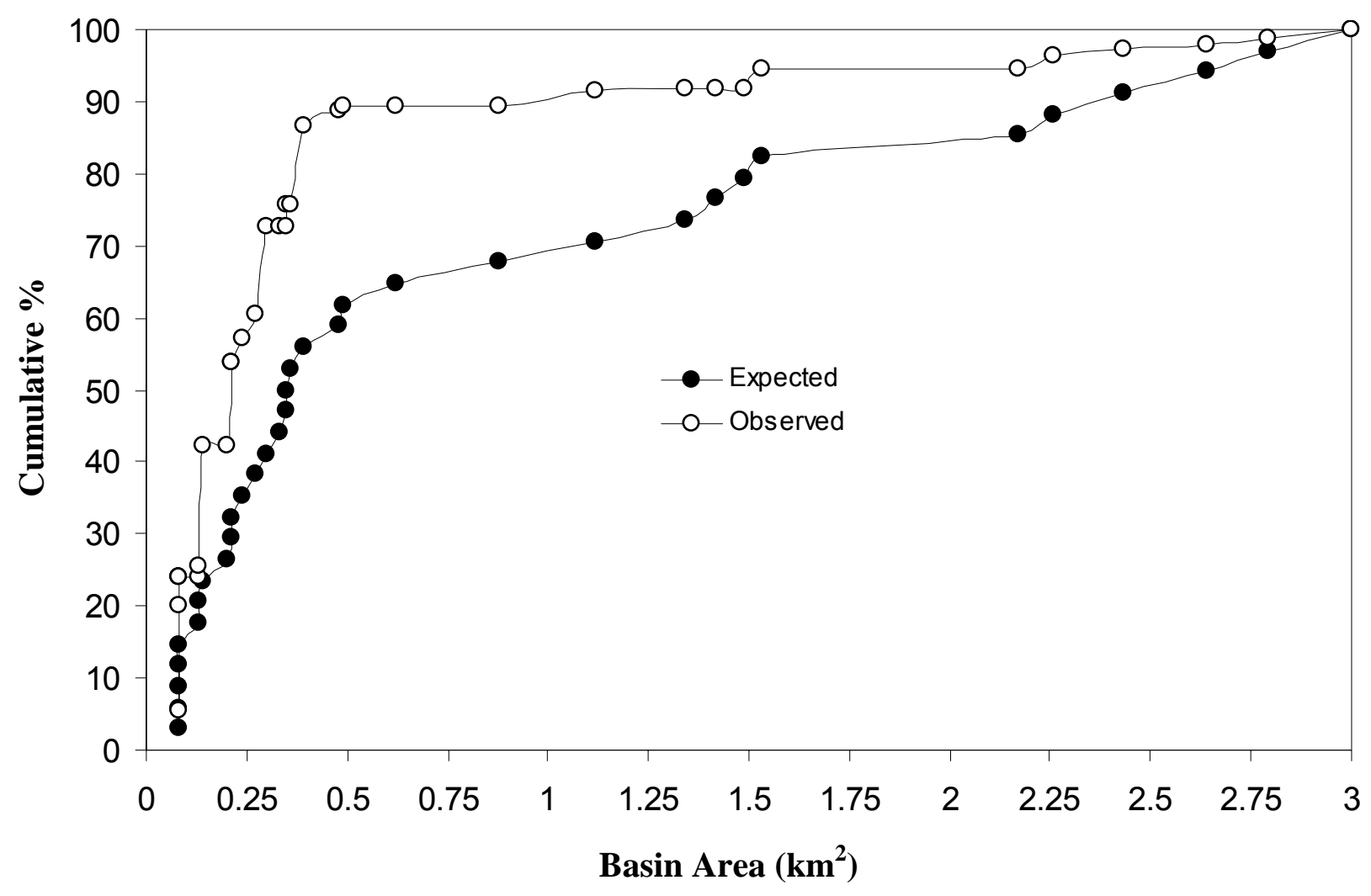

Figure 3. Relationship between the observed cumulative percent of juvenile brook trout density (\#/hectare) and the expected pattern based on the accumulation of available stream segments along a continuum of basin area between $0.8-3 \mathrm{~km}^{2}$. 

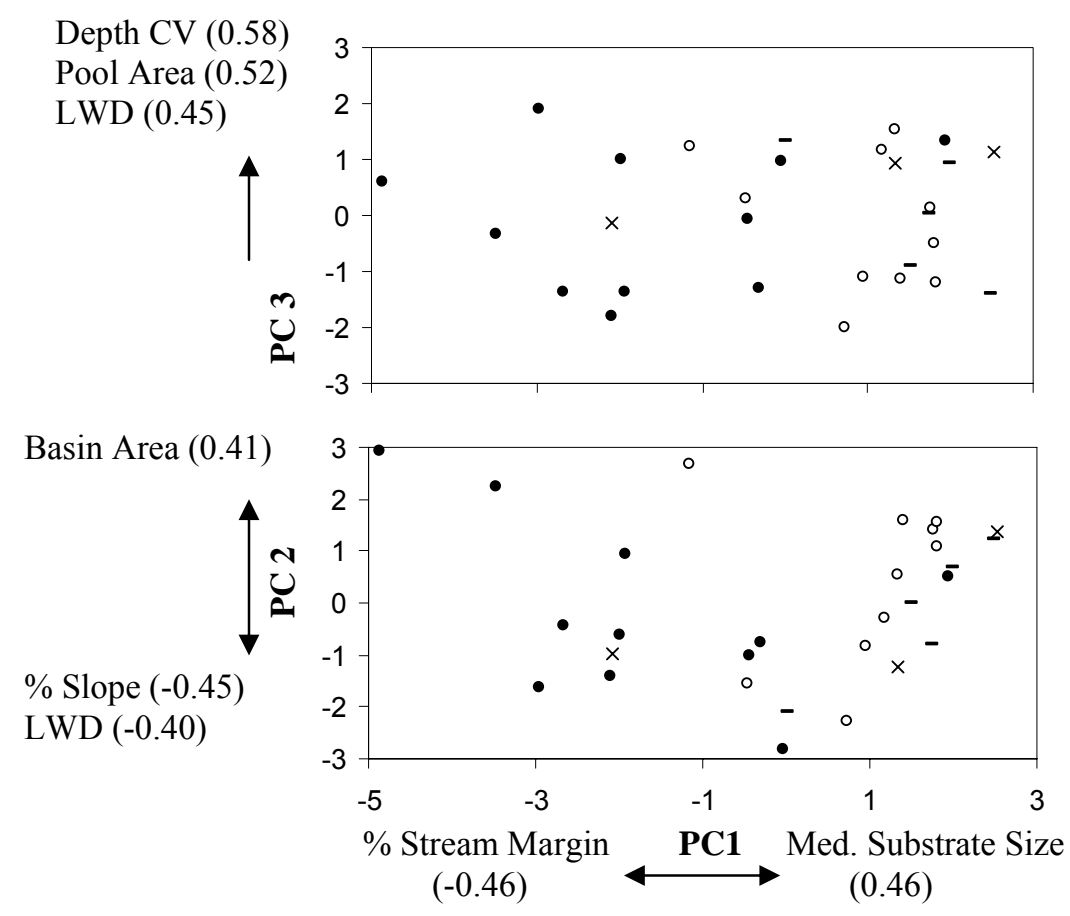

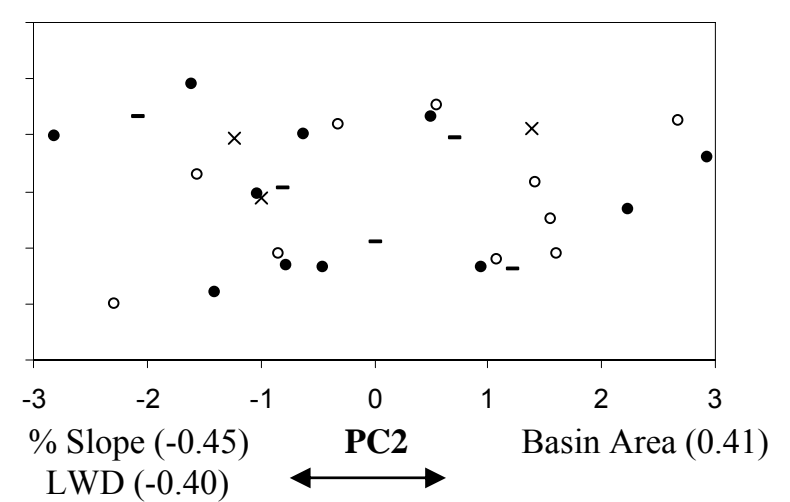

High

$\bigcirc$ Low

$\mathrm{x}$ Absent 1

- Absent 2

Figure 4. Relationships between major physical habitat gradients characterizing the perennial study reaches $(\mathrm{N}=29)$ within the upper Shavers Fork watershed. Groups differ by relative juvenile brook trout density. Absent-1 represents sites with no juveniles and "good" water quality (spring $\mathrm{pH}>5.0$ and spring alkalinity $>2.0 \mathrm{mg} / \mathrm{L} \mathrm{CaCO}$ ). Absent- 2 represents sites with no juveniles and "poor" water quality (spring $\mathrm{pH}<5.0$ and spring alkalinity $<2.0 \mathrm{mg} / \mathrm{L} \mathrm{CaCO}_{3}$ ). 
Spring alkalinity (0.42) 3

Spring Mon. $\mathrm{Al}^{+3}$ (0.90)
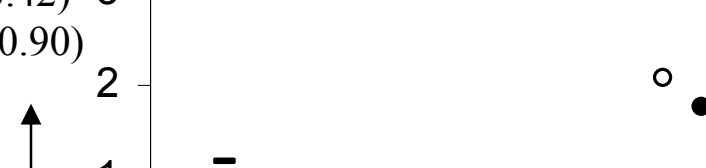

○

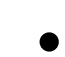

o

$\begin{aligned} & 1-- \\ & 0\end{aligned}-$

1

N -1

$\begin{array}{ll}U_{1} & -1 \\ & -2\end{array}$

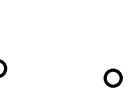

$\circ$

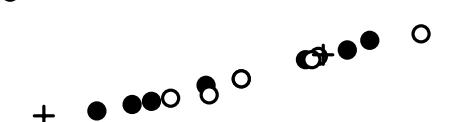

$+$

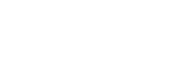

- High

- Low

+ Absent 1

- Absent 2

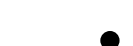

PC 1

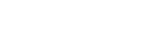

0

2

Spring $\mathrm{pH}(0.68)$

Spring alkalinity $(0.62)$

Figure 5. Relationships between major chemical habitat gradients characterizing the perennial study reaches $(\mathrm{N}=29)$ within the upper Shavers Fork watershed. Groups differ by relative juvenile brook trout density. Absent-1 represents sites with no juveniles and "good" water quality (spring $\mathrm{pH}>5.0$ and spring alkalinity $>2.0 \mathrm{mg} / \mathrm{L} \mathrm{CaCO}$ ). Absent-2 represents sites with no juveniles and "poor" water quality (spring $\mathrm{pH}<5.0$ and spring alkalinity $<2.0 \mathrm{mg} / \mathrm{L}$ $\left.\mathrm{CaCO}_{3}\right)$. 


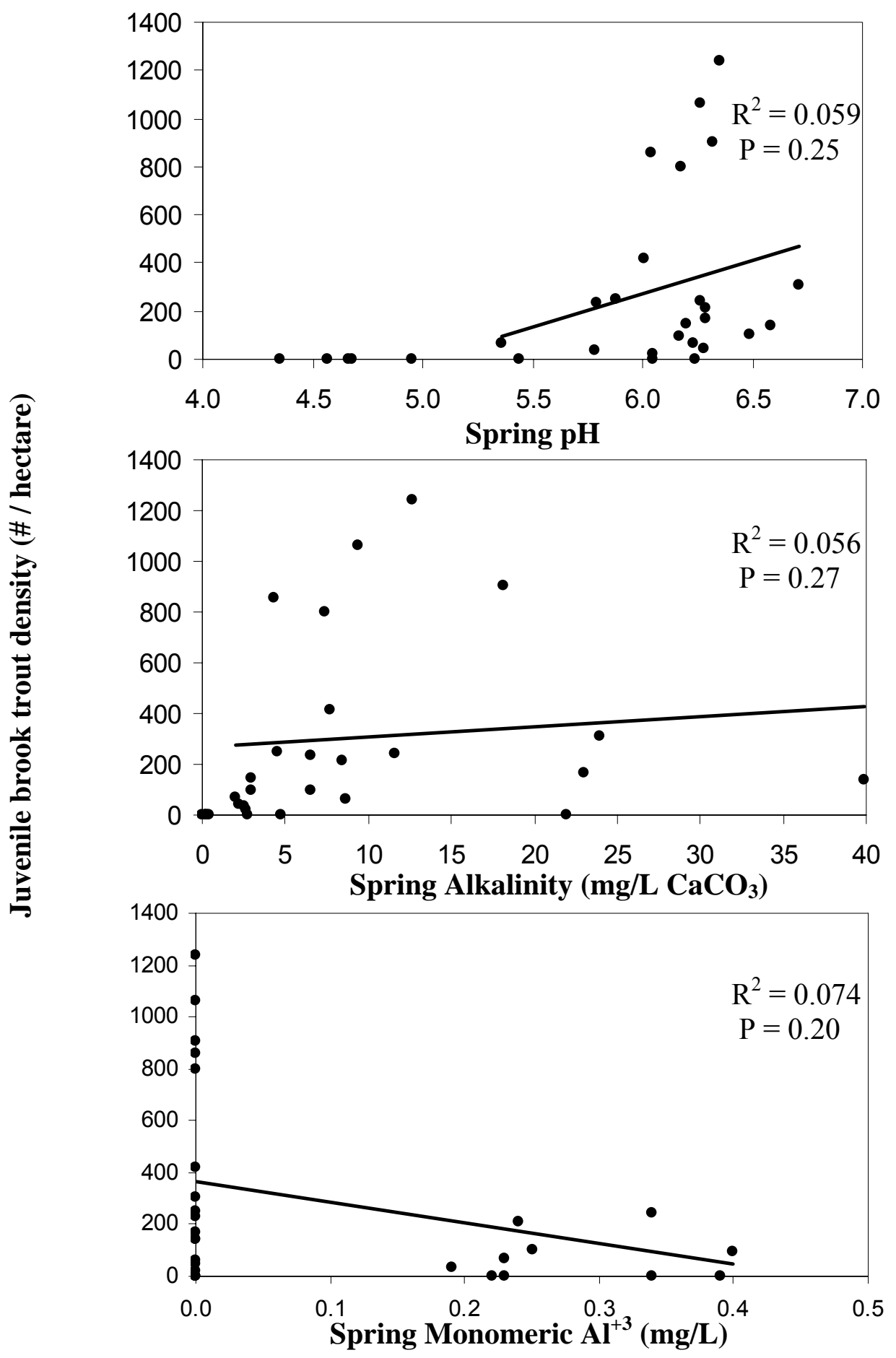

Figure 6. Relationship between $\mathrm{pH}$, alkalinity $\left(\mathrm{mg} / \mathrm{L} \mathrm{CaCO}_{3}\right)$, monomeric $\mathrm{Al}^{+3}$, and juvenile brook trout density (\# / hectare) for 29 perennial stream reaches within the upper Shavers Fork watershed. 


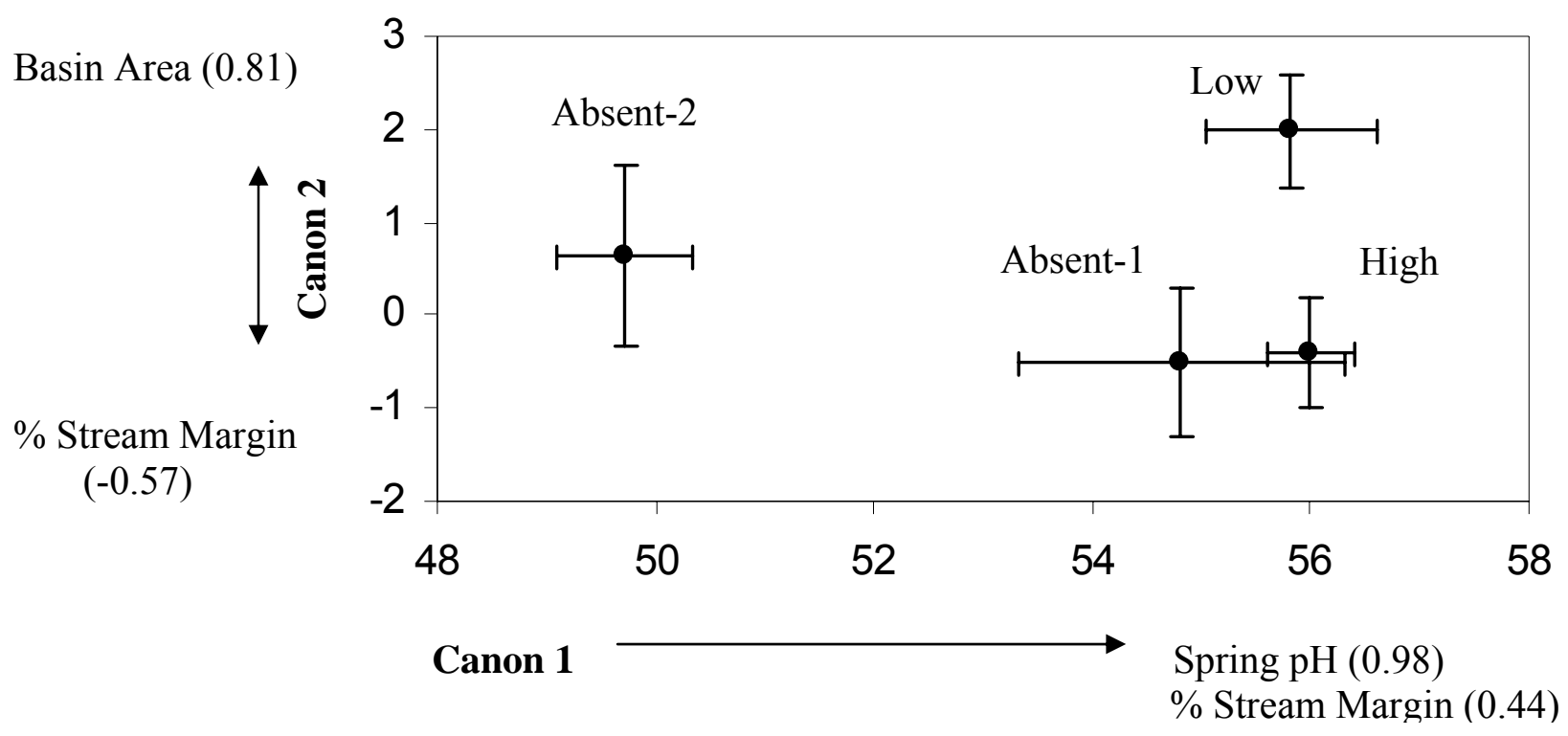

Figure 7. Mean canonical scores (error bars $=95 \%$ C.I.) used to discriminate between the 4 relative juvenile density groups (high $\mathrm{N}=11$, low $\mathrm{N}=10$, absent-1 $\mathrm{N}=3$, absent-2 $\mathrm{N}=5$ ) as identified by hierarchal classification. The absent-1 group represents sites with no juveniles and "good" water quality ( $\mathrm{pH}>5.0$, alkalinity $\left.>2 \mathrm{mg} / \mathrm{L} \mathrm{CaCO}_{3}\right)$. The absent- 2 group represents sites with no juveniles and "poor" water quality ( $\mathrm{pH}<5.0$, alkalinity $<2 \mathrm{mg} / \mathrm{L} \mathrm{CaCO} \mathrm{Ca}_{3}$. Significant discriminating parameters for each canonical axis are listed followed by their respective Pearson correlation coefficients. 


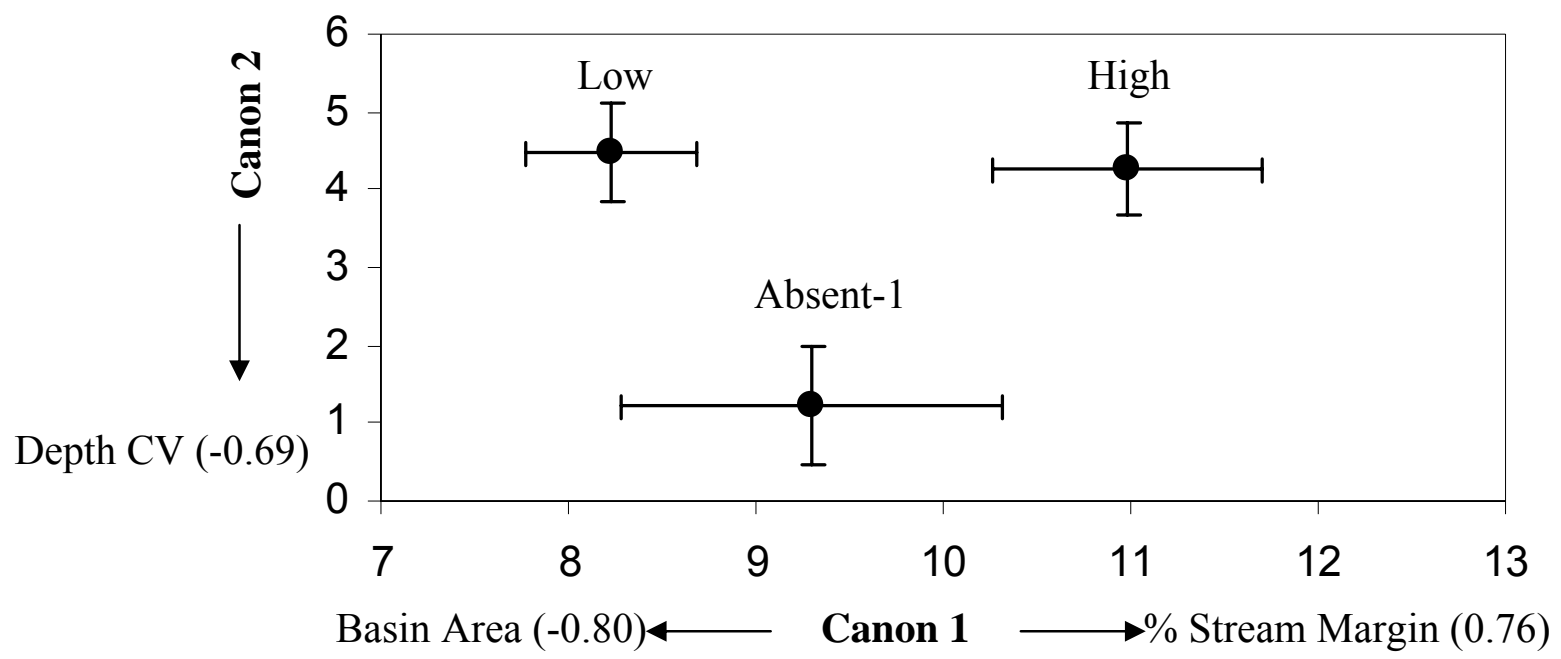

Figure 8. Mean canonical scores (error bars $=95 \%$ confidence intervals) used to discriminate between the 3 relative juvenile density groups with "good" water quality (high $\mathrm{N}=11$, low $\mathrm{N}=$ 10 , absent-1 $\mathrm{N}=3$ ) as identified by hierarchal classification. The absent-1 group represents sites with no juveniles and "good" water quality $(\mathrm{pH}>5.0 \text {, alkalinity }>2 \mathrm{mg} / \mathrm{L} \mathrm{CaCO})_{3}$. Significant discriminating parameters for each canonical axis are listed followed by their respective Pearson correlation coefficients. 


\title{
Chapter 2
}

Spatial Variation in Brook Trout (Salvelinus fontinalis) Population Dynamics in an Appalachian Watershed

\begin{abstract}
The upper Shavers Fork is a $5^{\text {th }}$ order, high elevation watershed located in the Allegheny Plateau region of eastern West Virginia. Throughout this region extensive resource extraction and development have resulted in the decline of wild brook trout populations. Effective management aimed at restoring these populations to historic levels and ensuring long term persistence will require a watershed-scale perspective. The overriding objective of this study was to understand where the brook trout population in the upper Shavers Fork watershed fits along the continuum of watershed-scale metapopulation models. Specifically, we wanted to (1) describe the spatial and temporal patterns of brook trout distribution (2) quantify the extent of linkages within and among small basin area tributaries and large basin area main stem habitat (3) quantify the spatial and temporal variability in brook trout demographic rates for small basin area tributaries and large basin area main stem habitat at both the reach- and watershed- scales, and (4) examine data for evidence of metapopulation, source-sink, and patchy population structure. We conducted spatially continuous surveys of brook trout population size structure and post reproductive demographic rates throughout 3 study regions, each consisting of a 1-2km main stem reach and several small basin area tributary networks. Additionally, physical habitat and water quality was measured continuously throughout each of the small basin area tributary networks. We found that the upper Shavers Fork brook trout population is a complex mosaic of elements derived from source-sink, metapopulation, and patchy population models. The majority of the brook trout population within the sampled regions was concentrated within larger reaches of small basin area tributary networks. Movement within small tributary networks
\end{abstract}


suggested that most brook trout were fairly sedentary, although longer range movements were observed. We observed limited interactions between small tributary networks and main stem habitat as well as among small tributary networks. Across all spatial scales, brook trout apparent survival was generally high and consistent; however, seasonal immigration rates were highly variable. Immigration rate appeared to be the dominant mechanism influencing population change at the tributary network reach- and main stem reach-scales. Brook trout populations at the small basin area tributary network-scale decreased seasonally due to seasonally consistent losses and low rates of immigration. Population persistence within these tributary networks was primarily a function of local recruitment, whereas immigration was the dominant demographic process in larger main stems. These results indicate that within small tributary networks brook trout populations best fit a patchy population model. Tributary to tributary interactions are consistent with a metapopulation model. Finally, tributary main stem interactions are consistent with source (tributary) - sink (main stem) model of spatial population structure. 


\section{Introduction}

Natural populations inhabit a mosaic of habitat types that vary spatially and temporally in quality (Watkinson and Sutherland 1995). These patchy landscapes are characterized by the size, shape, spatial distribution, and degree of isolation of available habitats (Fahrig and Merriam

1994). The interaction of these landscape characteristics with species life history strategies, environmental stochasticity, and human interaction has emerged as a central theme in population ecology (Wiens 1996). Habitat patchiness is believed to affect most every aspect of spatial population ecology (Bjornstad et al. 1998), and a thorough understanding of its effects is essential to the successful management of animal populations at multiple scales (Fausch et al. 2002).

Stream fishes provide a good example of organisms inhabiting systems characterized by patches of different habitat types that vary spatially and temporally. Lotic habitats can be described as a riverscape of hierarchically organized systems comprised of small- (micro and macrohabitats), intermediate- (stream reach and sub-basin), and large-scale (drainage network) patches (Frissell et al. 1986, Fausch et al. 2002). The observed patterns of riverscape heterogeneity are set by a variety of biotic and abiotic factors operating in different ways on habitat patches across the range of spatial scales (Vannote 1980, Frissell 1986, Schlosser and Angermeier 1995, Dunham and Rieman 1999, Fausch et al. 2002). Ultimately, large-scale factors such as climate, geology, and topography set the context for the local processes that form and maintain habitat patches at the smaller spatial scales (Frissell et al. 1986). These factors influence the quality of a given patch and create an inherent spatial heterogeneity between and among patches (Frissell 1986). 
Stream fishes often use a variety of habitat types in order to complete their life cycle and ensure population persistence (Schlosser and Angermeier 1995, Fausch et al. 2002). Spatially distinct habitat patches are defined by an organism's ecological requirements (Moilanen and Hanski 1998) which often differ both within and among species. The quality of a given patch is in part a function of the degree of complementation or proximity of ecological requirements that are essential for the persistence of an organism (Dunning et al. 1992, Schlosser 1995). The persistence of stream fish populations is dependent on access to non-substitutable "complementary" habitats such as reproductive, foraging, and refuge areas (Schlosser 1991, Dunning et al. 1992). Conversely, "supplementary" or substitutable habitats increase an organism's chance of survival through increased growth and fitness, but are not required for population persistence (Dunning et al. 1992). Population persistence is dependent on the availability of complementary habitats (Rosenfeld 2003) while population productivity is contingent on availability of supplementary habitats (Petty et al. 2005).

Spatial heterogeneity within the riverscape provides stream fishes with critical habitats (Fausch et al. 2002); however, these habitat patches are often distributed in unequal proportions throughout lotic systems (Schlosser 1991, Fausch et al. 2002). In response to the patchy nature of stream networks and ontogenic shifts in habitat requirements, stream fishes must move in order to access suitable habitats for the completion of their life cycle (Roff 2002). Dispersal is an evolutionary stable strategy only when it results from active habitat selection based on quality (Holt 1985, Pulliam 1988). Individuals in variable habitats are rate-maximizing (Bernstein et al. 1988, Gowan and Fausch 2002) and have developed the ability to identify and select high quality sites which leads to increased fitness (Whitham 1980, Gowan and Fausch 2002). The availability of quality patches is finite and increased colonization within a given patch reduces 
overall fitness (Fretwell and Lucas 1970). Populations self-thin by dispersal from saturated patches into unoccupied lesser habitats thus increasing fitness (Fretwell and Lucas 1970, Rieman et al. 2000, Keeley 2001). This leads to a spatial structure of populations in fragmented or patchy habitats which is characterized by local increases in aggregation and clumping, as a result of active dispersal toward and selection for suitable habitat (Bjornstad et al. 1998).

Populations inhabiting spatially discrete habitats of varying quality experience different levels of fitness or reproductive success as a result of unequal resource abundance and predator pressure (Lewin 1989). This implies that spatial population structure is determined by variability in population demographic rates (births, deaths, immigration, emigration), which are habitat specific (Pulliam 1988, Dunham and Rieman 1999). Consequently, components of habitat spatial structure such as patch size, shape, spatial distribution, and degree of isolation affect the local demographic processes and ultimately determine the spatial distribution of individuals across all scales (Rieman and McIntyre 1993, Dunham and Rieman 1999).

A variety of theoretical models have been developed to describe how variable habitats affect local demographic rates and ultimately the spatial distribution of individuals on the landscape. Metapopulation (Levins 1969, Levins 1970), source-sink (Pulliam 1988), and patch dynamics, as well as variations of each, have been used to describe how populations are regulated and persist within heterogeneous environments (Harrison 1991). Each of these models embrace the idea that local demographic rates regulate populations across the landscape and demography is a function of patch specific conditions (Harrison 1991). These models differ in the nature of their spatial variation in demographic rates (Harrison 1991).

Metapopulation theory assumes an assemblage of populations inhabiting spatially distinct patches connected by dispersal, which persist in a stochastic equilibrium between local 
extinction and colonization of suitable patches (Levins 1969, Levins 1970). The "classic" metapopulation model is represented by numerous similar sized populations that are subject to extinction with equal but temporally independent probabilities (Levins 1969, Levins 1970). The regional persistence of metapopulations relies on recolonization from adjacent populations (Levins 1969, Levins 1970); however, movement rates are low enough that adjacent populations do not function as a single patchy population (Schlosser and Angermeier 1995). The abundance of individuals within a given patch is strongly influenced by the nature of the boundaries between it and other patches (Dunning et al. 1992, Dunham and Rieman 1999). Isolated patches are less likely to be re-colonized in response to dispersal restrictions (Dunning et al. 1995, Hill et al. 1996). However, corridors of suitable habitat improve the colonization potential (Dunning et al. 1992, Bjornstad et al. 1998) and ultimately the persistence of the regional population (Schlosser and Angermeier 1995, Dunham and Rieman 1999), by reducing travel costs, increasing dispersal rates, and increasing learning (Bjornstad et al. 1998).

Source-sink theory suggests that spatially distinct source habitats act as net exporters of surplus individuals which maintain populations within sink habitats through active dispersal (Pulliam 1988). Sources and sinks are characterized by local demographic rates (Pulliam 1988, Dunning et al. 1992). Sources are permanently occupied habitats (Harrison 1991) where births exceed deaths and emigration exceeds immigration, while sinks are habitats where the opposite is true (Pulliam 1988). Emigration from sources to sinks is primarily a rate-dependent process (Fretwell and Lucas 1970, Pulliam 1988) which sets the population size within the sinks (Schlosser and Angermeier 1995).

Patchy populations are similar to the classic metapopulation model in that it assumes an assemblage of populations fluctuating independently (Harrison 1991). The two models differ in 
their regional dispersal rates (Harrison 1991). Dispersal rates within a patchy population are extremely high and exceed patch specific extinction rates (Schlosser and Angermeier 1995). As a result, individual interactions across habitat boundaries best resemble a single highly mobile population (Schlosser and Angermeier 1995). This model likely represents populations that require a variety of complementary habitats distributed across multiple spatial and temporal scales (Harrison 1991, Dunning et al. 1992, Schlosser 1995).

It is unlikely that populations of stream fishes fit neatly into any of these watershed-scale models of population dynamics, but likely fall somewhere along a continuum between each of these models (Figure 1). Regardless of the exact location along this continuum, it is increasingly obvious that understanding patterns of population demographic parameters (e.g. reproduction, distribution, dispersal, survival) across multiple spatial and temporal scales is essential information required by manages to promote population persistence (Schlosser and Angermeier 1995, Fausch et al. 2002). Understanding these patterns means that we recognize the types of habitat patches required for population persistence, their arrangement and degree of connectivity throughout the riverscape, and how these factors affect local demographic rates and population structure (Schlosser and Angermeier 2002). Only when we obtain this information will we be able to address the principles for effective research and management of lotic fishes proposed by Fausch et al. (2002, see Table 1).

Over the past century the range and abundance of native brook trout (Salvelinus fontinalis) populations throughout much of the Appalachian Mountains have been reduced. Population loss is due to numerous factors such as acid precipitation, resource extraction (e.g. timber and coal), and encroachment of non-native salmonids leading to the degradation of critical brook trout habitat across multiple scales (Larson and Moore 1985, Flebbe 1994, 
Wigington et al. 1996, Galbreath et al. 2001). The upper Shavers Fork watershed has been used by Petty and his students as a model for the problems facing brook trout populations in this region (Goujot 2001, Bopp 2002, Thorne 2004, Hansbarger 2005, Petty et al. 2005, Petty and Thorne 2005). Their research has embraced the dynamic riverscape view (Fausch et al. 2002) and invested considerable effort in describing the spatial heterogeneity of the system and its role in structuring the brook trout population (e.g. distribution, mobility, resource use, productivity). Currently we know that brook trout populations within the upper Shavers Fork use resources at the watershed-scale and the population is structured in part by the spatial arrangement of reproductive habitat and access to high quality foraging sites. Specifically we know that (1) almost all reproduction occurs in small to very small tributary networks, (2) individuals are spread throughout the watershed with highest densities in small tributaries, (3) within larger water bodies, individuals are highly mobile, and (4) population productivity (i.e. growth and consumption) is highest in larger water bodies due to increased primary productivity, invertebrate biomass, and prey fish density (Figure 2). However, we currently do not fully understand (1) the variability in small tributary networks as potential sources of recruits to larger water bodies, (2) the degree of dispersal among tributaries or from tributaries to the main stem and back, (3) the spatial variability in population demographic rates, and (4) the location of the upper Shavers Fork along the continuum of population demographic models. This information would be extremely valuable to the management of the upper Shavers Fork brook trout population as well as other populations throughout Appalachia.

\section{Objectives}

The overriding objective was to understand where the brook trout population in the upper Shavers Fork watershed fits along the continuum of population demographic models. 
Specifically, we wanted to (1) describe the spatial and temporal patterns of brook trout distribution (2) quantify the extent of linkages within and among small basin area tributaries and large basin area main stem habitat (3) quantify the spatial and temporal variability in brook trout demographic rates for small basin area tributaries and large basin area main stem habitat at both the reach- and watershed- scales, and (4) examine data for evidence of metapopulation, sourcesink, and patchy population structure.

\section{Study Area}

Our study was conducted throughout 3 regions of the upper Shavers Fork watershed of the Cheat River, located in the Monongahela River basin (Figure 3). The upper Shavers Fork is a $5^{\text {th }}$ order $\left(139 \mathrm{~km}^{2}\right)$ high elevation $(>1000 \mathrm{~m})$ watershed located in Pocahontas and Randolph counties of West Virginia on the eastern edge of the Allegheny Plateau physiographic province (Figure 3). Each study region consisted of numerous (range $=2-10, \mathrm{~N}_{\text {total }}=15$ ) small basin area tributary networks and 1 main stem segment (1-2km long). Tributary networks were short (main channel typically $<1 \mathrm{~km})$ small basin area systems $\left(<3 \mathrm{~km}^{2}\right)$ that drained directly into the Shavers Fork main stem. The location of each tributary network coincided with 1 of 3 main stem segments (Figure 3) known to support a relatively large brook trout population throughout the year. Consequently, each study region can be characterized as a combination of critical brook trout reproductive and nursery habitat as well as high quality supplemental foraging habitat (Petty et al. 2005). As a result of local variability in bedrock geology consisting of sandstone, shale, conglomerate, and coal (Waite et al. 2000) and regionally high acid precipitation (NADP 2000) tributary networks cover the full range of instream physical habitat, canopy cover, dissolved chemistry, slope, and basin area. Brook trout were generally the only species present within the small tributary networks. However, the main stem reaches supported a productive 
cold / cool water fish assemblage consisting of mottled sculpin (Cottus bairdi), western blacknose dace (Rhinichthys obtusus), longnose dace (Rhinichthys cataractae), rosyside dace (Clinostomus funduloides), mountain red belly dace (phoxinus oreas), fantail darter (Etheostoma flabellare), johnny darter (Etheostoma nigrum), greenside darter (Etheostoma blennioides), sharpnose darter (Percina oxyrhynchus), creek chub (Semotilus atromaculatus), river chub (Nacomis micropogon), Cheat minnow (Pararhinichthys bowersi), white sucker (Catostomus commersoni), northern hog sucker (Hypentelium nigricans), brown trout (Salmo trutta), and rainbow trout (Oncorhynchus mykiss).

\section{Methods}

\section{Sampling design}

Stream systems are longitudinal mosaics of habitat patches and continuous assessments of fish populations are essential in order to obtain a context-specific understanding of the various processes influencing population responses to riverscape heterogeneity (Fausch et al. 2002, Torgersen et al. In Press). Our research within the upper Shavers Fork watershed has adopted the "dynamic riverscape" view described by Fausch et al. (2002). Consequently, we conducted spatially continuous surveys of brook trout population size structure and post reproductive demographic rates throughout each of the 3 study regions. Additionally, physical habitat and water quality was measured continuously throughout each of the small basin area tributary networks. We did not assess the local physico-chemical habitat within the 3 main stem segments. In order to assign some degree of spatial identity to these continuous measurements, individual networks were separated into a series of adjacent reaches 40 times the mean wetted width in length. Due to the small size of our stream networks reach lengths were $150 \mathrm{~m}$ long (Angermeier and Karr 1986, Yoder and Smith 1999), unless they had to be shortened because of insufficient length (short tributaries and uppermost reaches) or presence of anthropogenic 
barriers. In the occasion $(\mathrm{N}=3)$ that a stream reach was truncated by some anthropogenic barrier (railroad / culvert), the length of the affected reach was shortened and a new full reach began upstream of the barrier. Main stem segments were not separated into spatially discrete reaches; instead they were handled as a single large reach within each of the study regions.

\section{Brook trout sampling and marking}

Brook trout populations were sampled seasonally (spring - June 2004, summer - August 2004, fall - October 2004, and spring - June 2005) throughout each of the study regions during base flow conditions. Three to six person teams, depending on stream size, sampled brook trout with backpack electrofishing units (Smith-Root, DC, $60 \mathrm{hz}, 400-600 \mathrm{~V}$ ), following single-pass procedures, and a combination of dip and seine nets. Brook trout electrofishing capture probabilities within the upper Shavers fork are consistent between size-classes and seasons but not across a wide range of stream sizes (Petty et al. 2005). However, sufficient evidence exists suggesting that brook trout capture probabilities across the range of basin areas considered in this study are high and predictable (see Chapter 1of this document and Petty et al. 2005).

Seasonal sampling was conducted continuously throughout each study region. Tributary sampling began at the start of the most downstream reach (i.e. confluence) and continued in an upstream direction until two full reaches $(300 \mathrm{~m})$ were found to be void of all fish species or the stream's origin was reached. If a distance of $300 \mathrm{~m}$ was exceeded without identifying the presence of any fish species, it was assumed that no brook trout occurred within upstream reaches. Continued sampling beyond $300 \mathrm{~m}$ would likely produce little information relative to the additional sampling effort (Angermeier and Karr 1986, Yoder and Smith 1999). The main stem was not separated into distinct reaches, but was sampled as one large continuous reach. Each main stem section was sampled, in its entirety, each season. 
All trout captured were identified to species, anesthetized in clove oil $($ concentration $=$ $40 \mathrm{mg} / \mathrm{L})$, and measured for standard length (SL) $( \pm 1 \mathrm{~mm})$ and weight $( \pm 0.1 \mathrm{~g})$. At the time of first capture, brook trout greater than $60 \mathrm{~mm}$ (SL) were given a unique mark sequence (3 - 6 separate marks) with colored elastomer dyes (Northwest Marine Technology) as described by Petty et al. (2005). Limitations in the marking procedure required that small brook trout $(<$ $60 \mathrm{~mm}$ ) be given a tributary network- or main stem reach-specific batch-mark (1-2 marks) beginning in the summer (August 2004) sampling period. After marking, fish were returned to their approximate location of capture.

For each seasonal sample, we separated brook trout into 1 of 3 size-classes based on frequency distributions of brook trout lengths pooled across all sampled sites (Figure 4). The juvenile class is a true representation of age and represents individuals known to have been produced the previous fall. The small and large adult classes likely do not represent a true distinction in age. The term "adult" was simply used to represent individuals that were not in their first year of life and in the case of most small adults may not represent reproductive maturity. A stock size of $115 \mathrm{~mm}$ (SL) (Anderson and Neumann 1996) was used to differentiate between these two classes.

\section{Instream Habitat}

Physical habitat surveys were conducted within each tributary reach at base flow conditions during summer 2005 following protocols similar to those described by Petty et al. (2005). Efforts combined visual estimation and transect based sampling to quantify a variety of physical habitat variables. Additionally, water quality was recorded seasonally concurrent with fish sampling. Ten habitat parameters were assessed at the reach scale throughout each tributary network: basin area $\left(\mathrm{km}^{2}\right)$, channel slope $(\%)$, mean depth $(\mathrm{cm})$, depth variability, mean velocity 
$(\mathrm{cm} / \mathrm{s})$, cover availability, wetted channel width $(\mathrm{m})$, pool area $\left(\mathrm{m}^{2}\right)$, large woody debris (LWD) $\left(\mathrm{m}^{2} / \mathrm{m}^{2}\right)$, and $\mathrm{pH}$. This represents a list of previously suggested parameters important to fish population post reproductive demographic parameters, size structure, and stability (Fausch et al. 1988).

Basin area was mapped at the downstream end of each reach using a flow accumulation grid in Arc GIS 9.1 spatial analysis software. Mean channel slope was measured with a hand held clinometer $( \pm 1 \%)$ and survey rod. Working in an upstream direction, a thalweg profile was developed by measuring depth $( \pm 1 \mathrm{~cm})$, average current velocity $( \pm 1 \mathrm{~cm} / \mathrm{s})$, and distance to cover $( \pm 0.5 \mathrm{~m})$ at 30 points spaced $5 \mathrm{~m}$ apart within the primary current seam. Spacing of sample points along the thalweg was slightly modified from the recommendations of Simonson et al. (1994). Depth variability was represented as the coefficient of variation ([standard deviation/mean]*100) of mean depth. Average velocity was measured with a Marsh McBirney digital flow meter at $60 \%$ of the water depth. Distance to cover was measured as the distance from the thalweg point to the nearest structural element with potential to provide refuge for a 200mm fish (Simonson et al. 1994). Wetted width $( \pm 0.1 \mathrm{~m})$ was measured every $50 \mathrm{~m}$ and averaged throughout the reach. Pool area was obtained by multiplying the visually estimated total length and width of each pool and summing throughout the reach. Twenty percent of all pool dimensions were measured $( \pm 0.1 \mathrm{~m})$ and used to derive a correction factor for visual estimations (Dolloff et al. 1997). LWD was assessed by categorizing all stems located within the active stream channel (includes root wads, spanners, and standing dead) into 1 of 12 categories based on visually estimated lengths $(1-2 \mathrm{~m}, 2-5 \mathrm{~m}, 5-10 \mathrm{~m},>10 \mathrm{~m})$ and widths $(0.1-0.2 \mathrm{~m}, 0.2-0.3 \mathrm{~m}$, $>0.3 \mathrm{~m})$. LWD density $\left(\mathrm{m}^{2} / \mathrm{m}^{2}\right)$ was calculated as the sum of the total area represented by each category (\# stems * median length * median width) divided by the wetted stream area. Water 
quality $(\mathrm{pH})$ was measured at 50m intervals throughout the watershed. Reach specific $\mathrm{pH}$ was represented as the average of all measurements taken within the reach.

\section{Statistical Analysis}

Our first objective was to determine the factors that influence the spatial and temporal patterns of brook trout distribution. The reach specific proportional abundance (\# caught within a given reach / \# caught across total sampled area) of each size-class was used as a seasonal measure of relative abundance and spatial distribution throughout the study area. Correlation analysis was used to infer the degree of temporal stability in the spatial distribution of each sizeclass. In addition, correlation analysis was used to determine the degree of similarity in the spatial distribution of each of the 3 size-classes. Chi-square goodness-of-fit was used to determine if brook trout of each size-class were distributed throughout the study sites proportional to the available area sampled. Bivariate plots and stepwise multiple regression was used to determine which local habitat parameters were most important in explaining the spatial distribution of each size-class. This analysis could only be done at the reach scale within small basin area tributaries because we did not collect physico-chemical habitat data within the main stem. Due to high correlation among local physical habitat parameters, principle component analysis was used to reduce linear dependency and data redundancy, across all perennial sites, by generating new fully uncorrelated composite variates (McGarigal et al. 2000). Principle component scores, distance from main stem, and $\mathrm{pH}$ were selected for regression analysis. Variables were included in the model if $P<0.15$. The significance level $(\alpha)$ used for acceptance of the overall model was 0.05 . All statistical tests were judged at this level unless otherwise noted. 
The second objective was to determine the extent of brook trout movements within small basin area tributary networks, between tributary and main stem habitat, and among individual tributaries. Within tributary movement patterns were inferred from recapture data pooled across the 15 small tributary networks. Only seasonally consecutive recaptures (captured at time $e_{t}$ and recaptured at time $t_{t+1}$ ) were used in this analysis. Direction of movement was represented twodimensionally as up or downstream. Due to scale limitations we were forced to represent distance moved as the number of reaches between consecutive recaptures. For example, an individual captured at time $e_{t}$ in reach \# 1 and recaptured at time $\mathrm{t}_{t+1}$ in reach \# 3 would be assigned a "2" for movement. One-way analysis of variance (ANOVA) was used to test for differences in seasonal movement patterns. A post hoc Duncan's test was used to determine which seasons differed significantly. Juvenile movement patterns could not be assessed within tributary networks because individuals in 2004 were too small to be given an individual mark and we had a limited availability of suitable batch-marks. Predetermined sampling protocol precluded us from assessing the direction and magnitude of fish movements for all size-classes within the main stem. However, the movement of individuals between tributary networks and the main stem as well as among individual tributaries was assessed by evaluating the proportions of each size-class that were found to have moved across tributary / main stem and tributary / tributary boundaries.

Our final objective was to quantify the dominant patterns of brook trout post reproductive demographic parameters (apparent survival, immigration, local recruitment) at the reach- and watershed-scale. We used mark-recapture data and maximum likelihood estimators in the program MARK to generate apparent survival and immigration probabilities separately for small and large adults at the reach- (tributary and main stem) and small basin area tributary network- 
scale (Burnham and Anderson 1999). We could not assess demographic parameters for the juvenile size-class over any spatio-temporal scale due to marking limitations. Our assessment of brook trout population parameters (apparent survival, immigration) followed Pollock's robust design (Peterson et al. 2004). We assumed that populations at each scale were closed to gains (from births and immigration) and losses (from deaths and emigration) during each seasonal sample and open between subsequent seasonal samples.

In order to obtain a more accurate assessment of season-, site-, and age-class-specific survival and immigration probabilities mean brook trout capture probability $($ tributary $=0.72$, main stem $=0.62)$ from previous studies within the upper Shavers Fork watershed (see: Chapter lof this document and Petty et al. 2005) were used to fix capture probabilities in open population estimators in program MARK. We used the Cormack-Jolly-Serber model in program MARK to estimate apparent survival $(\Phi)(1-[$ mortality + emigration] $)$ and the Pradel model (recruitment only) to estimate immigration $(\Gamma)$ (1-probability that fish captured at time ${ }_{\mathrm{T}}$ were present at time $\mathrm{T}_{\mathrm{T}}$ 1). Immigration rate was calculated as $\left(\left[\Gamma * \mathrm{~N}_{\mathrm{t}}\right] / \mathrm{N}_{\mathrm{t}-1}\right)$.

Apparent survival and immigration estimates were generated from scale- (tributary reach, main stem reach, and small basin area tributary network) and size-class-specific capture histories that do not reflect local recruitment from one size-class to the next. Local recruitment was addressed by generating separate fall-spring survival and immigration estimates that reflect the transition of one size-class to the next larger size-class. Local recruitment was modeled during the fall-spring period because at this time juvenile brook trout have completed a full year of life and recruit into the small adult population. Similarly (89\%) of small adults that grew large enough during our study to be reclassified as large adults $(\mathrm{N}=78)$ did so during this time period. The differences in the observed spatial and temporal patterns of apparent survival and 
immigration resulting from these two capture histories can be attributed to local recruitment. Limitations in batch marking of the juvenile size-class restricted us from assessing local recruitment at the within tributary network reach-scale; consequently, recruitment analysis was restricted to the small basin area tributary network- and main stem reach-scales.

We used an analysis-of-covariance (ANCOVA) to assess seasonal variation in brook trout demographic parameters separately for small and large adults. At the reach-scale we tested for variation in apparent survival and immigration rate due to season and individual small tributary networks with basin area and distance from main stem as covariates. In order to account for non-independence of stream reaches individual tributary networks were used as blocking factors. At the whole tributary network-scale we tested for variation in apparent survival and immigration rate due to season and basin area. A post hoc Duncan's Test was used to determine which seasons differed if an affect was identified.

\section{Results}

Seasonal sampling efforts resulted in a total of 4,195 brook trout captures from single and multiple observations of approximately 1,098 juveniles, 1,203 small adults, and 465 large adults. Juveniles, small adults, and large adults made up approximately $37 \%(\mathrm{~N}=1534), 46 \%(\mathrm{~N}=$ 1915), and $18 \%(\mathrm{~N}=746)$ of the total captures respectively. Throughout the study, a total of 467 juveniles where batch marked, and a total of 919 small adults and 336 large adults were individually marked. Recaptured individuals made up a majority of the seasonal catch for each size-class (Table 1). Although a large proportion of each seasonal sample consisted of recaptured individuals, approximately two-thirds of small $(58 \%, \mathrm{~N}=694)$ and large $(61 \%, \mathrm{~N}=$ 284) adults were only observed once. 
Brook trout distribution- Juvenile, small adult, and large adult brook trout were captured across the range of stream sizes from headwater segments draining $<0.08 \mathrm{~km}^{2}$ to main stem habitat draining more than $60 \mathrm{~km}^{2}$. Individuals of each size-class were patchily distributed throughout the network of sampled reaches. The proportion of the total seasonal catch of each size-class within each reach (tributary and main stem) varied considerably among reaches; although, the distribution pattern was fairly stable over time, especially for adults (Figure 5). Due to the high temporal stability in the spatial distribution of each size-class, all of the subsequent results reflect the average reach-specific proportional abundance for each size-class across the landscape. Brook trout of all size-classes were disproportionately concentrated in a small percentage of the total sampled area (Chi-Square statistics: juveniles $X^{2}=357.67, P<$ 0.0001, small adults $X^{2}=408.96, P<0.0001$, large adults $\left.X^{2}=86.31, P<0.0001\right)$ located within small basin area stream networks (Figure 6 and 7). In fact, main stem habitat made up $73 \%$ of the total sampled area and on average only supported 7,11 , and $29 \%$ of juveniles, small adults, and large adults respectively. Brook trout within each size-class had similar distributions throughout the sampled area; although, large adults displayed a more even distribution across the sampled area than did juveniles and small adults (Figure 6). The spatial arrangement of small adults was highly correlated to that of the juvenile size-class. Similarly, the spatial distribution of large adults closely resembled that of the small adult size-class and to a lesser extent that of the juvenile size-class (Figure 6 and 8).

Within tributary networks, three ecologically meaningful physical habitat gradients were derived from correlated physical habitat measurements using PCA. Principle components 1, 2, and 3 (henceforth: PC 1, PC 2, and PC 3 respectively) represent a stream size, slope, and complexity gradient respectively (Table 2). At the within tributary reach-scale, the occurrence of 
brook trout was at least in part related to local hydrology, water quality, slope, mean depth, and availability of cover. In general, ephemeral stream reaches $(\mathrm{N}=13)$ did not support brook trout at any time. When brook trout were observed in these ephemeral systems they were always within $50 \mathrm{~m}$ of a perennial reach. The majority of the sampled perennial stream reaches maintained an average $\mathrm{pH}>5.0$; although those that $\operatorname{did}$ not $(\mathrm{N}=7)$ were typically devoid of brook trout. Stream reaches with a slope $>15 \%$, mean depth $<7 \mathrm{~cm}$, and / or a mean distance to cover $>1 \mathrm{~m}$ generally did not support brook trout, while no clear pattern was observed within reaches not exceeding these critical thresholds (Figure 9). No minimum basin area was observed below which brook trout of any size were consistently absent (Figure 9). However, we did observe a general lack of all brook trout within small basin area reaches that were shallow and had limited cover (i.e. PC 1) (Figure 10). No pattern was observed between the average proportional abundance of any size-class and pool area, LWD density, depth C. V., flow velocity, PC 2 or PC 3 (Figure 9 and 10).

Within small tributary networks the distribution pattern of each size-class was related to local habitat gradients and $\mathrm{pH}$ (Table 3). The average proportional abundance of each size-class increased with factors related to stream size. Consequently, extreme headwater reaches (within $300 \mathrm{~m}$ of the stream origin) rarely supported a high proportion of the brook trout population.

Within larger downstream portions of tributary networks juveniles tended to be associated within lower gradient, lower complexity reaches. Small adults were more abundant in lower complexity reaches with a higher average $\mathrm{pH}$, while large adults were only associated with higher average $\mathrm{pH}$ (Table 3).

Movement- Patterns of size-class specific dispersal suggest that the majority of brook trout inhabiting small basin area tributary networks exhibited restricted movement although a 
small fraction of individuals in each size-class were highly mobile. Movement within tributary networks was low seasonally for both small and large adults, indicated by a high percent recapture within release sites (Figures 11 and 12). However, each seasonal sample revealed that approximately $20-30 \%$ of the small and large adult populations moved across reach boundaries (Figures 11 and 12). The magnitude of this movement was generally low, although movements of $150-450 \mathrm{~m}$ were regularly observed (Figures 11 and 12 ). In addition, temporal variation in movement patterns was observed in small (ANOVA; $F=11.6, \mathrm{df}=2, P<0.0001)$ and large (ANOVA; $F=4.55, \mathrm{df}=2, P<0.0117$ ) adults. In general, small and large adults tended to move upstream during the spring-summer and summer-fall periods and downstream over the fall-spring period (Figure 11 and 12).

We observed limited movement among small tributary networks and main stem habitats for all size classes throughout the course of the study. A total of 6 juveniles (1.4\%), 30 small adults (4.3\%), and 5 large adults (2.2\%) were recaptured outside the original small basin area network in which they were originally marked. Fifty nine percent of these individuals (juvenile $\mathrm{N}=4$, small adult $\mathrm{N}=16$, large adult $\mathrm{N}=4$ ) were recaptured within the main stem, while the remaining $41 \%$ (juvenile $\mathrm{N}=2$, small adult $\mathrm{N}=14$, large adult $\mathrm{N}=1$ ) were recaptured within a separate small tributary network (Table 4, Figure 13). None of these individuals were observed returning to the small network in which they were originally marked. No juveniles, 2 small adults (1.5\%) and 1 large adult ( $0.8 \%)$ originally marked within the main stem were recaptured in a small tributary network.

Within tributary network reach- scale population demography- Within tributary networks, apparent survival estimates showed that study reaches varied considerably in their ability to support both small and large adult brook trout. Within each seasonal sample some 
reaches exhibited high retention while others appeared to be "flow-through" type patches. Across seasonal samples, small adults experienced lower apparent survival estimates than did large adults; although, mean survival was high for both size classes (Table 5). A given reach's ability to support adult brook trout was generally consistent from season-to-season, although this pattern was stronger for large adults relative to small adults (Figure 14). Variation in reach specific survival was partly attributed to tributary network association (ANCOVA; small adult: $F$ $=3.65, \mathrm{df}=12, P<0.0001$; large adult: $F=5.23, \mathrm{df}=9, P<0.0001)$; however, within individual tributary networks survival increased with increasing basin area (small adult: $F=$ 12.92, $\mathrm{df}=1, P=0.0004$; large adult: $F=4.62, \mathrm{df}=1, P=0.0336$ ). Distance to main stem influenced survival of small adults $(F=9.10, \mathrm{df}=1, P=0.003)$ but not large adults $(F=2.58, \mathrm{df}$ $=1, P=0.1110$ ). In general, small adult survival increased with increasing distance from main stem habitat. The spatial patterns of small adult survival did not vary seasonally $(F=2.46, \mathrm{df}=$ 2, $P=0.0888$ ); however, the spatial pattern of large adult survival did show temporal variation $(F=6.04, \mathrm{df}=2, P=0.0032)$. Large adult survival was higher during the spring-summer period than the fall-spring period, while the summer-fall period did not differ from other sampling periods (Table 5). Correlation analysis showed that small adult survival was positively related to habitat factors associated with stream size (PC 1) during the spring-summer season and slope (PC 2) during the summer-fall and fall-spring period (Table 6, Figure 15). Large adult survival was not significantly correlated to dominant physical habitat gradients in any season (Table 6, and Figure 16).

No clear spatial or temporal pattern was observed in within-tributary network reach specific immigration rates of small or large adults. Across seasons, small adult immigration rates were higher than those of large adults (Table 5). Mean immigration rates for both small and 
large adults were generally high (Table 5), although consistent patterns in reach-to-reach immigration rates were not observed (Figure 17). No differences in small adult reach specific immigration rates were due to tributary network association, basin area, or distance to main stem (ANCOVA; Full Model: $F=1.04, \mathrm{df}=16, P=0.4238$ ). Some variation in large adult reach specific immigration rates was due to distance from main stem $(F=5.49, \mathrm{df}=1, P=0.0208)$, but not tributary network association $(F=1, \mathrm{df}=9, P=0.4406)$ or basin area $(F=3.22, \mathrm{df}=1$, $P=0.752$ ). In general large adult immigration rates increased in reaches farther from the main stem. This pattern was consistent over time $(F=1.27, \mathrm{df}=2, P=0.2834)$. Correlation analysis showed no significant relationship between small adult immigration and dominant physical habitat gradients (Table 7 and Figure 18). Large adults were positively correlated to factors associated with channel slope (PC 2) during the spring-summer period (Table 7, Figure 19). Local apparent survival and immigration rates combined to set the reach scale rate of population change. Rates of population change showed spatial and temporal variability for both small and large adults (Figures 20 and 21). A given reach's ability to support adult brook trout was generally consistent from season-to-season; however local immigration rates fluctuated considerably. Consequently, local immigration rates were the primary mechanism responsible for determining the observed rate of population change at the reach-scale.

Tributary network-scale population demography- Apparent survival estimates showed that small basin area tributary networks varied considerably in their ability to support both small and large adult brook trout. Across seasons, small adults experienced lower apparent survival than did large adults (Table 5). Seasonally, mean apparent survival estimates at the whole tributary network-scale were higher than those observed at the reach-scale (Table 5). A given tributary network's ability to support adult brook trout was generally consistent from season-to- 
season, although this pattern was stronger for large adults relative to small adults (Figure 14). Small adult apparent survival at the tributary network-scale was a function of basin area (ANCOVA; $F=4.43, \mathrm{df}=1, P=0.0425$ ) where larger stream networks had higher apparent survival. The spatial patterns of small adult survival at the small tributary network-scale were temporally stable (ANCOVA; $F=0.52, \mathrm{df}=2, P=0.6001$ ) (Figure 14). Similarly, patterns of large adult survival were both spatially and temporally stable (ANCOVA; Full Model: $F=0.21$, $\mathrm{df}=3, P=0.8899)($ Table 5, Figure 14). Mean seasonal immigration rates were low and inconsistent for both small and large adults at the tributary network-scale (Table 5, Figure 17). Immigration rates did not differ among tributary networks or seasons for small adults (ANCOVA; Full Model: $F=0.77, \mathrm{df}=3, P=0.5194$ ) or large adults (ANCOVA; Full Model: $F$ $=1.77, \mathrm{df}=3, P=0.1772)($ Table 5).

Brook trout population size within our small basin area tributary networks decreased seasonally due to seasonally consistent losses and low rates of immigration. Over an annual time scale populations were fairly stable and maintained due to high rates of local recruitment during the fall-spring period (Figure 22 and 23). When apparent survival is modeled to reflect losses owing to recruitment into the next highest size-class we observed no shift in the spatial or temporal pattern of small adult survival. This demonstrates that the loss did not significantly affect the population size of small adults at the watershed-scale. When immigration rates of small adults are modeled to reflect gains resulting from juvenile recruitment we observed a shift in the temporal pattern in that small adult immigration varied seasonally $(F=5.53, \mathrm{df}=2, P=$ 0.0082) with fall-spring having a significantly higher immigration rate. This demonstrates that the small adult population size increases significantly due to local recruitment of juveniles. When immigration rates of large adults is modeled to reflect gains owing to small adult 
recruitment we observed a shift in the temporal pattern in that large adult immigration varies seasonally $(F=27.45, \mathrm{df}=2, P<0.0001)$ with fall-spring having a significantly higher immigration rate. This shift illustrates that losses to the small adult population (although not significant) due to recruitment is realized as a significant increase in the large adult population during the fall-spring period.

Main stem reach-scale population demography- Across seasons, small adults experienced lower apparent survival than large adults within main stem reaches (Table 5). Apparent survival for both small and large adults was consistently lower within the mainstem compared to rates observed at the within tributary network reach- and whole tributary network-scales (Table 5). Although apparent survival was generally low within main stem reaches, a given reach's ability to support brook trout was consistent over time (Figure 14). Seasonal immigration rates for both small and large adults were high although generally inconsistent (Table 5, Figure 17). Across seasons, immigration appears to be the dominate mechanism influencing population change of both small and large adults within main stem reaches (Figure 22 and 23)

\section{Discussion}

This study suggests that the brook trout population within the upper Shavers Fork watershed is structured, at least in part, by the spatial arrangement of small basin area tributary networks. The brook trout population within the upper Shavers Fork consists of both sedentary and mobile individuals. Movement within small basin area tributary networks was common, although displacement was generally low. Large-scale movements from tributary networks to the main stem as well as between tributary networks were observed. Across all spatial scales, seasonal estimates of population demographic rates suggested that apparent survival was generally high and consistent, while immigration rates were highly variable. Consequently, 
seasonal patch-specific rates of population change were primarily influenced by variable immigration. Results of this study suggest that the structure of the upper Shavers Fork brook trout population is a complex mosaic of elements found in source-sink, metapopulation, and patchy population models. At the small tributary network-scale habitat patches primarily act as local isolates while nested patches can be characterized by patchy population dynamics. At the upper Shavers Fork watershed-scale the structure of the brook trout population appears to be a combination of source-sink / metapopulation dynamics.

Distribution- The spatial arrangement of small basin area tributary networks appears to be the dominant factor influencing the distribution of brook trout within the upper Shavers Fork watershed. This conclusion is supported by three findings. First, small basin area systems provide critical reproductive habitat. Second, brook trout were found to occur in the highest abundances in small basin area systems, and all size-classes were under represented within main stem habitat. This means that the spatial distribution of each size-class was predominately centered on key reproductive areas. Finally, strong season-to-season correlations were observed in the distribution of brook trout, which implies that the relative abundance of all size-classes within different areas remained constant. More importantly this suggests that each size-class was seasonally associated with reproductive habitat.

Convincing evidence suggests that within the upper Shavers Fork watershed small basin area systems act as non-substitutable reproductive habitat (Petty et al. 2005). Petty et al. demonstrated that more than $80 \%$ of all reproductive effort, within Second Fork, a $4^{\text {th }}$ order tributary system of upper Shavers Fork, was concentrated within reaches draining less than $3 \mathrm{~km}^{2}$. In fact, some of the smallest basin area reaches $\left(<0.5 \mathrm{~km}^{2}\right)$ within this critical range may be the most productive reproductive habitat (see Chapter 1 this document). 
The highest abundances of brook trout within our study regions were observed within small basin area tributary networks (i.e. reproductive habitat). Brook trout of all sizes were observed across the physical gradients (stream size, slope, complexity) characterizing the tributary networks. Within these small networks brook trout abundance was positively correlated with factors associated with stream size (i.e. basin area, depth, cover). Larger habitat patches are often characterized by increased complexity, habitat diversity, and food resources which can support a more diverse size structure and larger overall population (Horan et al. 2000). It is interesting, considering our continuous sampling efforts, that we did not observe a critical basin area below which brook trout were consistently absent. However, small basin area stream reaches that were both shallow and lacked suitable cover generally did not support brook trout. It is well known that brook trout are often associated with cover (Lohr and West 1992, Stoneman and Jones 2000) especially in the presence of predator pressures (Lohr and West 1992). This suggests that basin area alone is likely an insufficient measure of brook trout occurrence.

In addition to cover availability, reach intermittency and water quality appeared to influence the distribution of brook trout within these small tributary networks. Brook trout were rarely observed in intermittent stream reaches or perennial stream reaches with "poor" water quality. Drought conditions in spring 2005 revealed that several reaches commonly devoid of fish were in fact intermittent. Drought may combine with movement behavior (e.g. emigration from or refusal to immigrate into intermittent reaches) to explain the absence of regional fishes from local sites (Angermeier and Winston 1998, Albanese et al. 2004). Within perennial reaches, brook trout were rarely observed within reaches with an average $\mathrm{pH}<5.0$. This is likely due to reduced reproductive success in accordance with low acid neutralizing capacity (ANC) set by bedrock geology. The upper Shavers Fork watershed is primarily influenced by the Pottsville 
and Mauch Chunk groups. Welsh and Perry (1997) found that the Pottsville group yielded little ANC, and within reaches associated with this group conditions often exceeded the acidic threshold $(\mathrm{pH} \approx 5.0)$ for brook trout. Petty et al. (2005) documented that brook trout, within this system, often attempted to reproduce in poorly buffered headwater reaches only to realize full recruitment failure.

The spatial distribution of all size-classes was highly correlated and concentrated within small tributary networks. These findings are consistent with Beard and Carline (1991) who showed that all sizes of brown trout in Appalachian streams were associated with reproductive habitat. Similarly, Petty et al. (2005) showed that the distribution of juvenile and small adult brook trout was highly correlated with key reproductive habitat. However, the distribution of large adult brook trout was seasonally unstable and centered on factors other than those influencing reproduction, such as high quality foraging sites (Petty et al. 2005). Similar to Petty et al. (2005), we did observe size-class specific shifts in resource use, although to a lesser magnitude. It is commonly recognized that stream fishes use resources at multiple scales in order to complete there life cycle (Fausch et al. 2002). The fact that we did not observe largescale differences in habitat use between size-classes suggests that small basin area tributary networks may provide the full range of habitat complementation (Dunning et al. 1992).

Movement- Mobility is common in organisms occupying a variable environment. Stream salmonids regularly move in order to track changing environmental conditions (Gowan and Fausch 2002). Gowan and Fausch (2002) showed that the location of high quality foraging sites varied considerably across seasons. Mobile salmonids are often characterized by reduced condition or dominance and are presumably seeking more productive habitats in order to maximize energy intake at the reach-scale (Riley et al. 1992, Gowan and Fausch 1996, Gowan 
and Fausch 2002). However, Hilderbrand and Kershner (2004) found no difference in condition between mobile and resident cutthroat trout and concluded that mobile fish seem to be of two types, those in poor condition that must move and those in good condition that can exploit quality patches. Small-scale movements are typically centered on accessing local habitat patches that increase growth and survival (Gowan and Fausch 2002). Large-scale movements permit access to habitats used by different life-history stages (Dunning et al. 1992), and are essential for persistence of individual populations and metapopulations (Schlosser and Angermeier 1995, Rieman and Dunham 2000).

We observed a considerable amount of spatial and temporal variation in brook trout movement patterns. Most movements were small-scale (i.e. restricted, reach-to-reach interactions) but low rates of larger-scale movements within and among tributary networks were regularly observe. Movement occurs along a continuum between sedentary and highly mobile that changes at the population and individual levels depending on the time scale chosen (Hilderbrand and Kershner 2004). This study suggests that movement of individual brook trout within the upper Shavers Fork ranges across this continuum and represents both the sedentary and mobile extremes. The presence of both sedentary and mobile salmonids is common in the literature (Flick and Webster 1975, Riley et al. 1992, Gowan and Fausch 1996, Petty et al. 2005). We did not attempt to determine if restricted or wider ranging movements were performed by the same groups of individuals each season, which may indicate variable life history strategies. However, the movement of stream-dwelling salmonids is likely related to habitat quality not life history strategy (Bahr and Shrimpton 2004). The movement patterns of salmonid fishes are flexible and individuals often display periods of both mobile and sedentary behavior in response to local conditions and energetic needs (Hilderbrand and Kershner 2000). This pattern likely 
best represents the movement dynamics of brook trout within small tributary networks of the upper Shavers Fork watershed.

The majority of the brook trout occupying small basin area tributaries displayed local movements, where if movement was detected displacement was low. Patterns of local movement of stream fishes are not rare. In 1959, Gerking established the "restricted movement paradigm" suggesting that the majority of stream fishes are sedentary, living their entire life within fairly small reaches of stream. Numerous studies have re-evaluated the concept of restricted movement (Gowen et al. 1994, Gowen and Fausch 1996, Rodriguez 2002) and suggested that sampling biases associated with mark-recapture studies mask the fact that movement of stream fishes (especially salmonids) are indeed common (Gowen et al. 1994, Rodriguez 2002). It is unlikely that these common biases influenced our results given the scale of our study and use of continuous sampling. Consequently, local small-scale movement is likely the norm within small basin area tributaries of the upper Shavers Fork.

Within tributary dispersal patterns varied seasonally. We observed more frequent and wider ranging movements by small adults relative to large adults. It is possible that large adults within small tributaries have well established territories and a more static existence relative to small adults that have yet to establish themselves into the dominance hierarchy (Riley et al. 1992). Net movement was upstream from late spring thru fall and downstream during the winter and early spring period. Seasonal variation in dispersal has been observed in numerous brook trout populations (Flick and Webster 1975, Gowan and Fausch 1996, Riley et al. 1992, Curry et al. 2002). No clear explanation exists for the directional movements observed in this study. Upstream movements were likely aimed at gaining access to suitable reproductive / over wintering habitat. Brook trout within this system concentrate reproduction within very small 
stream reaches (Petty et al. 2005, Chapter 1 this document). These critical areas are presumably characterized by groundwater inputs, suitable cover, stable flow conditions, and reduced predation (Petty et al. 2005), which may also serve as high quality over wintering habitat (Cunjak 1996). Downstream movements during early spring were likely aimed at accessing larger more complex habitats with increased productivity and growth potential during early spring (Horan et al. 2000, Bopp 20002, Thorne 2005). An alternative explanation is that reduced flows during spring 2005 forced individuals to seek out larger downstream reaches with a reduced potential for stream drying.

The main stem habitat within the upper Shavers Fork is extremely productive relative to tributary habitat. Bopp (2002) showed that invertebrate biomass within the main stem was as much as 10 times that observed in small basin area tributaries. Thorne (2005) demonstrated that consumption and growth of brook trout was much higher within main stem versus tributary habitat. Consequently, Petty et al. (2005) characterized main stem habitat as high quality supplementary habitat. Although movement from small unproductive tributary networks into the main stem has obvious advantages with regards to maximizing energy, these movements were rarely observed. Mark-recapture efforts are biased against detecting long range movements (Gowan et al. 1994, Gowan and Fausch 1995), and it is possible that highly mobile individuals moving from tributaries into the mainstem could move beyond the boundaries of our study regions resulting in an underestimate of this type of movement. We attempted to minimize this bias by sampling long mainstem reaches $(1-2 \mathrm{~km})$ although the benefit of this was variable and dependant on a given tributaries location within the sampling regions. Regardless, movement rates from tributaries into the main stem were fairly low. This was likely due to movement restrictions between these two habitat types. The tributary networks considered in this study 
were typically high gradient systems with numerous barriers to movement (e.g. steep slopes, debris jams, and subsurface flows). Typical movement barriers often occurred within close proximity to the confluence of the tributary and the main stem, likely making frequent movement between these habitat types difficult.

If individuals did move into the main stem they were likely subject to potential interaction with non-native salmonids and often unsuitable water temperatures during the summer months. Competition with non-native salmonids has been shown to reduce the fitness of native brook trout throughout Appalachia causing them to seek residence in small tributary systems (Larson and Moore 1985, Larson et al. 1995). Although interactions between brook trout and non-native salmonids are likely within this watershed they have not been formally quantified. Hansbarger (2005) showed that summer water temperatures in the Shavers Fork main stem often exceed the thermal maxima established for brook trout. In these instances trout were forced to seek out coldwater inputs often in the form of tributary inputs (Hansbarger 2005). Additionally, low recapture rates of marked brook trout within the main stem indicates high mobility and / or high mortality (Petty et al. 2005, Thorne 2005, this study), both of which suggest the main stem is generally unsuitable for brook trout. It is possible that the main stem acts as a productive movement corridor between small basin area tributary networks. Approximately half of the brook trout that moved from a small tributary network into the main stem eventually left the main stem and entered a new tributary network.

Population demographics- Apparent survival was generally high and consistent for both small and large adults. Both size-classes experienced the highest apparent survival at the whole tributary network-scale and lowest within main stem habitat. Across seasons and spatial scales, small adults experienced lower apparent survival rates than did large adults. Site- and scale- 
specific variation may be due to habitat quality, suggesting that small tributary networks, as a whole, provide more suitable conditions for brook trout survival relative to mainstem habitats. Size-class differences in apparent survival appear to be context specific. Our results mirror those described by Petty et al. (2005) suggesting that within the upper Shavers Fork large adult brook trout are dominant and are capable of establishing and defending territories. Conversely, Carlson and Letcher (2003) reported that the highest apparent survival rates observed in a second-order system of the Connecticut River Basin were experienced by small adult brook and brown trout. Differences in habitat requirements, movement patterns, emigration rates, and competitive advantage may cause variation in apparent survival between size-classes (Carlson and Letcher 2003). Variation between small and large adults in our study was likely due to differences in ability to establish and defend suitable territories.

We observed significant within tributary reach-scale variability in apparent survival for both small and large adults. Apparent survival increased with increasing basin area. Our results compliment those of Petty et al. (2005) who reported that the highest apparent survival within a large tributary network was observed within small headwater reaches. The small headwater reaches considered by Petty et al. (2005) are, in fact, similar in size to our largest reaches. Together, these studies imply that brook trout apparent survival within the upper Shavers Fork peaks within the largest reaches of small systems. This is likely due to factors associated with habitat complexity, patch geometry, and barriers to dispersal. Larger patches are often characterized by increased complexity, habitat diversity, and food resources (Horan et al. 2000) which should reduce competitive interactions and promote residency (Keeley 2001). In addition, larger patches contain more area and small scale movements generally do not encounter patch boundaries (Hill et al. 1996). The ability to access high quality foraging habitat (e.g. main stem) 
is likely reduced by barriers to dispersal which are common within small streams (Riley et al. 1992). Consequently, brook trout within this system tend to occupy the most productive patches (i.e. largest patches) within close proximity to quality reproductive habitat. The possibility that barriers to dispersal increase site fidelity within small streams is further supported by the fact that we observed a positive relationship between small adult apparent survival and distance from mainstem.

Immigration rates varied considerably both within and across spatial scales. Consistent patterns in brook trout immigration rates at the tributary network reach-scale were generally lacking, although there was considerable site-to-site variation. We observed seasonally consistent immigration of large adult brook trout into headwater reaches. This result was surprising considering Petty et al. (2005) reported increased immigration by this size-class into large systems throughout most of the year. This contradiction suggests that patterns of large adult distribution may be context specific. We did not observe any relationships between local physical habitat and small adult brook trout immigration. Similarly, Petty et al. (2005) was unable to relate small adult immigration rates to specific regions within a large tributary network. It is possible that the lack of a pattern in small adult immigration within this region is because this size-class is less adept at establishing and defending territories (Riley et al. 1992).

Summed estimates of apparent survival and immigration rates allowed us to examine spatial and temporal trends in brook trout population growth rates and determine the extent to which population abundance was influenced by local survival or dispersal. Within our study area, apparent survival showed considerable spatial variation but little temporal change across all spatial scales. This suggests that population abundance decreases consistently and predictably from tributary network-to-tributary network and from reach-to-reach. Conversely, immigration 
rates were both spatially and temporally variable across all spatial scales. Consequently, local immigration was the dominate mechanism responsible for determining the rate of population change at the tributary reach- and main stem reach-scale. However, variable immigration rates did not play the same role at the whole tributary network-scale, because at this scale immigration was often very low or not observed and, therefore, did little to affect population change. Our results are consistent with several other studies. Petty et al. (2005) reported that seasonal estimates of brook trout immigration rates were highly variable and ultimately determined population size at the reach-scale. Gowan and Fausch (1996) showed that immigration was the dominate mechanism leading to increased abundance of stream-dwelling brook trout. Gowan and Fausch (1996) noted that brook trout were immigrating into their study reaches from distant patches not simply redistributing themselves among reaches, which was often the case in our study.

Small basin area tributary networks, in general, acted as local isolates. These systems received insufficient immigration from external habitats to sustain populations over the course of the study. Populations, however, did persist largely due to local reproduction. Other research within the upper Shavers Fork has reported similar findings. Petty et al. (2005) noted that headwater reaches within this region were generally not influenced by immigration. Thorne (2004) mentioned that a large proportion of seasonal samples within these small headwater systems consisted of previously marked individuals, suggesting low rates of population turnover. The majority of the small tributary networks were self sustaining throughout the duration of the study, although interactions between tributary networks and main stem habitat as well as among tributary networks were observed. 
Population structure- This study suggests that the structure of the upper Shavers Fork brook trout population is a complex mosaic of elements found in each of the watershed-scale metapopulation models (Figure 24). At the scale of the upper Shavers Fork watershed, it appears that the brook trout population is a collection of numerous patchy populations connected in a source sink / metapopulation context. Habitat patches nested within small basin area tributary networks and within the mainstem primarily reflect a patchy population. Support for patchy population dynamics among reaches of small tributary networks is centered on two factors. First, movement across reach boundaries was common for both small and large adults, meaning that patches were fairly connected. Second, we observed some degree of ontogenetic shifts in habitat use by brook trout residing within small basin area tributaries, demonstrating that individuals moved throughout the tributary networks in order to access more suitable habitat. Similarly, high rates of immigration suggest patchy population dynamics throughout the mainstem. Estimates of population growth based on summed estimates of apparent survival, immigration rates, and local recruitment provided evidence for source-sink interactions between small tributary networks and main stem habitat. Local recruitment was the dominant process responsible for the maintenance of brook trout populations within small tributary networks. Main stem reaches, however, were relatively unaffected by local recruitment and relied on immigration from external sources for population persistence. Furthermore, reduced survival and high rates of immigration combine to suggest high levels of population turnover within the main stem. Small tributary networks did provide a source of immigrants to the main stem; however, no single small tributary network or group of networks stood out as a dominate source of brook trout to main stem habitats. It appears that small tributary networks acted in aggregate as a source that supplied individuals to the mainstem through a constant slow leak. Support for 
metapopulation structure is based on the observed low rate of brook trout movement between small tributary networks.

The complexities of natural populations pose challenges to understanding the dynamics of populations inhabiting variable environments, but results from large-scale studies such as this will likely prove critical for the successful long-term management of aquatic ecosystems (Dunham and Rieman 1999, Fausch et al. 2002). The successful restoration and conservation of brook trout populations throughout this region requires an understanding of key processes that influence the persistence of populations or metapopulations (Rieman and Dunham 2000). Without a thorough understanding of how metapopulations are structured it is unlikely that these processes will be identified, thus limiting the effect of management activities (Cooper and Mangel 1998). Given that reproductive habitat and dispersal were found to be critical elements in structuring the upper Shavers Fork brook trout population, we suggest that watershed-scale efforts designed to preserve the physical and chemical integrity of reproductive habitat as well as restoring the connectivity between habitat patches be considered essential management priorities. 


\section{References}

Albanese, B., P. L. Angermeier, and S. Dorai-Raj. 2004. Ecological correlates of fish movement in a network of Virginia streams. Canadian Journal of Fisheries Science 61:857-869.

Anderson, R. O. and R. M. Neumann. 1996. Length, weight, and associated structural indices. Pages 447-482 in B.R. Murphy and D.W. Willis, editors: Fisheries Techniques, 2nd edition. American Fisheries Society, Bethesda, MD.

Angermier, P. L. and J. R. Karr. 1986. Applying an index of biotic integrity based on streamfish communities: considerations in sampling and interpretation, North American Journal of Fisheries Management 6:418-427.

Angermier, P. L. and M. R. Winston. 1998. Local vs. regional influences on local diversity in stream fish communities of Virginia. Ecology 79:911-927.

Bahr, M. A., and J. M. Shrimpton. 2004. Spatial and quantitative patterns of movement in large bull trout (Salvelinus confluentus) from a watershed in north-western Bristish Columbia, Canada, are due to habitat selection and not differences in life history. Ecology of Freshwater Fish 13:294-304.

Beard, T. D., and R. F. Carline. 1991. Influence of spawning and other stream habitat features on spatial variability of wild brown trout. Transactions of the American Fisheries Society 120:711-722.

Bernstein, C., A. Kacelnik, and J. R. Krebs. 1988. Individual decisions and the distribution of predators in a patchy environment. Journal of Animal Ecology 57:1007-1026.

Bopp, J. 2002. The combined effects of water chemistry, canopy cover, and basin area on benthic macroinvertebrates along a central Appalachian stream continuum. Thesis submitted to the Davis College of Agriculture, Forestry, and Consumer Sciences, West Virginia University.

Bjornstad, O., H. P. Anderssen, and R. A. Ims. 1998. Effects of habitat patchiness and connectivity on the spatial ecology of the root vole Microtus oeconomus. Journal of Animal Ecology 67:127-140.

Burnham, K. P., and D. R. Anderson. 1998. Model selection and inference: a practicle information theoretic approach. Springer-Verlag, New York.

Carlson, S. M., and B. H. Letcher. 2003. Variation in brook and brown trout survival within and among seasons, species, and age classes. Journal of Fish Biology 63:780-794.

Cooper, A. B., and M. Mangel. 1998. The dangers of ignoring metapopulation structure for the conservation of salmonids. Fisheries Bulletin 97:213-226. 
Cunjak, R. A. 1996. Winter habitat of selected stream fishes and potential impacts from landuse activity. Canadian Journal of Fisheries and Aquatic Sciences 53:267-282.

Curry, R. A., D. Sparks, and J. V. D. Sande. 2002. Spatial and temperal movements of a riverine brook trout population. Transactions of the American Fisheries Society 131:551-560.

Dolloff, A. C., H. E. Jennings, and M. D. Owens. 1997. A comparison of basin-wide and representative reach habitat survey techniques in three southern Appalachian watersheds. North American Journal of Fisheries Management 17:339-347.

Dunham, J. B., and B. E. Rieman. 1999. Metapopulation structure of bull trout: influences of physical, biotic, and geometrical landscape characteristics. Ecological Applications 9:642-655.

Dunning, J. B., B. J. Danielson, and H. R. Pulliam. 1992. Ecological processes that affect populations in complex landscapes. Oikos 65:169-175.

Fahrig, L., and G. Merriam. 1994. Conservation of fragmented populations. Conservation Biology 8:50-59.

Fausch, K. D., C. L. Hawkes, and M. G. Parsons. 1988. Models that predict standing crop of stream fish from habitat variables: 1950-1985. Gen. Tech. Rep. PNW-GTR-213. Portland, OR: U.S. Department of Agriculture, Forest Service, Pacific Northwest Research Station. 52 p.

Fausch, K. D., C. E. Torgersen, C. V. Baxter, and H. W. Li. 2002. Landscapes to riverscapes: bridging the gap between research and conservation of stream fishes. Bioscience 52:483-497.

Flebbe, P. A. 1994. A regional view of the margin: salmonid abundance and distribution in the southern Appalachian Mountains of North Carolina and Virginia. Transactions of the American Fisheries Society 123:657-667.

Flick, W. A., and D. A. Webster. 1975. Movement, growth, and survival in a stream population of wild brook trout (Salvelinus fontinalis) during a period of removal of non-trout species. Journal of the Fisheries Research Board of Canada 32:1359-1367.

Fretwell, S. D., and H. L. Lucas. 1970. On territorial behavior and other factors influencing habitat distribution in birds. I. Theoretical development. Acta Biotheoretica 19:16-36.

Frissel, C. A., W. J. Liss, C. E. Warren, and M. D. Hurley. 1986. A hierarchical framework for stream habitat classification: viewing streams in a watershed context. Environmental Management 10:199-214.

Galbreath, F. F. 2001. Persistence of native southern Appalachian brook trout populations in the Pigeon River system, N.C. North American Journal of Fisheries Management 21:927-934. 
Gerking, S. D. 1959. The restricted movement of fish populations. Biological Review 34:221242

Goujot, R. C. 2002. Geology, Surface Hydrology, and Fish Habitat Relationships in the upper Shavers Fork Drainage Basin, West Virginia. Thesis submitted to the Eberly College of Arts and Sciences, Department of Geology and Geography, West Virginia University.

Gowan, C., M. K. Young, K. D. Fausch, and S. C. Riley. 1994. Restricted movement in resident stream salmonids: a paradigm lost? Canadian Journal of Fisheries and Aquatic Sciences 51:2626-2637.

Gowan, C., and K. D. Fausch. 1996. Long-term demographic responces of trout populations to habitat manipulation in six Colorado streams. Ecological Applications 6:931-946.

Gowan, C., and K. D. Fausch. 1996. Mobile brook trout in two high-elevation streams: reevaluating the concept of restricted movement. Canadian Journal of Fisheries and Aquatic Sciences 53:1370-1381.

Gowan, C., and K. D. Fausch. 2002. Why do foraging stream salmonids move during summer? Environmental Bilology of Fishes 64:139-153.

Hansbarger, J. L. 2005. Trout movement and habitat use in the upper Shavers Fork of the Cheat River West Virginia. Thesis submitted to the Davis College of Agriculture, Forestry, and Consumer Sciences, West Virginia University.

Harrison, S. 1991. Local extinction in a metapopulation context: an empirical evaluation. Biological Journal of the LinneanSociety 42:73-88.

Hilderbrand, R. H., and J. L. Kershner. 2000. Movement patterns of stream-resident cutthroat trout in Beaver Creek, Idaho-Utah. Transactions of the American Fisheries Society 129:11601170 .

Hilderbrand, R. H., and J. L. Kershner. 2004. Are there differences in growth and condition between mobile and resident cutthroat trout? Transactions of the American Fisheries Society 133:1042-1046.

Hill, J. K., C. D. Thomas, and O. T. Lewis. 1996. Effects of habitat patch size and isolation on dispersal by Hesperia comma butterflies: implications for metapopulation structure. Journal of Animal Ecology 65:725-735.

Holt, R. D. 1985. Population dynamics in two-patch environments: some anomalous consequences of an optimal habitat distribution. Theoretical Popululation Biology 28:181-208.

Horan, D. L., J. L. Kershner, C. P. Hawkins, and T. A. Crowl. 2000. Effects of habitat area complexity on Colorado River cutthroat trout density in Uinta Mountain streams. Transaction of the American Fisheries Society 129:1250-1263. 
Larson, G. L., and S. E. Moore. 1985. Encroachment of exotic rainbow trout into stream populations of native brook trout in the southern Appalachian mountains. Transactions of the American Fisheries Society 114:195-203.

Larson, G. L., S. E. Moore, and B. Carter. 1995. Ebb and flow of encroachment by nonnative rainbow trout in a small stream in the southern Appalachian Mountatins. Transactions of the American Fisheries Society 124:613-622.

Levins, R. 1969. Some demographic and genetic consequences of environmental heterogeneity for biological control. Bulletin of the Entomological Society of America. 15:237-240.

Levins, R. 1970. Extinction. Pages 77-107 in M. Gerstenhaber, ed. Some mathematical problems in biology. Mathematical Society, Providence, R.I.

Lewin, R. 1989. Sources and sinks complicate ecology. Science 234:477-478.

Lohr, S. C., and J. L. West. 1992. Microhabitat selection by brook and rainbow trout in a southern Appalachian stream. Transaction of the American Fisheries Society 121:729-736.

Keeley, E. R. 2001. Demographic responses to food and space competition by juvenile steelhead trout. Ecology 82:1247-1259.

McGarigal, K., S. Cushman, and S. Stafford. 2000. Multivariate statistics for wildlife and ecology research. Springer, New York.

Moilanen, A., and I. Hanski. 1998. Metapopulation Dynamics: Effects of habitat and landscape structure. Ecology 79:2503-2515.

NADP. 2000. http://nadp.sws.uiuc.edu. National Atmospheric and Deposition Program.

Peterson, D. P., K. D. Fausch, and G. C. White. 2004. Population ecology of an invasion: effects of brook trout on native cutthroat trout. Ecological Applications 14:754-772.

Petty, J. T., P. J. Lamothe, and P. M. Mazik. 2005. Spatial and seasonal dynamics of brook trout populations in a central Appalachian watershed. Transactions of the American Fisheries Society 134:572-587.

Petty, J. T. and D. W. Thorne. 2005. An ecologically based approach to identify restoration priorities in an acidic Appalachian watershed. Restoration Ecology 13:348-357.

Pulliam, H. R. 1988. Sources, sinks and population regulation. American Naturalist 132:652661. 
Riley, S. C., and K. D. Fausch, C. Gowan. 1992. Movement of brook trout (Salvelinus fontinalis) in four small subalpine streams in northern Colorado. Ecology of Freshwater Fish $1: 112-122$.

Rieman, B. E., B. R. Dickerson, E. Beever, R. D. Duncan, and G. L. Vinyard. 2000. Effects of food limitation and emigration on self-thinning in experimental minnow cohorts. Journal of Animal Ecology 69:927-934.

Rieman, B. E., and J. B. Dunham. 2000. Metapopulations and salmonids: a synthesis of life history patterns and empirical observations. Ecology of Freshwater Fish 9:51-64.

Rieman, B. E., and J. D. McIntyre. 1993. Demographic and habitat requirements for conservation of bull trout. U.S. Forest Service, Intermountain Research Station General Technical Report INT-302, Ogden, Utah, USA.

Rodriguez, M. A. 2002. Restricted movement in stream fish: the paradigm is incomplete, not lost. Ecology 83:1-13.

Roff, D. A. 2002. Life history evolution. Sunderland, MA: Sinauer Associates.

Rosenfeld, J. 2003. Assessing the habitat requirements of stream fishes: an overview and evaluation of different approaches. Transactions of the American Fisheries Society 132:953-968.

Schlosser, I. J. 1991. Stream fish ecology: a landscape perspective. Bioscience 41:704-712.

Schlosser, I. J. 1995. Critical landscape attributes that influence fish population dynamics in headwater streams. Hydrobiologia 303:71-81.

Schlosser, I. J., and P. L. Angermeier. 1995. Spatial variation in demographic processes of lotic fishes: Conceptual models, empirical evidence, and implications for conservation. American Fisheries Society Symposium 17:392-401.

Simonson, T. D., J. Lyons, and P. D. Kanehl. 1994. Quantifying fish habitat in streams: transect spacing, sample size, and a proposed framework. North American Journal of Fisheries Management 14:607-615.

Stoneman, C. L., and M. L. Jones. 2000. The influence of habitat features on the biomass and distribution of three species of southern Ontario stream salmonines. Transactions of the American Fisheries Society 129:639-657.

Torgersen, C. E., C. V. Baxter, H. W. Li., and B. A. McIntosh. In press. Landscape influences on longitudinal patterns of river fishes: continuous analysis if fish-habitat relationships. Pages xxx-xxx in R. M. Hughes, L. Wang, and P. W. Seelbach, editors. Influence of landscapes on stream habitats and biological assemblages. American Fisheries Society, Symposium xx, Bethesda, Maryland. 
Thorne, D. W. 2004. Spatial and seasonal variation in brook trout diet, growth, and consumption in a complex Appalachian watershed. Thesis submitted to the Davis College of Agriculture, Forestry, and Consumer Sciences, West Virginia University.

Vannote, R. L., G. W. Minshall, K. W. Cummins, J. R. Sedell, and C. E. Cushing. 1980. The river continuum concept. The Canadian Journal of Fisheries and Aquatic Sciences 37:130-137.

Waite, I. R., A. T. Herlihy, D. P. Larsen, and D. J. Klemm. 2000. Comparing strengths of geographic and non-geographic classifications of stream benthic macroinvertebrates in the MidAtlantic Highlands, USA. Journal of the North American Benthological Society 19:429-441.

Watkinson, A. R., and W. J. Sutherland. 1995. Sources, sinks and pseudo-sinks. Journal of Animal Ecology 64:126-130.

Welsh, S. A. and S. A. Perry. 1997. Acidification and fish occurrence in the upper Cheat River drainage, West Virginia. Journal of the American Water Resources Association 33:423-429.

Whitham, T. G. 1980. The theory of habitat selection: examined and extended using Pemphigus aphids. The American Naturalist 115:449-466.

Wiens, J. A. 1989. Spatial scaling in ecology. Functional Ecology 3:385-397.

Wigington, P. J., Jr., J. P. Baker, D. R. DeWalle, W. A. Kretser, P. S. Murdoch, H. A. Simonin, J. Van Sickle, M. K. McDowell, D. V. Peck, and W. R. Barchet. 1996. Episodic acidification of small streams in the northeast United States: episodic response project. Ecological Applications 6:374-388.

Yoder, C. O., and M. S. Smith. 1999. Using fish assemblages in a state biological assessment and criteria program: essential concepts and considerations. In Simon, T. P. Editor. 1999. Assessing the sustainability and biological integrity of water resources using fish communities. CRC press. New York, USA. 671p. 
Table 1. Summary of brook trout mark-recapture data. Juveniles were too small to be effectively marked in spring 2004.

Recruitment from one size class to the next occurred between the fall 2004 and spring 2005 sampling periods. Consequently, small adult recaptures during spring 2005 include juveniles marked in 2004; similarly, large adult recaptures in spring 2005 include small adults that reached a standard lenght of $115 \mathrm{~mm}$ by spring 2005 .

\begin{tabular}{|c|c|c|c|c|c|c|c|c|c|c|c|c|}
\hline \multirow{3}{*}{$\begin{array}{l}\text { Size/ } \\
\text { Class }\end{array}$} & \multicolumn{3}{|c|}{ Spring 2004} & \multicolumn{3}{|c|}{ Summer 2004} & \multicolumn{3}{|c|}{ Fall 2004} & \multicolumn{3}{|c|}{ Spring 2005} \\
\hline & $\#$ & $\#$ & $\#(\%)$ & \# & \# & $\#(\%)$ & \# & $\#$ & $\#(\%)$ & $\#$ & \# & $\#(\%)$ \\
\hline & Caught & Marked & Recaptures & Caught & Marked & Recaptures & Caught & Marked & Recaptures & Caught & Marked & Recaptures \\
\hline Juvenile & 300 & 0 & ---- & 384 & 336 & NA & 277 & 131 & $133(48)$ & 573 & ---- & NA \\
\hline Small Adult & 578 & 578 & ---- & 514 & 237 & $277(54)$ & 348 & 102 & $246(71)$ & 475 & ---- & $339(71)$ \\
\hline Large Adult & 215 & 215 & ---- & 191 & 75 & $116(61)$ & 130 & 45 & $85(65)$ & 209 & ---- & $157(75)$ \\
\hline Total & 1093 & 793 & ---- & 1089 & 315 & $393(36)$ & 755 & 291 & $464(62)$ & 1257 & ---- & 496 \\
\hline
\end{tabular}


Table 2. Factor loading scores for dominant instream physical habitat gradients derived from 86 perennial stream reaches within the upper Shavers Fork watershed. Only factor loadings $>|0.4|$ are presented

\begin{tabular}{lccc}
\hline & PC 1 & PC 2 & PC 3 \\
\hline Eigen Value & 2.12 & 1.90 & 1.36 \\
\% Contribution & 26.50 & 23.78 & 17.00 \\
\hline Basin Area $\left(\mathrm{km}^{2}\right)$ & 0.43 & ---- & ---- \\
Slope $(\%)$ & ---- & 0.63 & --- \\
Mean Depth $(\mathrm{cm})$ & 0.60 & --- & --- \\
Depth CV & ---- & ---- & 0.57 \\
Mean Velocity $(\mathrm{m} / \mathrm{s})$ & ---- & ---- & -0.63 \\
Mean Distance to Cover & -0.49 & --- & ---- \\
Pool Area $(\%)$ & --- & -0.44 & --- \\
LWD $\left(\mathrm{m}^{2} / \mathrm{m}^{2}\right)$ & --- & 0.50 & 0.41 \\
\hline
\end{tabular}


Table 3. Summary results of the multiple regression analysis relating the proportional abundance of juveniles, small adults, and large adults to principle components of instream physical habitat, distance from main stem, and average $\mathrm{pH}$.

\begin{tabular}{cccccc}
\hline $\begin{array}{c}\text { Age Class / } \\
\text { Habitat Variable }\end{array}$ & F-Value & D.F. & $\mathrm{R}^{2}$ Value & $\begin{array}{c}\text { Direction of } \\
\text { Effect }\end{array}$ & $P$-value \\
\hline \begin{tabular}{c} 
Juvenile \\
\hline $\begin{array}{c}\text { Size Gradient } \\
\text { (PC 1) }\end{array}$
\end{tabular} & 13.78 & 1 & 0.13 & Positive & 0.0004 \\
$\begin{array}{c}\text { Complexity Gradient } \\
\text { (PC 3) }\end{array}$ & 9.75 & 1 & 0.09 & Negative & 0.0025 \\
$\begin{array}{c}\text { Slope Gradient } \\
\text { (PC 2) }\end{array}$ & 4.08 & 1 & 0.04 & Negative & 0.05 \\
Full Model & 9.20 & 85 & 0.25 & & $<0.0001$
\end{tabular}

Small Adult

\begin{tabular}{cccccc}
\hline $\begin{array}{c}\text { Size Gradient } \\
\text { (PC 1) }\end{array}$ & 49.64 & 1 & 0.27 & Positive & $<0.0001$ \\
$\begin{array}{c}\text { Average pH } \\
\text { Complexity Gradient } \\
\text { (PC 3) }\end{array}$ & 12.14 & 1 & 0.11 & Positive & 0.0008 \\
Full Model & 6.55 & 1 & 0.05 & Negative & 0.0123 \\
& 20.17 & 85 & 0.42 & & $<0.0001$ \\
Large Adult & & & & & \\
\hline $\begin{array}{c}\text { Size Gradient } \\
\text { (PC 1) }\end{array}$ & 66.02 & 1 & 0.33 & Positive & $<0.0001$ \\
Average pH & 18.27 & 1 & 0.12 & Positive & $<0.0001$ \\
Full Model & 33.92 & 85 & 0.45 & & $<0.0001$ \\
\hline
\end{tabular}


Table 4. Total number of juvenile, small adult, and large adult brook trout originally marked in 1 of 15 small basin area stream networks and the number $( \pm 1 \%)$ that were found to have moved into and stayed within main stem habitat (movement type I) or moved into a different small basin area network (movement type 2). 0, $2(1.5 \%)$, and $1(0.8 \%)$ of juvenile, small adult and large adults respectively that were originally marked in the main stem were found to have entered a small basin area stream network. Numbers represent data pooled across all sample seasons.

\begin{tabular}{|c|c|c|c|c|c|c|c|c|c|c|}
\hline \multicolumn{2}{|c|}{$\begin{array}{l}\text { Watershed } \\
\text { Information }\end{array}$} & \multicolumn{3}{|c|}{$\begin{array}{l}\text { Size Class } \\
\text { (\# Marked) }\end{array}$} & \multicolumn{3}{|c|}{ Movement Type I } & \multicolumn{3}{|c|}{ Movement Type II } \\
\hline ID & $\begin{array}{l}\text { Basin } \\
\text { Area }\end{array}$ & Juveniles & $\begin{array}{l}\text { Small } \\
\text { Adults }\end{array}$ & $\begin{array}{l}\text { Large } \\
\text { Adults }\end{array}$ & Juveniles & $\begin{array}{l}\text { Small } \\
\text { Adults }\end{array}$ & $\begin{array}{l}\text { Large } \\
\text { Adults }\end{array}$ & Juveniles & $\begin{array}{l}\text { Small } \\
\text { Adults }\end{array}$ & $\begin{array}{l}\text { Large } \\
\text { Adults }\end{array}$ \\
\hline 1 & 0.20 & 0 & 2 & 0 & ---- & 0 & ---- & --- & $1(50)$ & ---- \\
\hline 2 & 0.36 & 51 & 169 & 42 & 0 & $2(1)$ & $2(5)$ & 0 & $4(2)$ & 0 \\
\hline 3 & 0.14 & 16 & 22 & 2 & $1(6)$ & $1(5)$ & 0 & 0 & 0 & 0 \\
\hline 4 & 0.30 & 61 & 72 & 27 & $1(2)$ & $2(3)$ & 0 & $1(2)$ & 0 & 0 \\
\hline 5 & 0.74 & 136 & 138 & 39 & 0 & $3(2)$ & $1(3)$ & 0 & $2(2)$ & 0 \\
\hline 6 & 0.27 & 14 & 9 & 1 & 0 & $2(22)$ & 0 & 0 & $2(22)$ & 0 \\
\hline 7 & 0.36 & 0 & 0 & 0 & ---- & ---- & ---- & ---- & ---- & ---- \\
\hline 8 & 0.21 & 7 & 9 & 5 & $1(14)$ & $1(11)$ & 0 & 0 & $1(11)$ & $1(20)$ \\
\hline 9 & 0.64 & 41 & 3 & 1 & $1(2)$ & 0 & 0 & $1(2)$ & 0 & 0 \\
\hline 10 & 0.39 & 23 & 61 & 15 & 0 & $1(2)$ & 0 & 0 & $3(5)$ & 0 \\
\hline 11 & 0.20 & 1 & 3 & 0 & 0 & 0 & 0 & 0 & 0 & 0 \\
\hline 12 & 0.21 & 0 & 0 & 0 & ---- & ---- & ---- & ---- & ---- & ---- \\
\hline 13 & 0.69 & 76 & 164 & 47 & 0 & $3(2)$ & 0 & 0 & $1(1)$ & 0 \\
\hline 14 & 1.50 & 7 & 142 & 42 & 0 & $1(1)$ & $1(2)$ & 0 & 0 & 0 \\
\hline 15 & 0.09 & 0 & 4 & 0 & ---- & 0 & ---- & ---- & 0 & ---- \\
\hline Total & ---- & 433 & 798 & 221 & $4(1)$ & $16(2)$ & $4(2)$ & $2(1)$ & $14(2)$ & $1(1)$ \\
\hline
\end{tabular}


Table 5. Seasonal mean, standard error, and ranges for small and large adult brook trout apparent survival $(\Phi)$, immigration $(\Gamma)$ rates, and rate of population change $(\lambda)$ across multiple spatial scales. Letters indicate significant differences at $\alpha=0.05$ level.

\begin{tabular}{|c|c|c|c|c|c|c|c|c|c|}
\hline \multirow{3}{*}{$\begin{array}{c}\text { Parameter / } \\
\text { Age Class }\end{array}$} & \multicolumn{9}{|c|}{ Seasonal Interval } \\
\hline & \multicolumn{3}{|c|}{ Sp04-Su04 } & \multicolumn{3}{|c|}{$\mathrm{Su} 04-\mathrm{Fa} 04$} & \multicolumn{3}{|c|}{ Fa04-Sp05 } \\
\hline & Mean & S.E. & Range & Mean & S.E. & Range & Mean & S.E. & Range \\
\hline & \multicolumn{9}{|c|}{ Tributary Network Reach-Scale } \\
\hline \multicolumn{10}{|l|}{ Apparent Survival } \\
\hline Small Adults & 0.48 & 0.04 & $0-1$ & 0.46 & 0.05 & $0-1$ & 0.38 & 0.05 & $0-1$ \\
\hline Large Adults & $0.62^{\mathrm{A}}$ & 0.05 & $0-1$ & $0.46^{\mathrm{AB}}$ & 0.05 & $0-1$ & $0.36^{\mathrm{B}}$ & 0.05 & $0-1$ \\
\hline \multicolumn{10}{|l|}{ Immigration Rate } \\
\hline Small Adults & 0.44 & 0.10 & $0-3.38$ & 0.49 & 0.14 & $0-5$ & 0.39 & 0.11 & $0-5$ \\
\hline Large Adults & 0.36 & 0.09 & $0-3$ & 0.21 & 0.05 & $0-1.57$ & 0.26 & 0.07 & $0-2$ \\
\hline \multicolumn{10}{|l|}{ Population Change } \\
\hline Small Adults & $0.92^{\mathrm{A}}$ & 0.10 & $0-4.38$ & $0.95^{\mathrm{A}}$ & 0.14 & $0-6$ & $0.77^{\mathrm{B}}$ & 0.12 & $0-5$ \\
\hline Large Adults & $0.98^{\mathrm{A}}$ & 0.09 & $0-3.45$ & $0.67^{\mathrm{B}}$ & 0.06 & $0-2.04$ & $0.62^{\mathrm{B}}$ & 0.09 & $0-2$ \\
\hline & \multicolumn{9}{|c|}{ Whole Tributary Network-Scale } \\
\hline Apparent Survival & & & & & & & & & \\
\hline Small Adults & 0.55 & 0.10 & $0-1$ & 0.43 & 0.10 & $0-0.83$ & 0.39 & 0.10 & $0-0.85$ \\
\hline Large Adults & 0.68 & 0.12 & $0-0.95$ & 0.60 & 0.10 & $0-0.84$ & 0.46 & 0.08 & $0-0.76$ \\
\hline \multicolumn{10}{|l|}{ Immigration Rate } \\
\hline Small Adults & 0.11 & 0.05 & $0-0.61$ & 0.52 & 0.31 & $0-4$ & 0.14 & 0.07 & $0-0.95$ \\
\hline Large Adults & 0.09 & 0.06 & $0-0.61$ & 0.02 & 0.01 & $0-0.1$ & 0.27 & 0.13 & $0-1$ \\
\hline \multicolumn{10}{|l|}{ Population Change } \\
\hline Small Adults & 0.67 & 0.13 & $0-1.61$ & 0.95 & 0.27 & $0-4$ & 0.53 & 0.14 & $0-1.71$ \\
\hline Large Adults & 0.77 & 0.14 & $0-1.47$ & 0.62 & 0.11 & $0-0.94$ & 0.73 & 0.15 & $0-1.76$ \\
\hline \multicolumn{10}{|c|}{ Main Stem Reach-Scale } \\
\hline Apparent Survival & & & & & & & & & \\
\hline Small Adults & 0.30 & 0.13 & $0-0.56$ & 0.29 & 0.12 & $0-0.58$ & 0.32 & 0.10 & $0-0.59$ \\
\hline Large Adults & 0.32 & 0.7 & $0.17-0.53$ & 0.36 & 0.6 & $0.19-0.55$ & 0.41 & 0.6 & $0.22-0.58$ \\
\hline \multicolumn{10}{|l|}{ Immigration Rate } \\
\hline Small Adults & $4.17^{\mathrm{A}}$ & 1.78 & $1-10.37$ & $1.17^{\mathrm{A}}$ & 0.41 & $0.39-2.33$ & $0.26^{\mathrm{B}}$ & 0.15 & $0-0.80$ \\
\hline Large Adults & 0.78 & 0.27 & $0.20-1.78$ & 0.90 & 0.22 & $0.50-1.67$ & 1.13 & 0.21 & $0.62-1.80$ \\
\hline \multicolumn{10}{|l|}{ Population Change } \\
\hline Small Adults & $4.47^{\mathrm{A}}$ & 1.82 & $1-10.91$ & $1.45^{\mathrm{AB}}$ & 0.30 & $0.75-2.33$ & $0.58^{\mathrm{B}}$ & 0.24 & $0-1.40$ \\
\hline Large Adults & 1.10 & 0.26 & $0.63-2.07$ & 1.26 & 0.19 & $0.89-1.96$ & 1.54 & 0.18 & $1.11-2.21$ \\
\hline
\end{tabular}


Table 6. Seasonal correlations between small and large adult brook trout apparent survival $(\Phi)$ and dominant instream physical habitat gradients. Significant correlations at $\alpha=0.05$ level are listed in bold.

\begin{tabular}{|c|c|c|c|c|c|c|}
\hline \multirow{2}{*}{$\begin{array}{l}\text { Size Class/ } \\
\text { Parameter } \\
\end{array}$} & \multicolumn{2}{|c|}{ Sp04-Su04 } & \multicolumn{2}{|c|}{$\mathrm{Su} 04-\mathrm{Fa} 04$} & \multicolumn{2}{|c|}{ Fa04-Sp05 } \\
\hline & $r$ & $p$ & $r$ & $p$ & $r$ & $p$ \\
\hline \multicolumn{7}{|l|}{ Small Adult } \\
\hline Stream Size (PC 1) & 0.34 & 0.013 & 0.15 & 0.290 & 0.27 & 0.058 \\
\hline Slope (PC 2) & 0.24 & 0.084 & 0.44 & 0.001 & 0.42 & 0.002 \\
\hline Complexity (PC 3) & 0.06 & 0.658 & -0.16 & 0.253 & -0.13 & 0.376 \\
\hline \multicolumn{7}{|l|}{ Large Adult } \\
\hline Stream Size (PC 1) & 0.19 & 0.226 & 0.28 & 0.064 & 0.24 & 0.122 \\
\hline Slope (PC 2) & 0.16 & 0.310 & 0.29 & 0.057 & 0.03 & 0.834 \\
\hline Complexity (PC 3) & -0.04 & 0.786 & 0.03 & 0.841 & -0.06 & 0.718 \\
\hline
\end{tabular}


Table 7. Seasonal correlations between small and large adult brook trout immigration $(\Gamma)$ rates and dominant instream physical habitat gradients. Significant correlations at $\alpha=$ 0.05 level are listed in bold.

\begin{tabular}{|c|c|c|c|c|c|c|}
\hline \multirow{2}{*}{$\begin{array}{l}\text { Size Class/ } \\
\text { Parameter }\end{array}$} & \multicolumn{2}{|c|}{$\mathrm{Sp04-Su04}$} & \multicolumn{2}{|c|}{$\mathrm{Su} 04-\mathrm{Fa} 04$} & \multicolumn{2}{|c|}{ Fa04-Sp05 } \\
\hline & $r$ & $p$ & $r$ & $p$ & $r$ & $p$ \\
\hline \multicolumn{7}{|l|}{ Small Adult } \\
\hline Stream Size (PC 1) & 0.19 & 0.173 & -0.13 & 0.356 & 0.09 & 0.549 \\
\hline Slope (PC 2) & 0.16 & 0.268 & -0.03 & 0.810 & 0.07 & 0.606 \\
\hline Complexity (PC 3) & -0.04 & 0.767 & 0.06 & 0.664 & -0.08 & 0.581 \\
\hline \multicolumn{7}{|l|}{ Large Adult } \\
\hline Stream Size (PC 1) & -0.03 & 0.8659 & -0.07 & 0.6586 & 0.22 & 0.1576 \\
\hline Slope (PC 2) & 0.30 & 0.0476 & 0.11 & 0.4739 & -0.29 & 0.0573 \\
\hline Complexity (PC 3) & -0.07 & 0.6543 & -0.13 & 0.3899 & 0.20 & 0.1940 \\
\hline
\end{tabular}




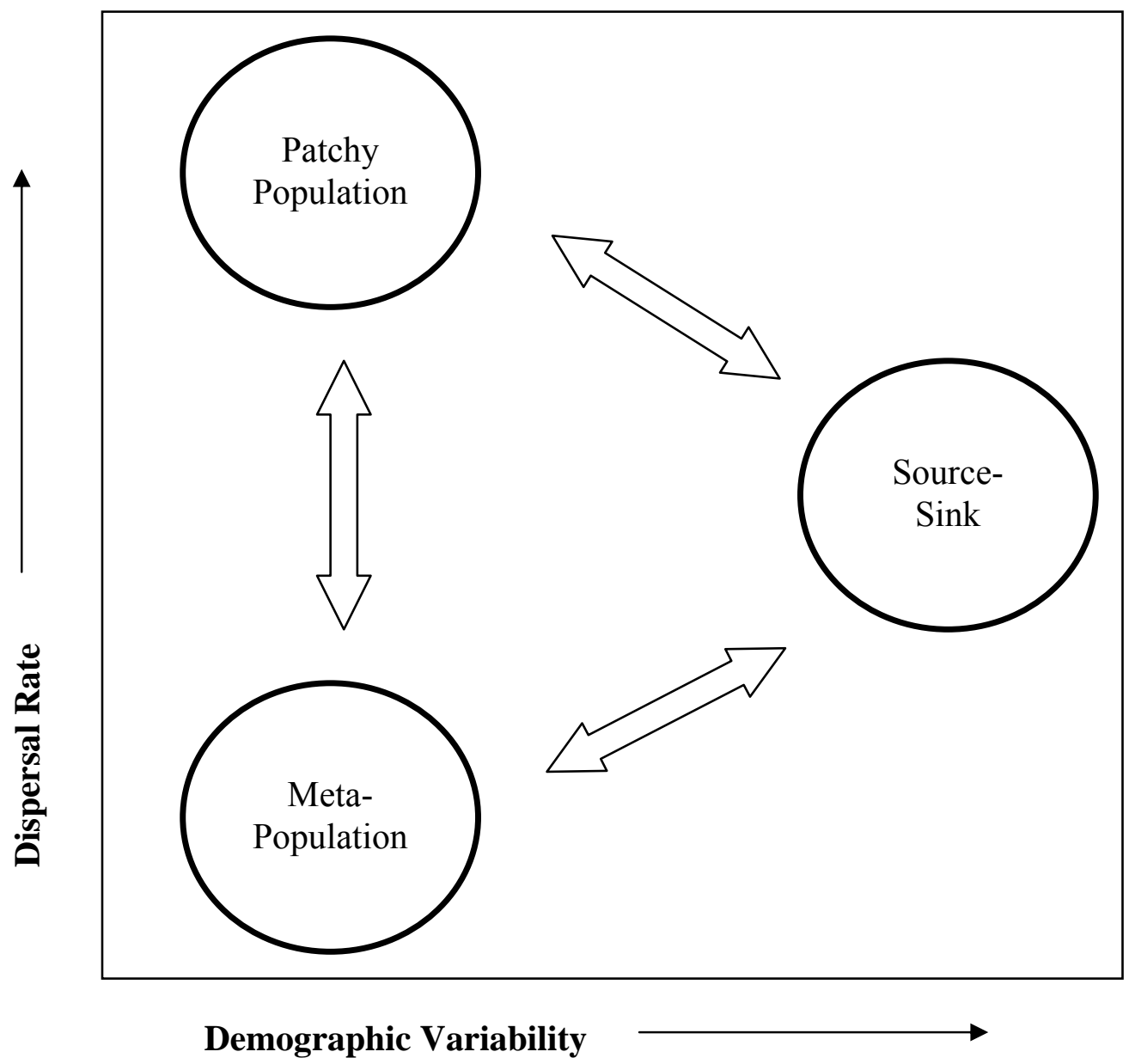

Figure 1. Location of the dominant watershed-scale metapopulation models along a continuum of between patch variability in demographic rates and dispersal rate. 

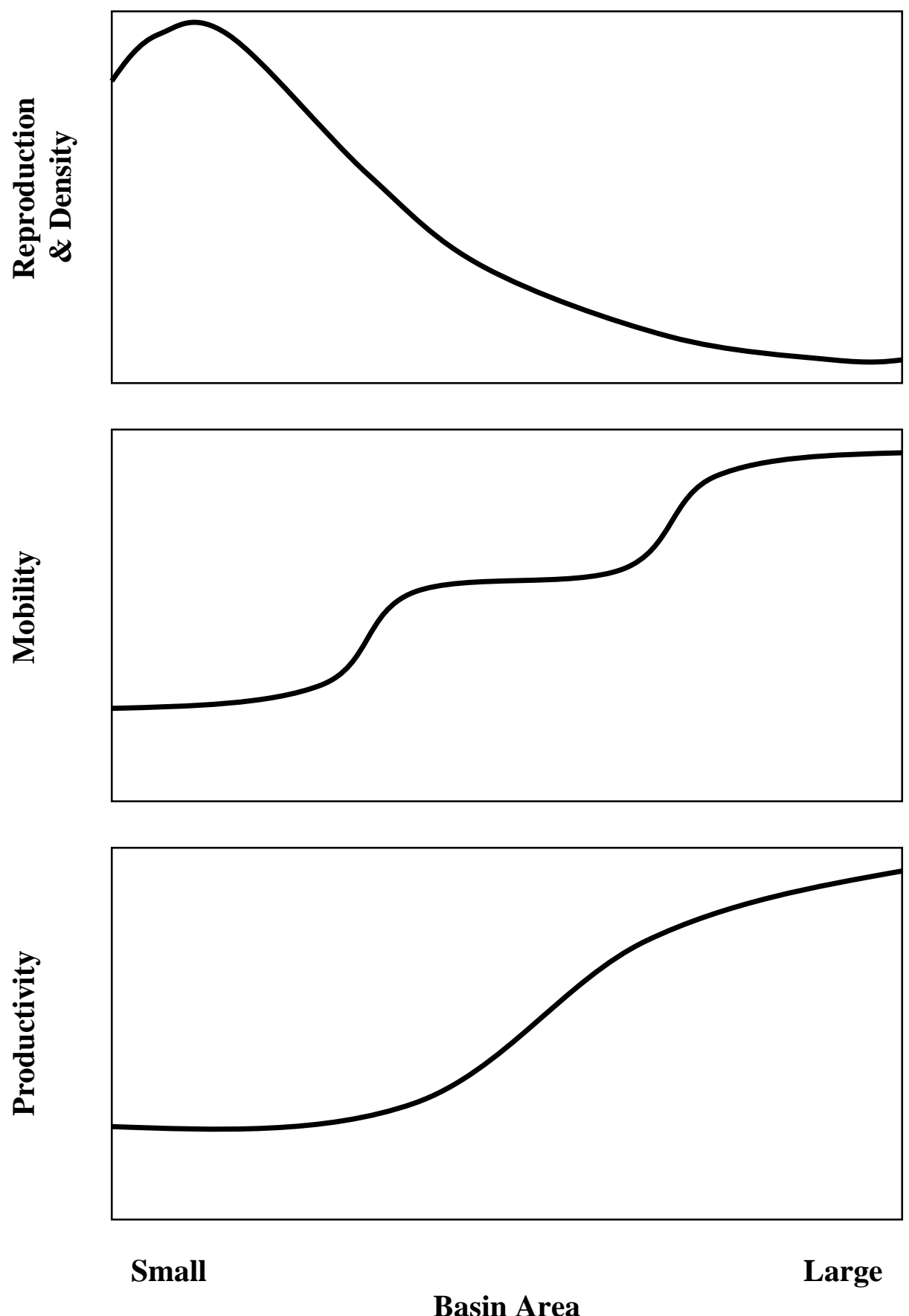

Figure 2. Representation of the current knowledge of the upper Shavers Fork brook trout population. 


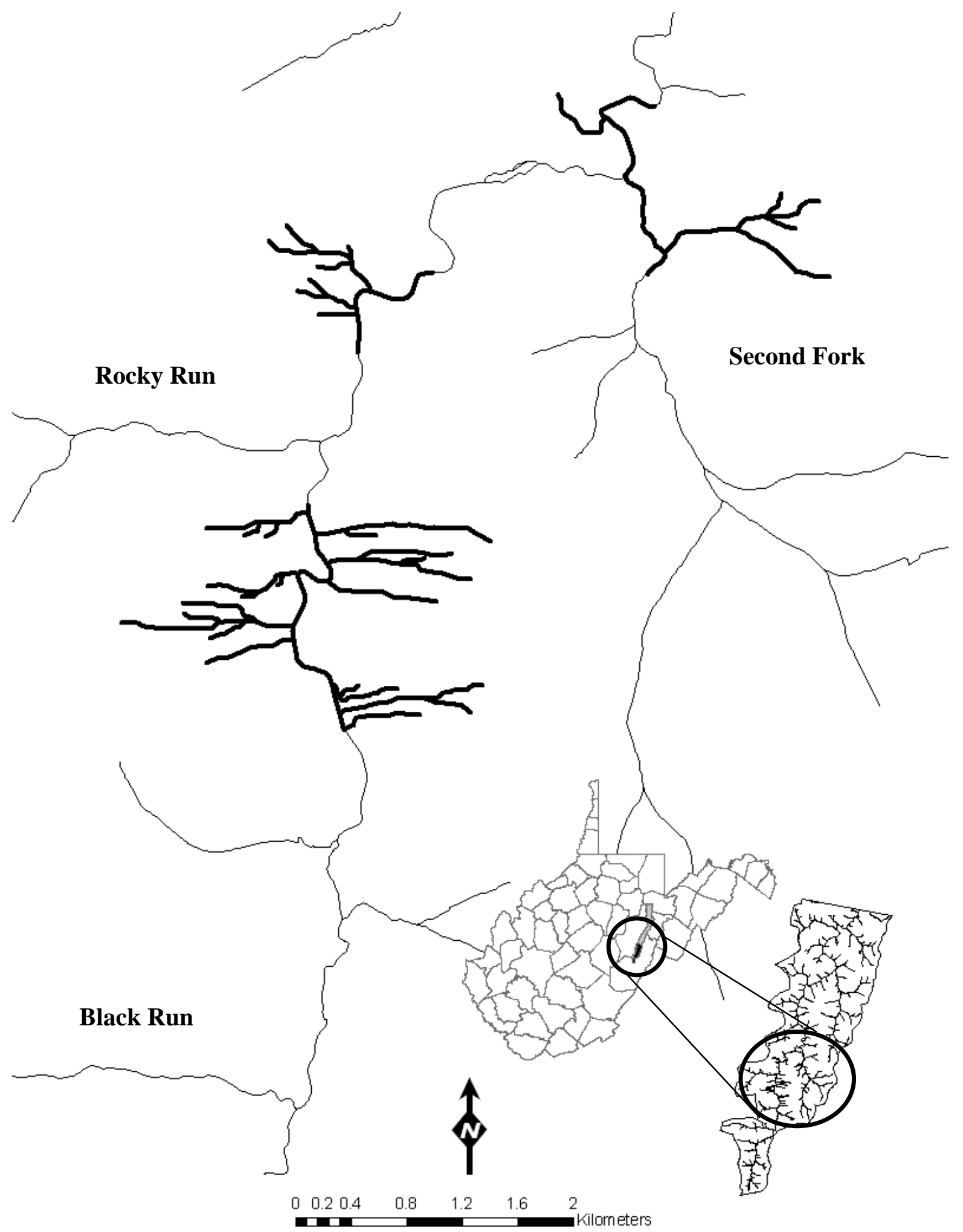

Figure 3. Location of the three study regions (heavy lines) within the upper Shavers Fork watershed of Pocahontas and Randolph counties, West Virginia (inset). 

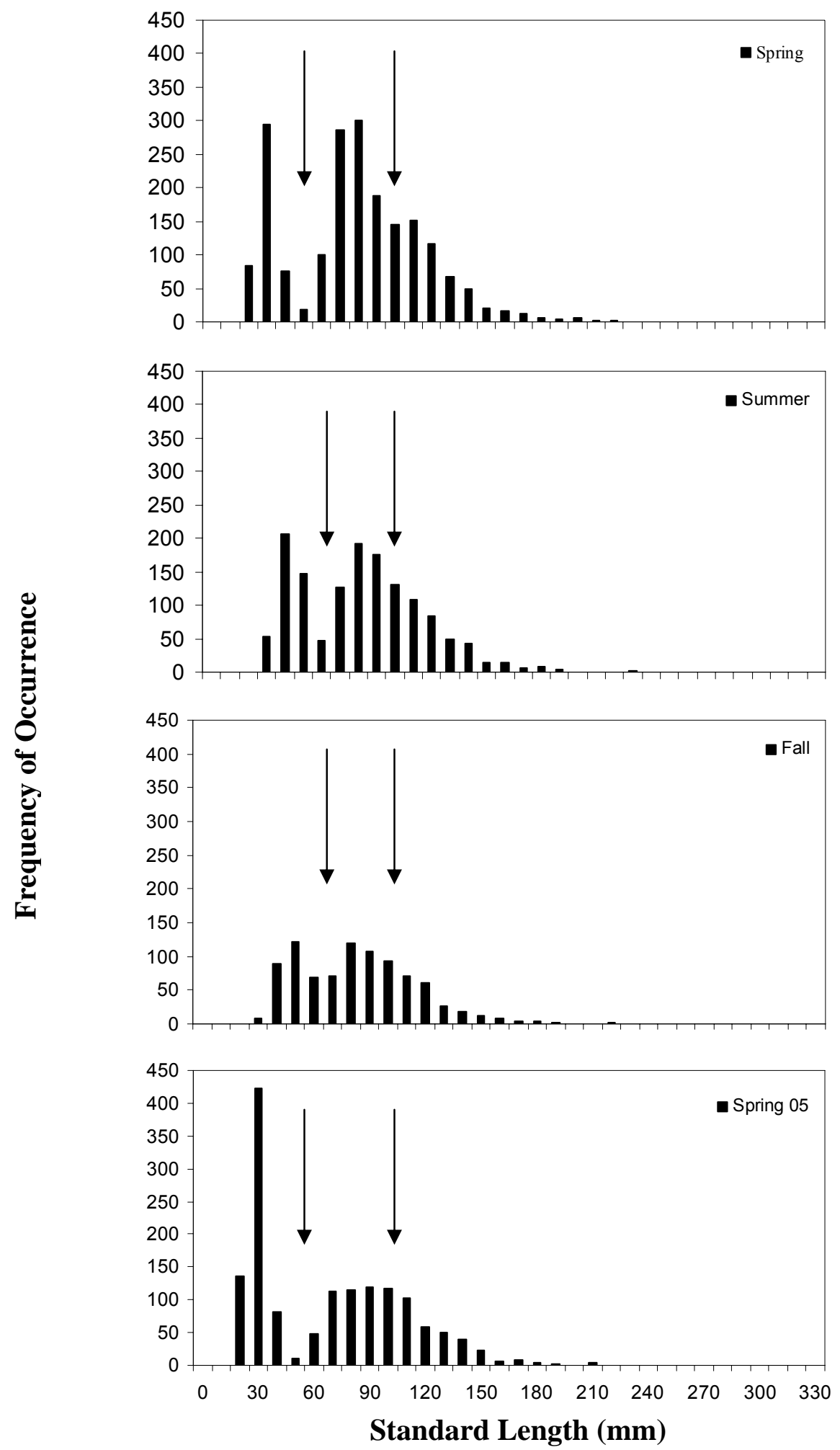

Figure 4. Seasonal brook trout length-frequency histograms used to classify all captured individuals into one of three size classes: juveniles, small adults, large adults. Lengths were pooled across all seasonally sampled sites. 


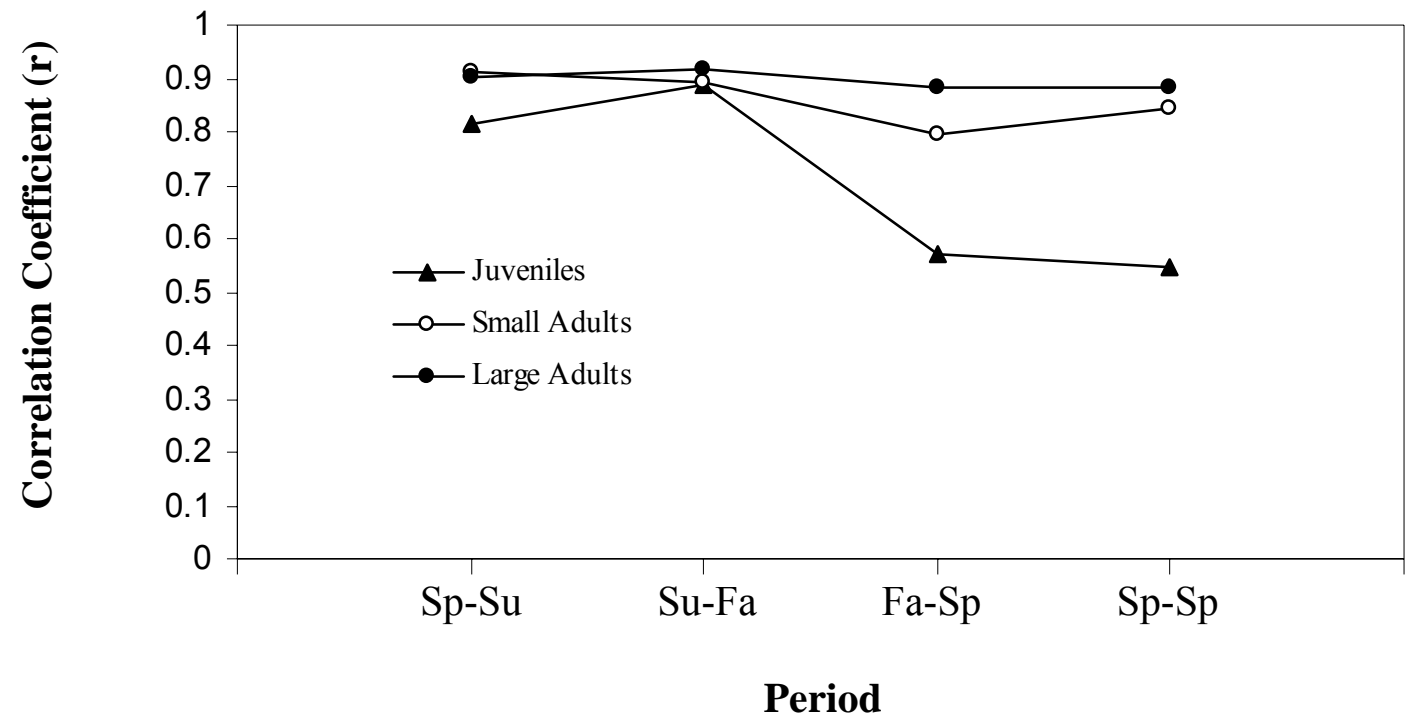

Figure 5. Season-to-season correlation of juveniles, small adult, and large adult proportional abundance across all sites (including main stem). 


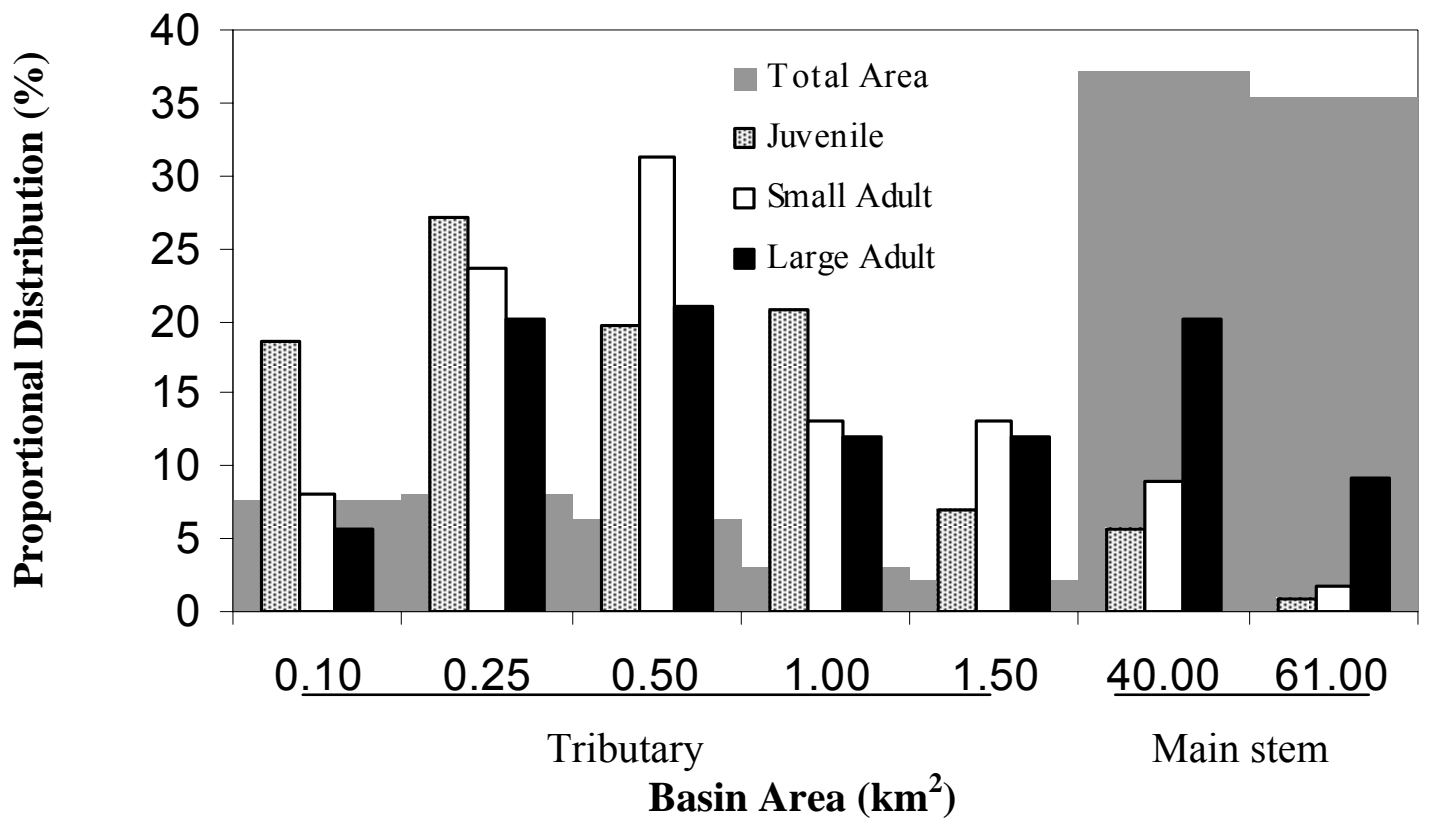

Figure 6. Average proportional abundance of juvenile, small, and large adult brook trout across the available range of stream sizes. 


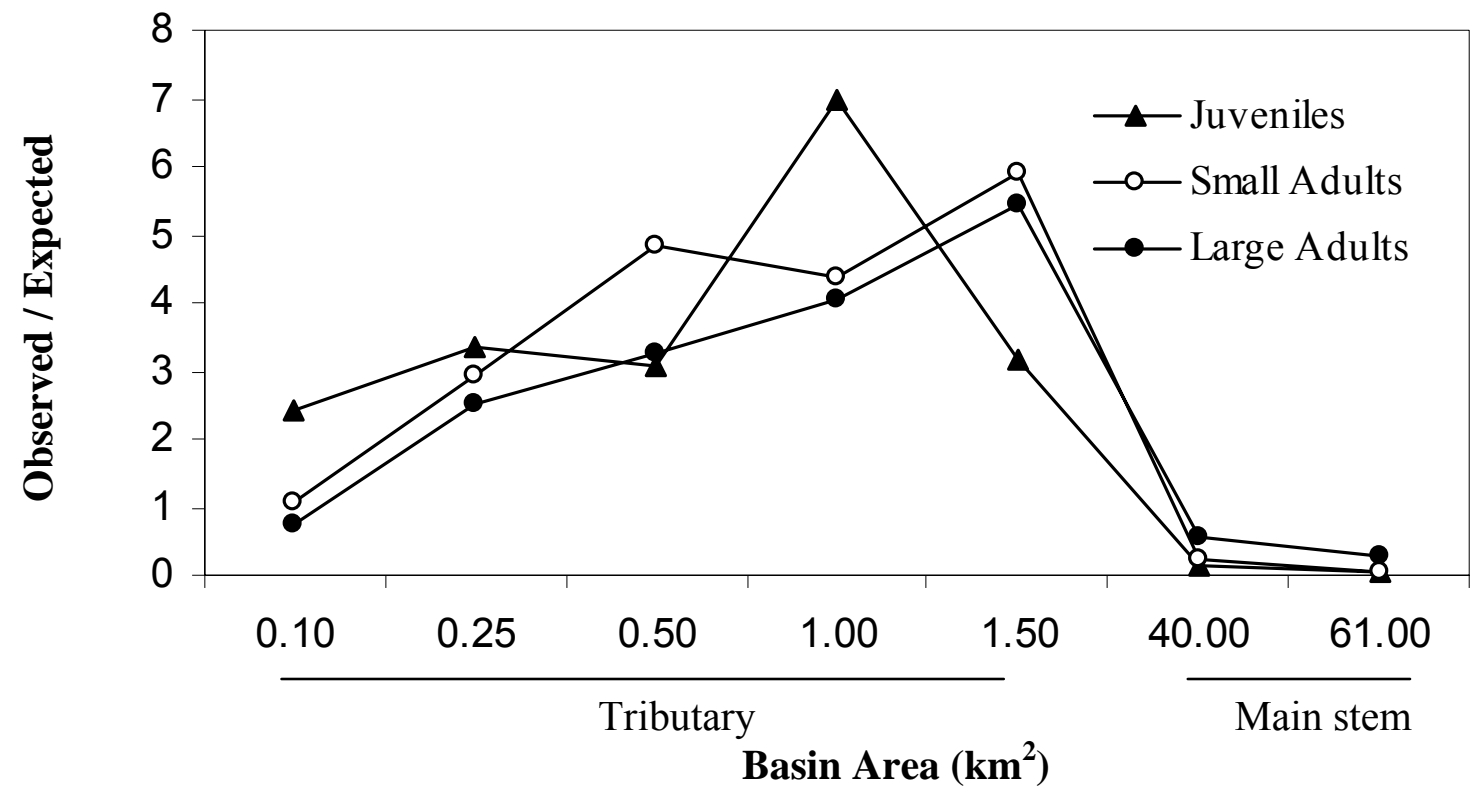

Figure 7. Ratio of the average observed number of juvenile, small adult and large adult brook trout to that expected based on the total area of stream within a range of basin area. 


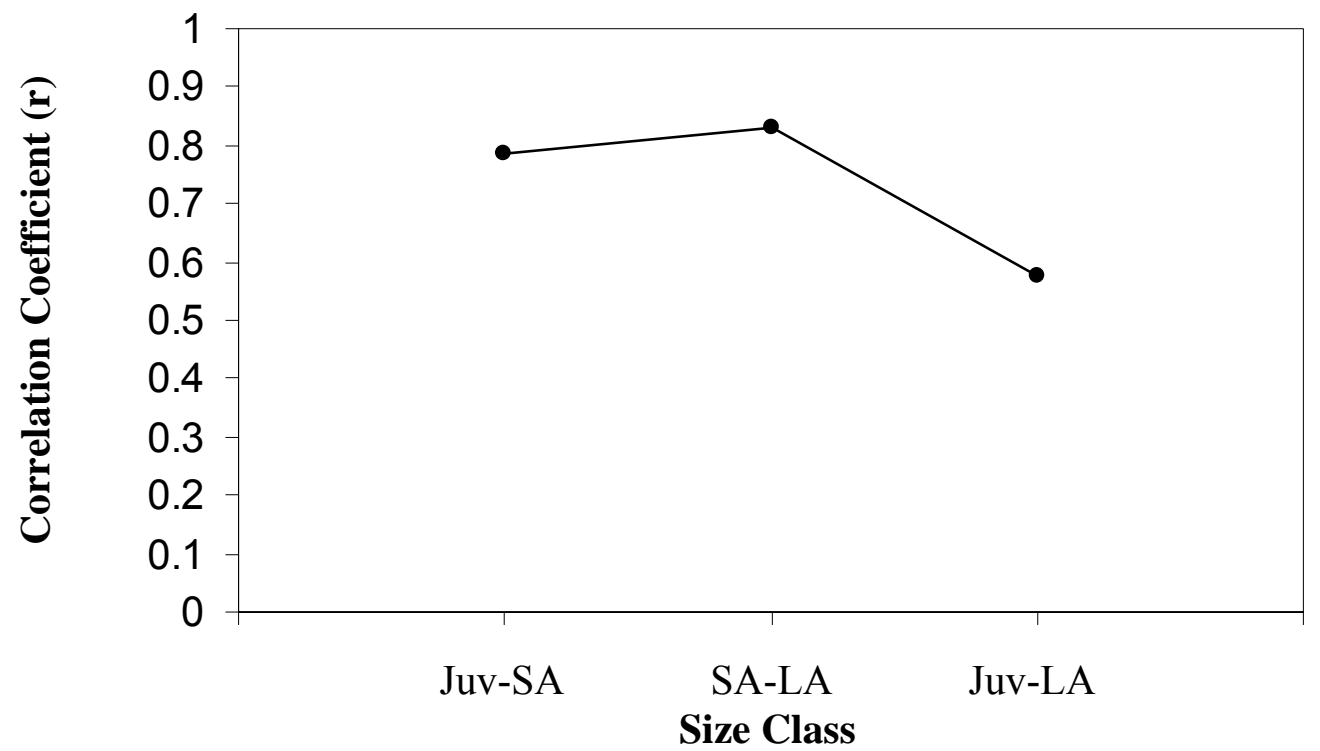

Figure 8. Size class-to-size class correlations across all sites (including main stem). 

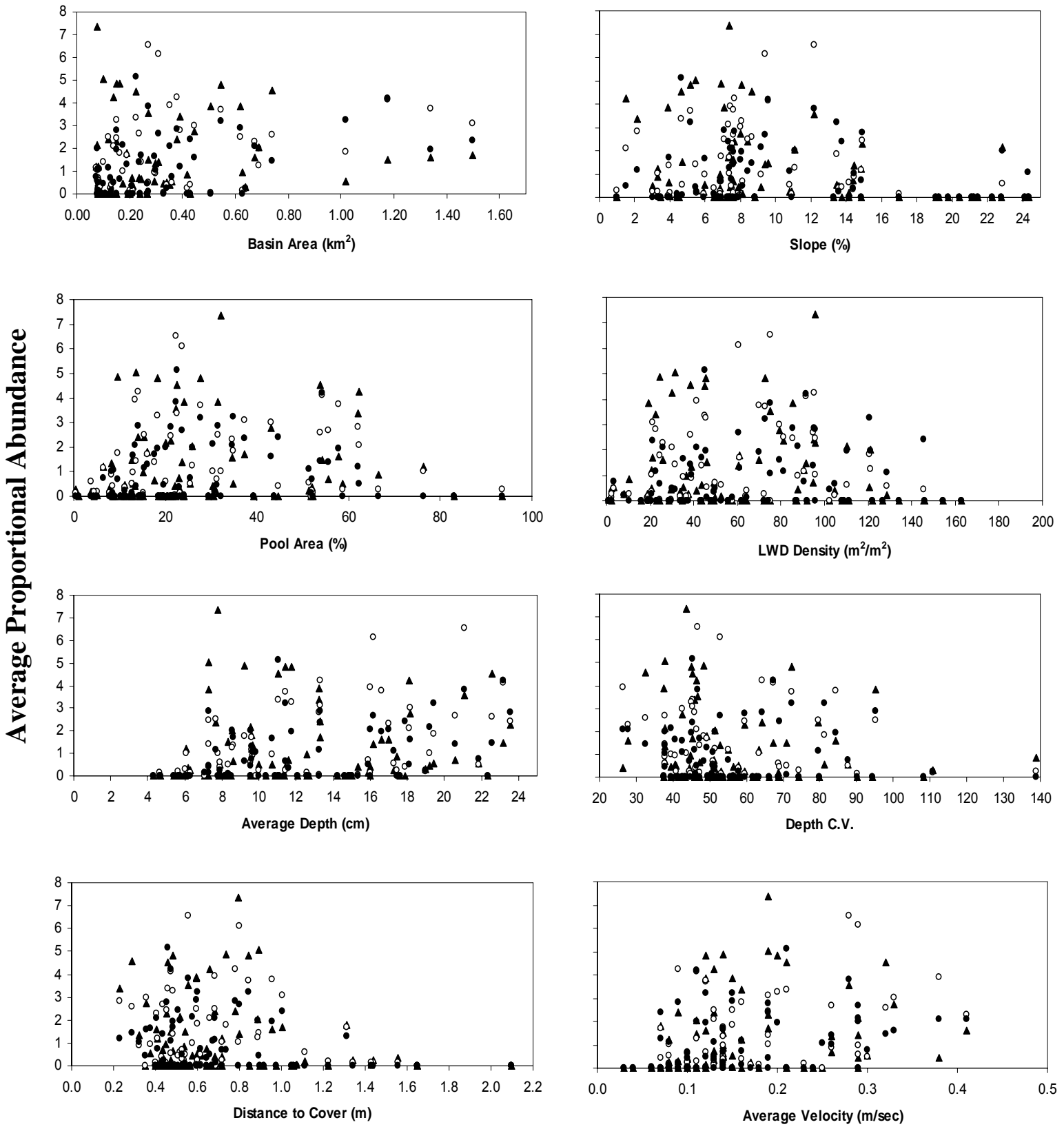

Figure 9. Average proportional abundance of brook trout within each size-class (juvenile = black triangles, small adults $=$ open circles, large adults $=$ closed circles) relative to reachspecific physical habitat parameters. 


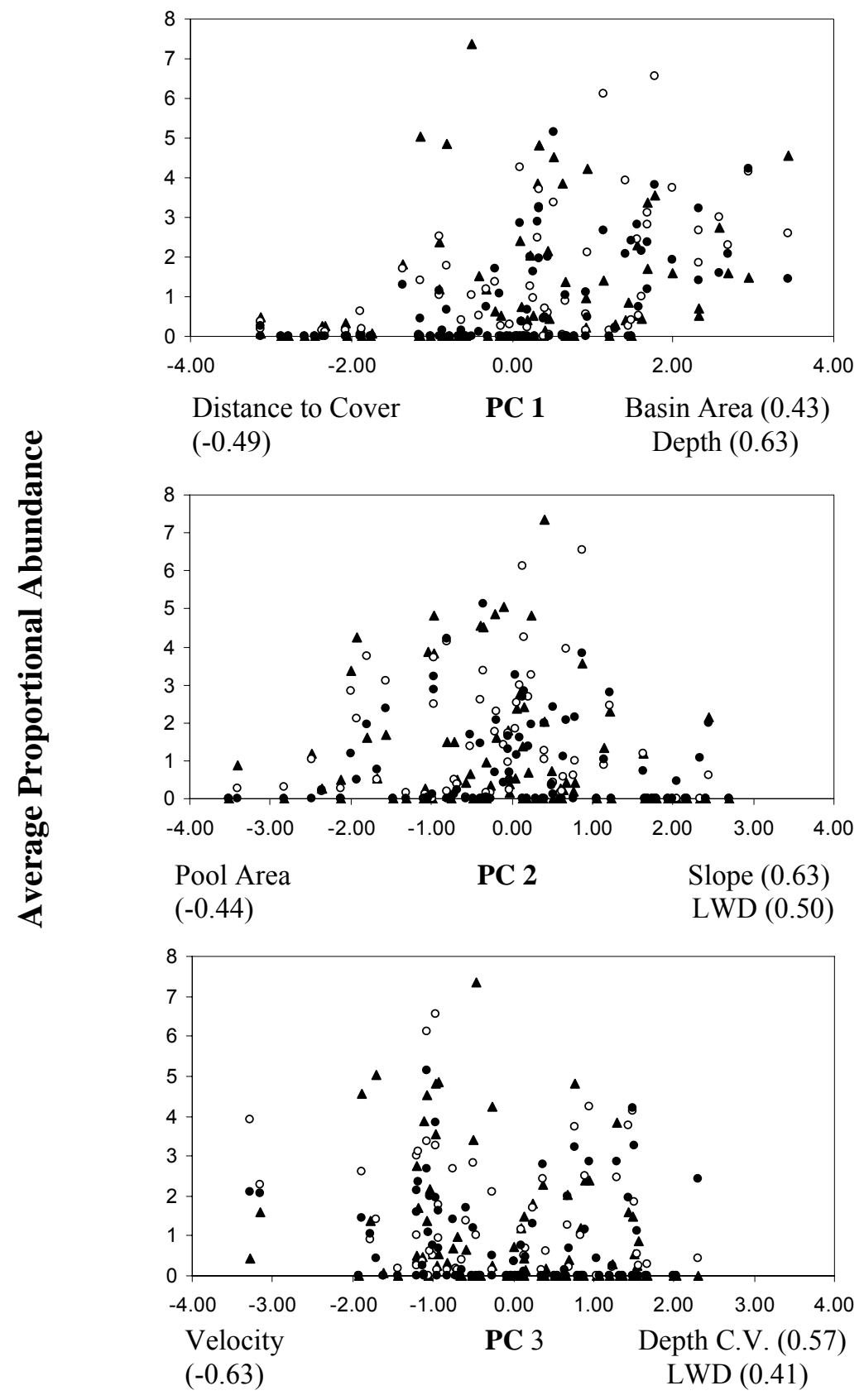

Figure 10. Average proportional abundance of brook trout within each size-class (juvenile $=$ black triangles, small adults $=$ open circles, large adults $=$ closed circles) relative to the dominant instream physical habitat gradients characterizing small basin area tributary networks. 

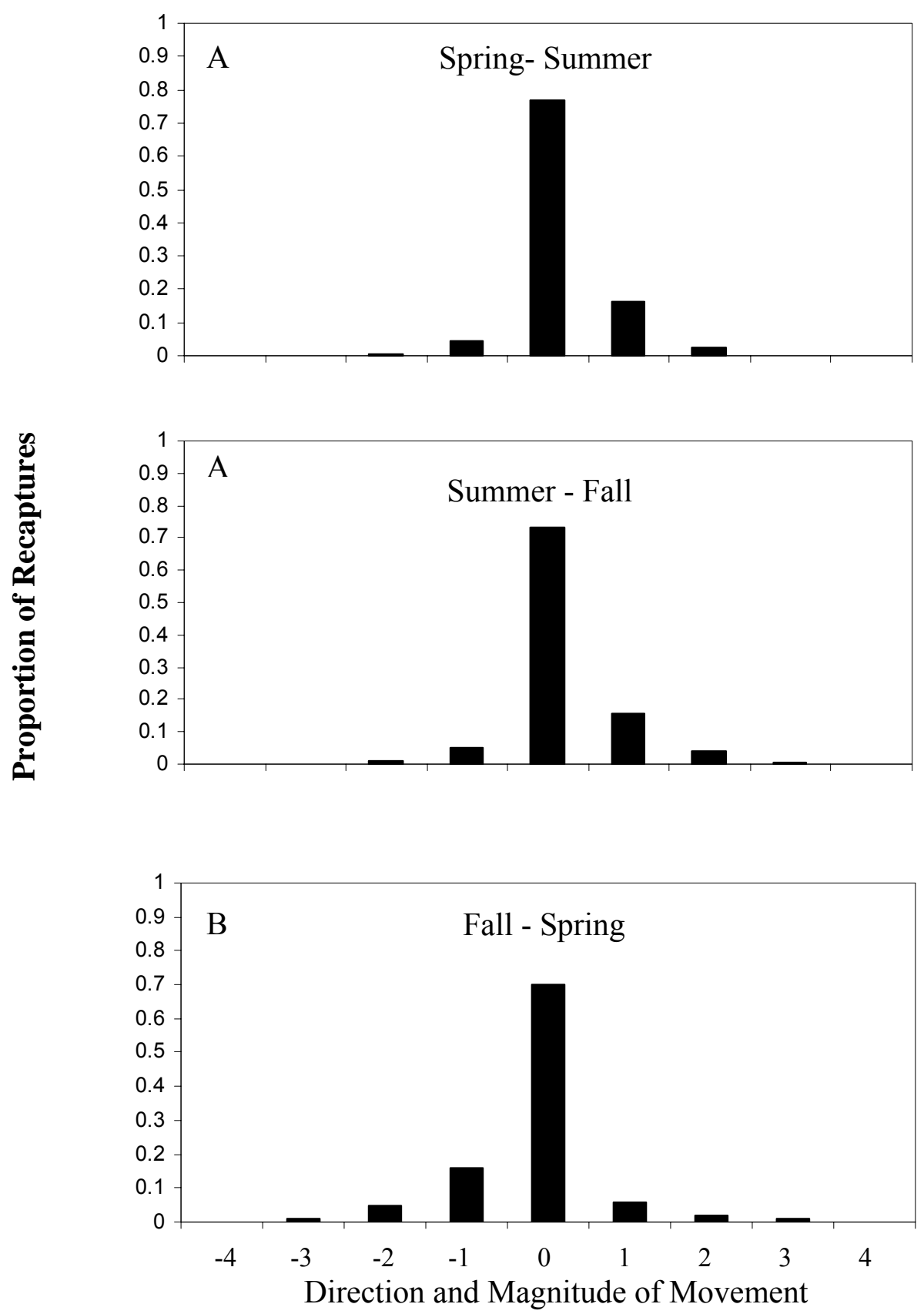

Figure 11. Temporal variation in the proportion of small adult recaptures relative to their direction and magnitude of movement within all small basin area stream networks. Positive values along the $\mathrm{X}$ axis indicate the number of reaches moved upstream, negative values indicate the number of reaches moved downstream. Letters indicate significant differences at $\alpha=0.05$ level. 

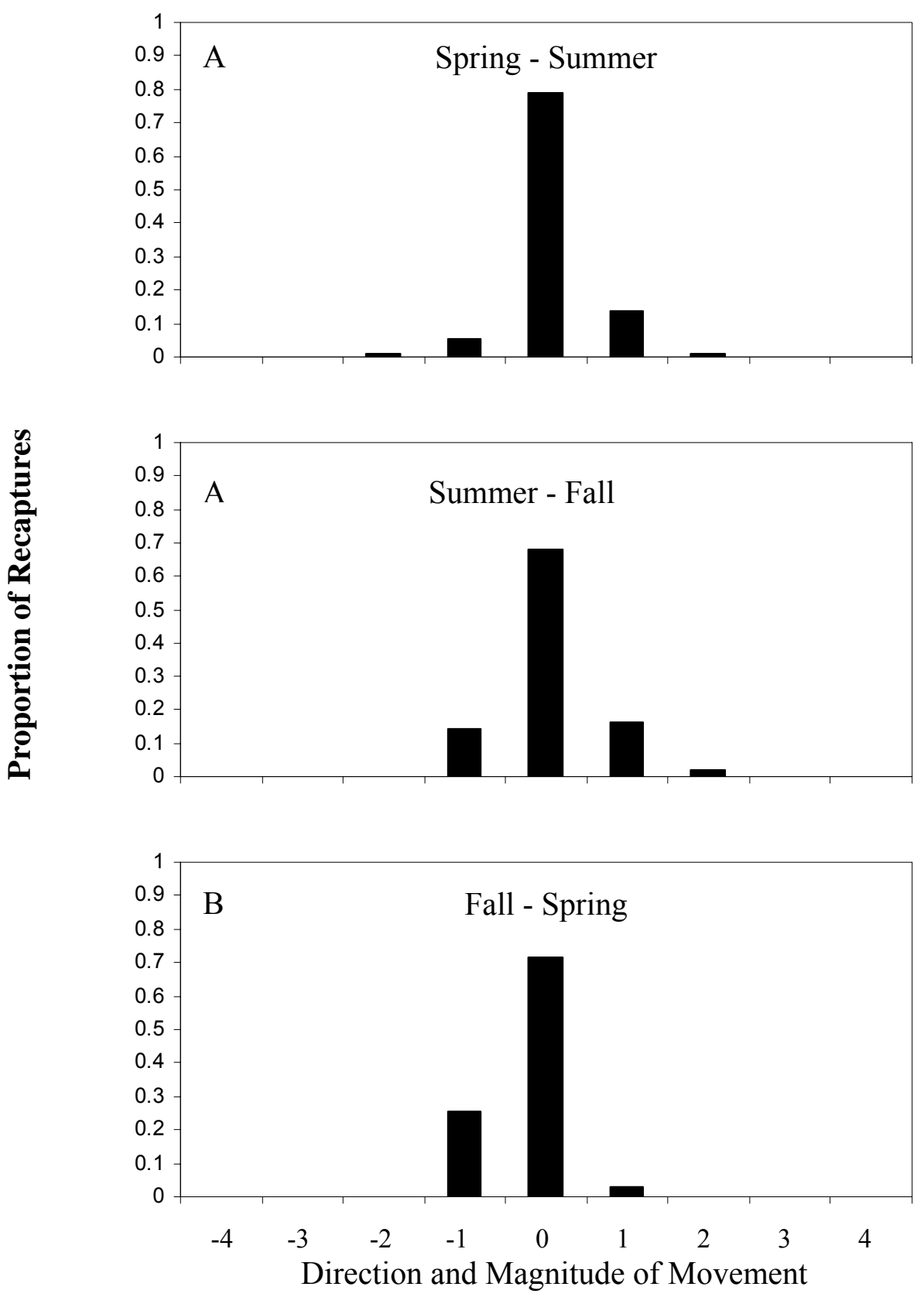

Figure 12. Temporal variation in the proportion of large adult recaptures relative to their direction and magnitude of movement within all small basin area stream networks. Positive values along the $\mathrm{X}$ axis indicate the number of reaches moved upstream, negative values indicate the number of reaches moved downstream. Letters indicate significant differences at $\alpha=0.05$ level. 

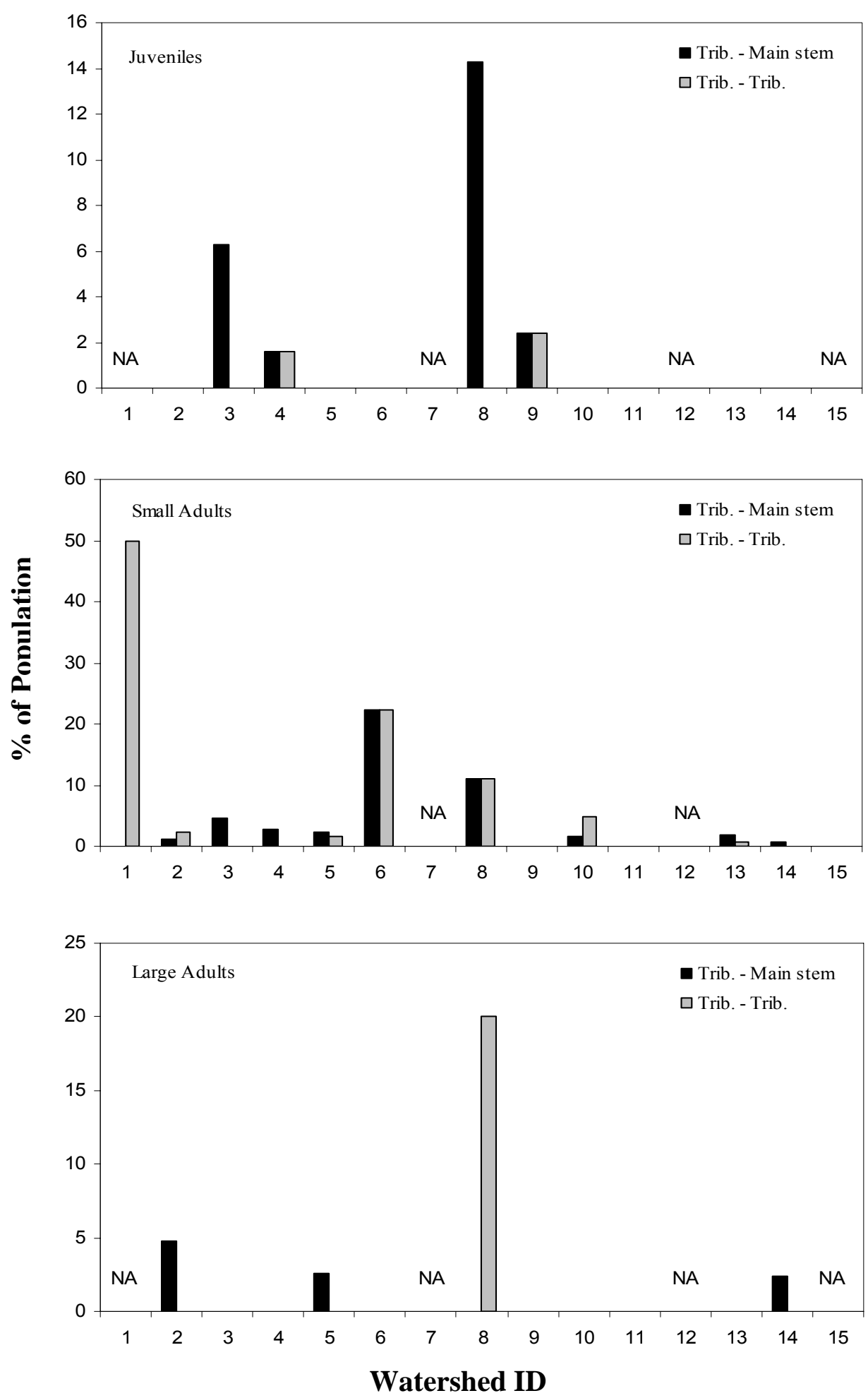

Figure 13. Percent of juvenile, small adult, and large adult brook trout originally marked in 1 of 15 small basin area stream networks that were found to have moved into and stayed within main stem habitat or moved into a different small basin area network. Percentages represent pooled data across all sample seasons. NA designates stream networks that did not support a given sizeclass. 


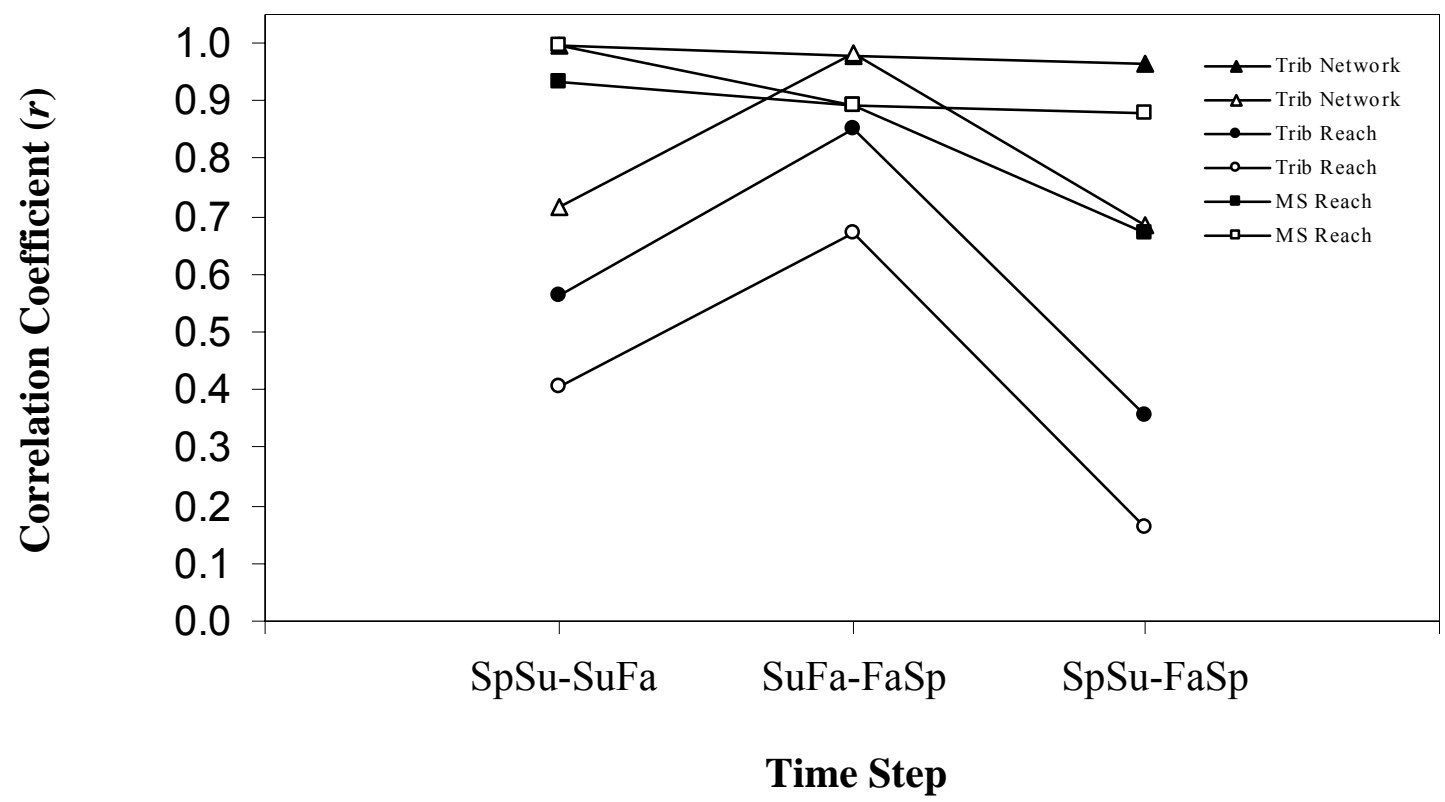

Figure 14. Season-to-season correlation of small and large adult apparent survival at the tributary network (triangles), tributary reach (circles), and main stem reach (squares) scales. Open symbols represent small adults, closed symbols represent large adults. 


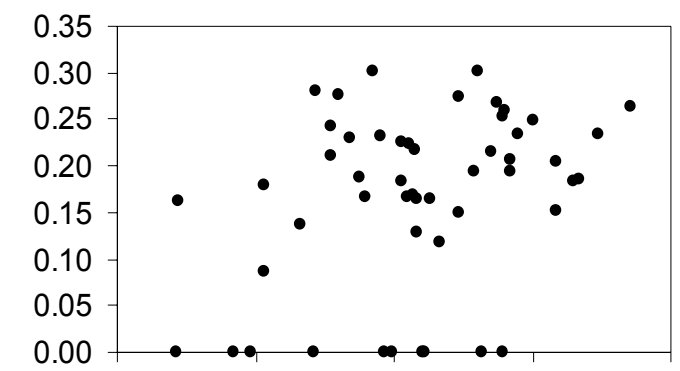

\section{Spring - Summer}
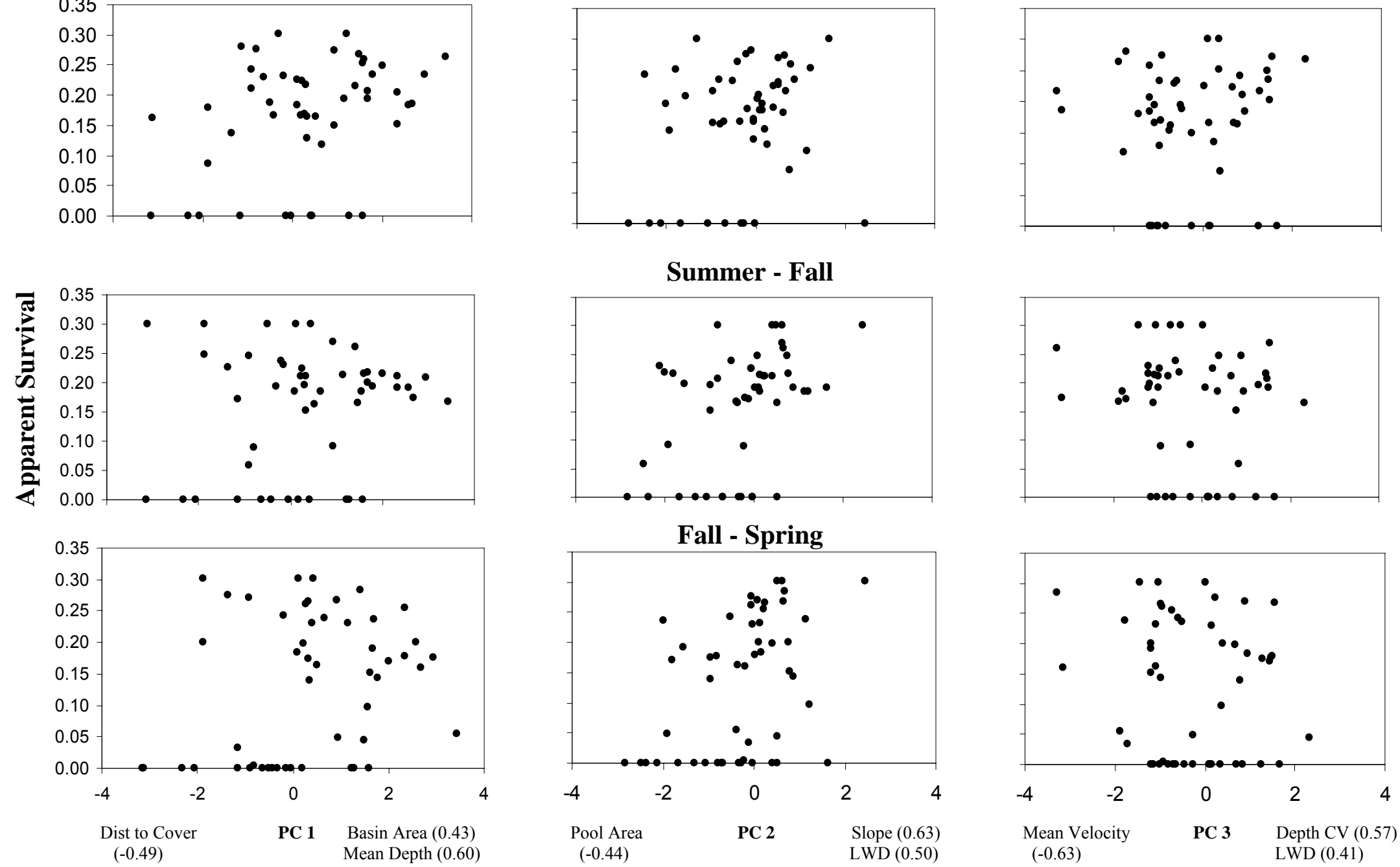

Figure 15. Seasonal relationships between small adult apparent survival (log+1 transformed) and dominant instream physical habitat gradients. 

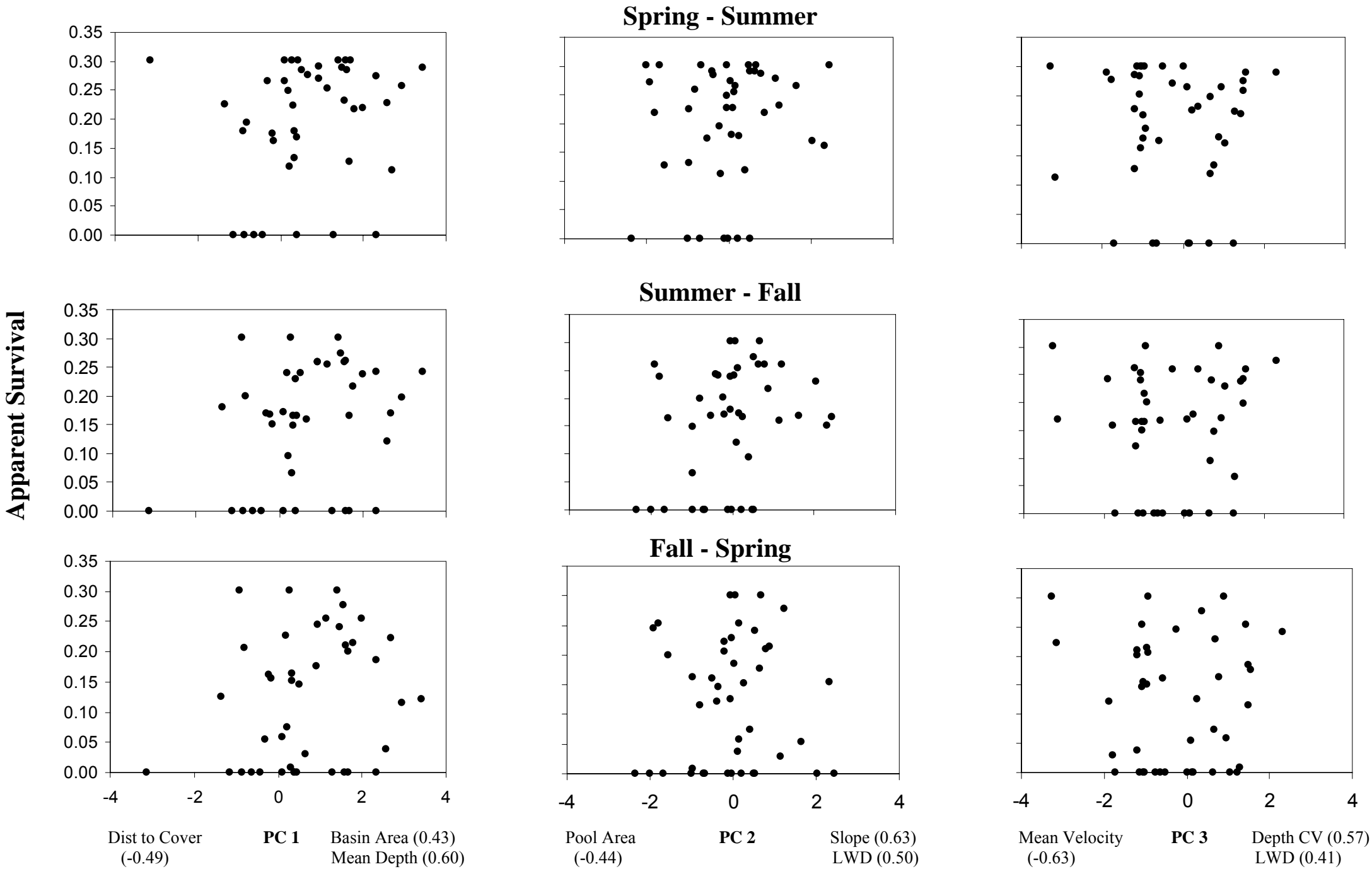

Figure 16. Seasonal relationships between large adult apparent survival (log +1 transformed) and dominant instream physical habitat gradients. 


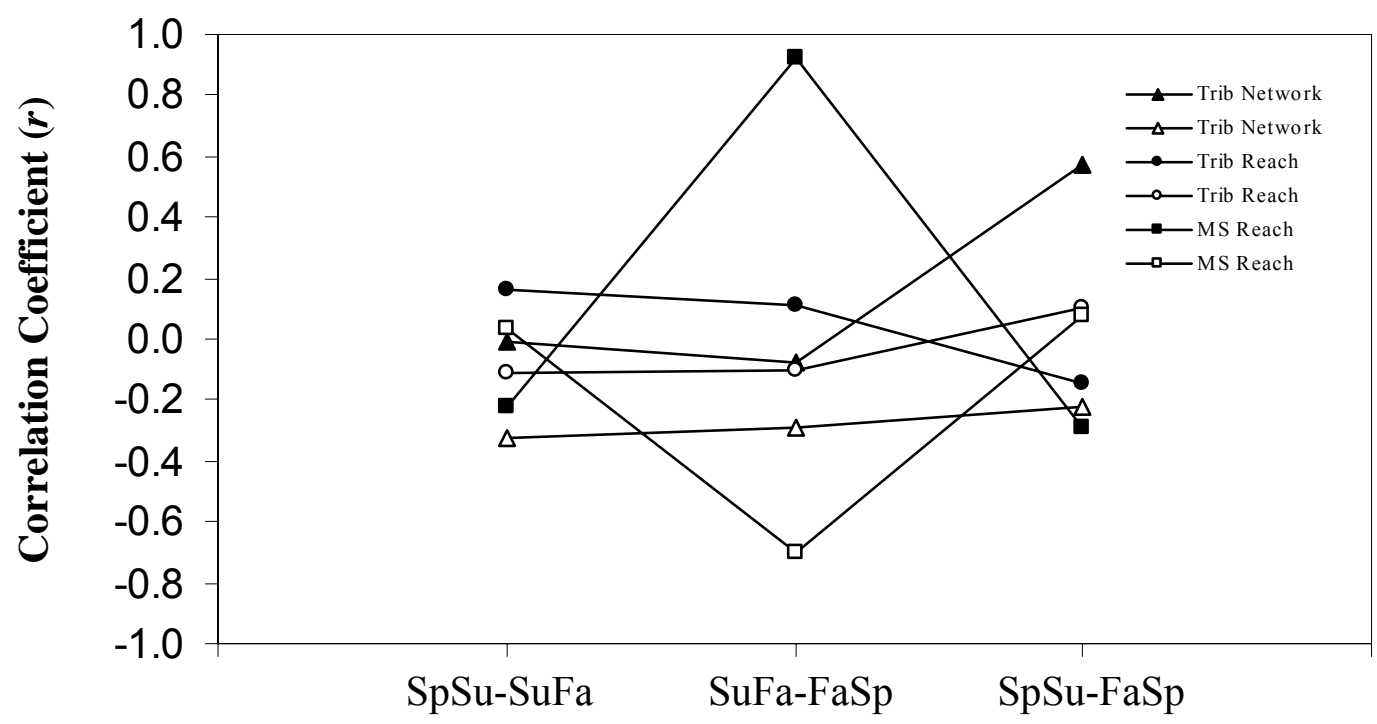

Time Step

Figure 17. Season-to-season correlations of small and large adult immigration rates at the tributary network (triangles), tributary reach (circles), and main stem reach (squares) scales. Open symbols represent small adults, closed symbols represent large adults. 

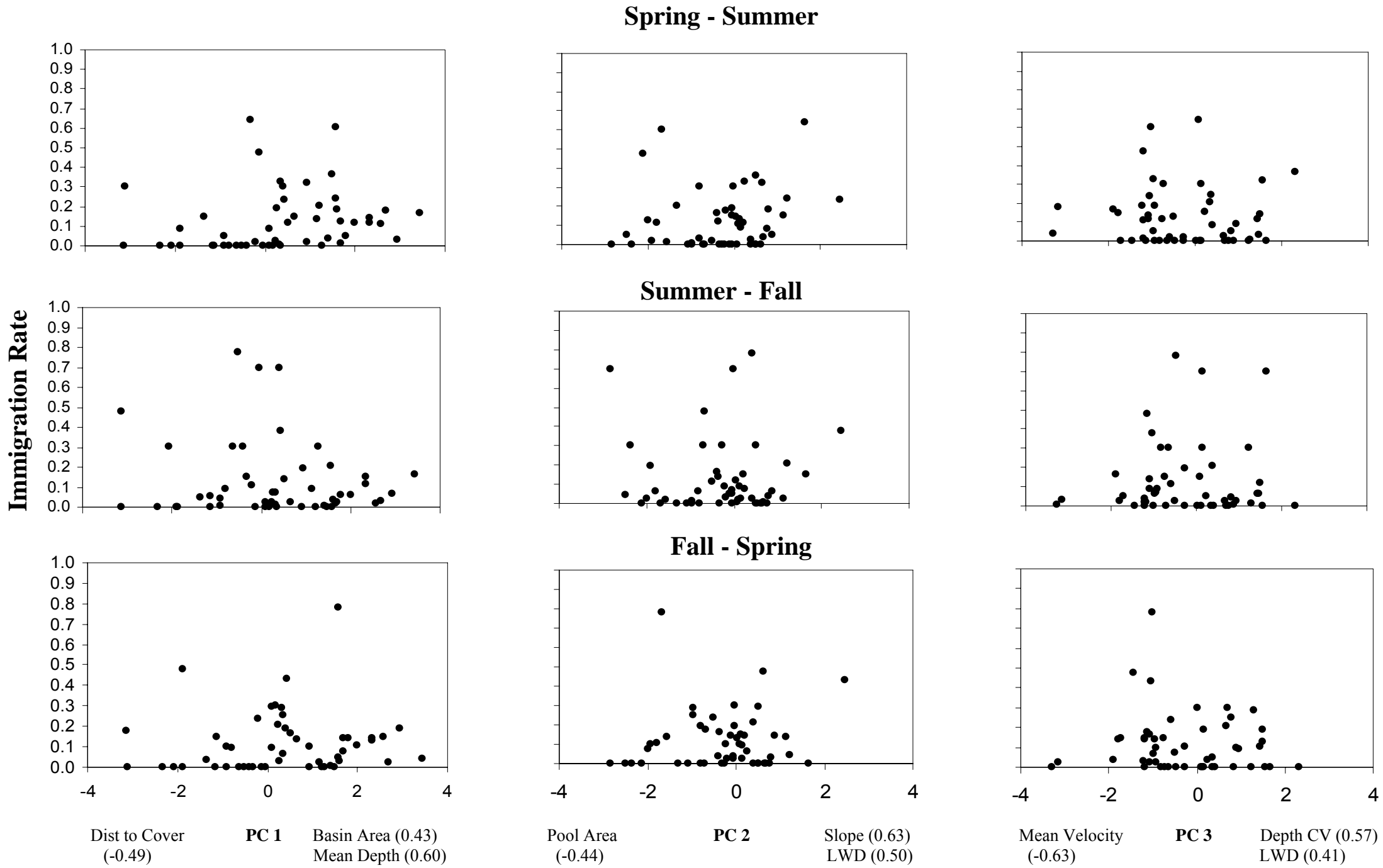

Figure 18. Seasonal relationships between small adult immigration rates (log +1 transformed) and dominant instream physical habitat gradients. 

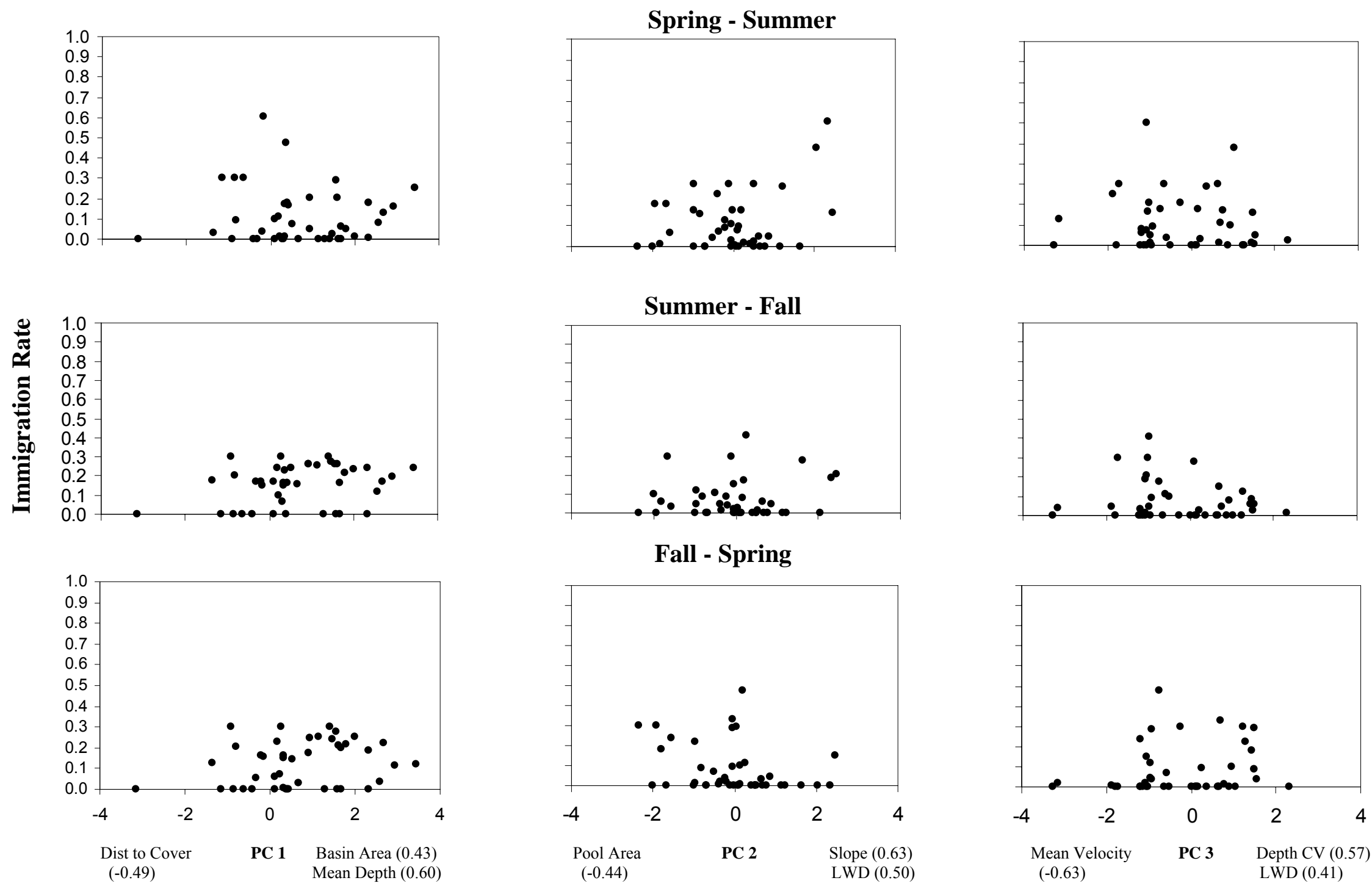

Figure 19. Seasonal relationships between large adult immigration rates (log +1 transformed) and dominant instream physical habitat gradients. 


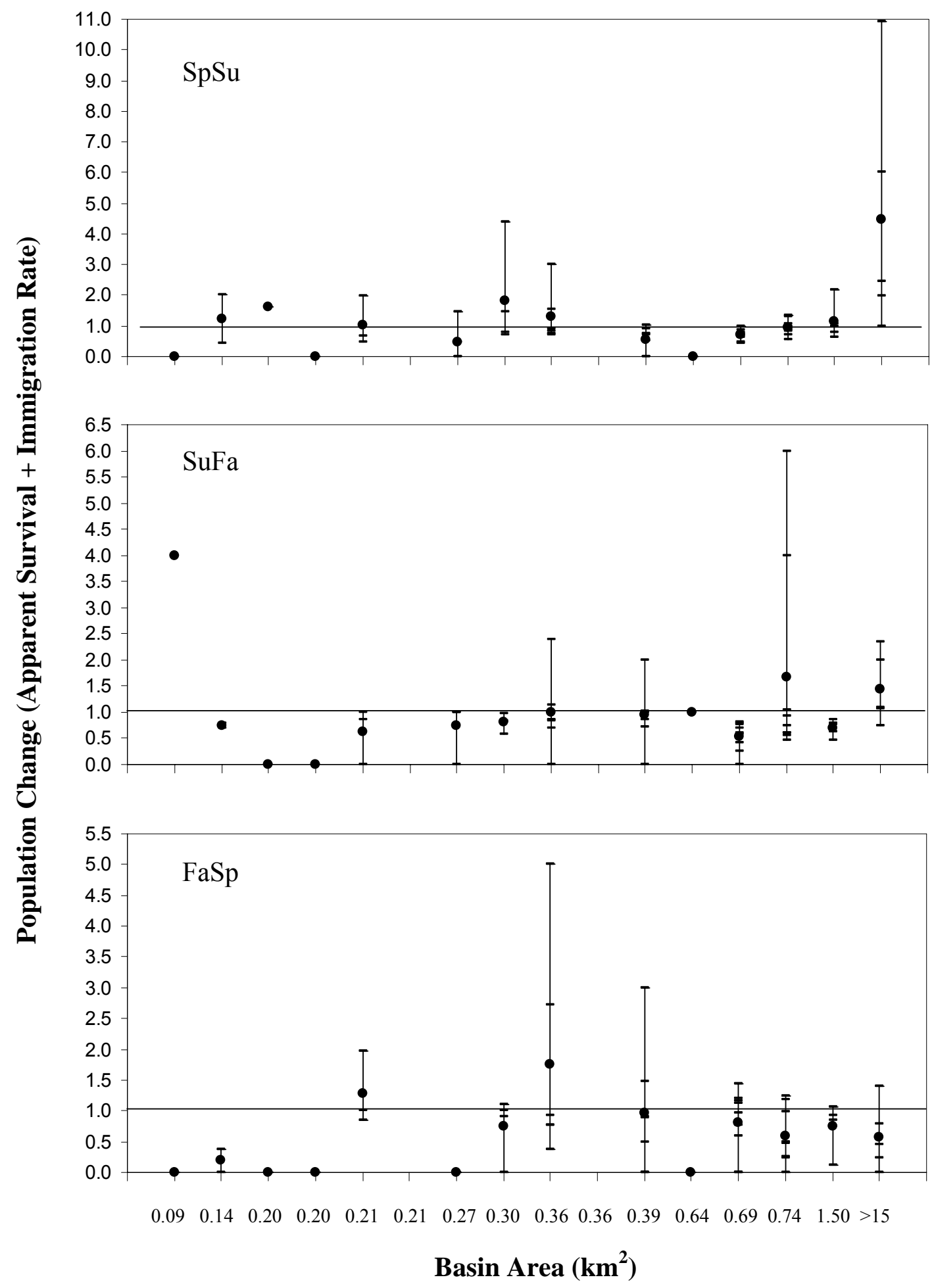

Figure 20. Seasonal reach-to-reach variation in small adult population change within 15 small tributary networks and the main stem. Solid dots represent the mean rate of population change across all reaches within a given tributary network. Hash-marks represent the rate of population change for each reach within a given tributary network. The main stem reaches are represented as $>15 \mathrm{~km}^{2}$. A value of 1 represents no population change. 

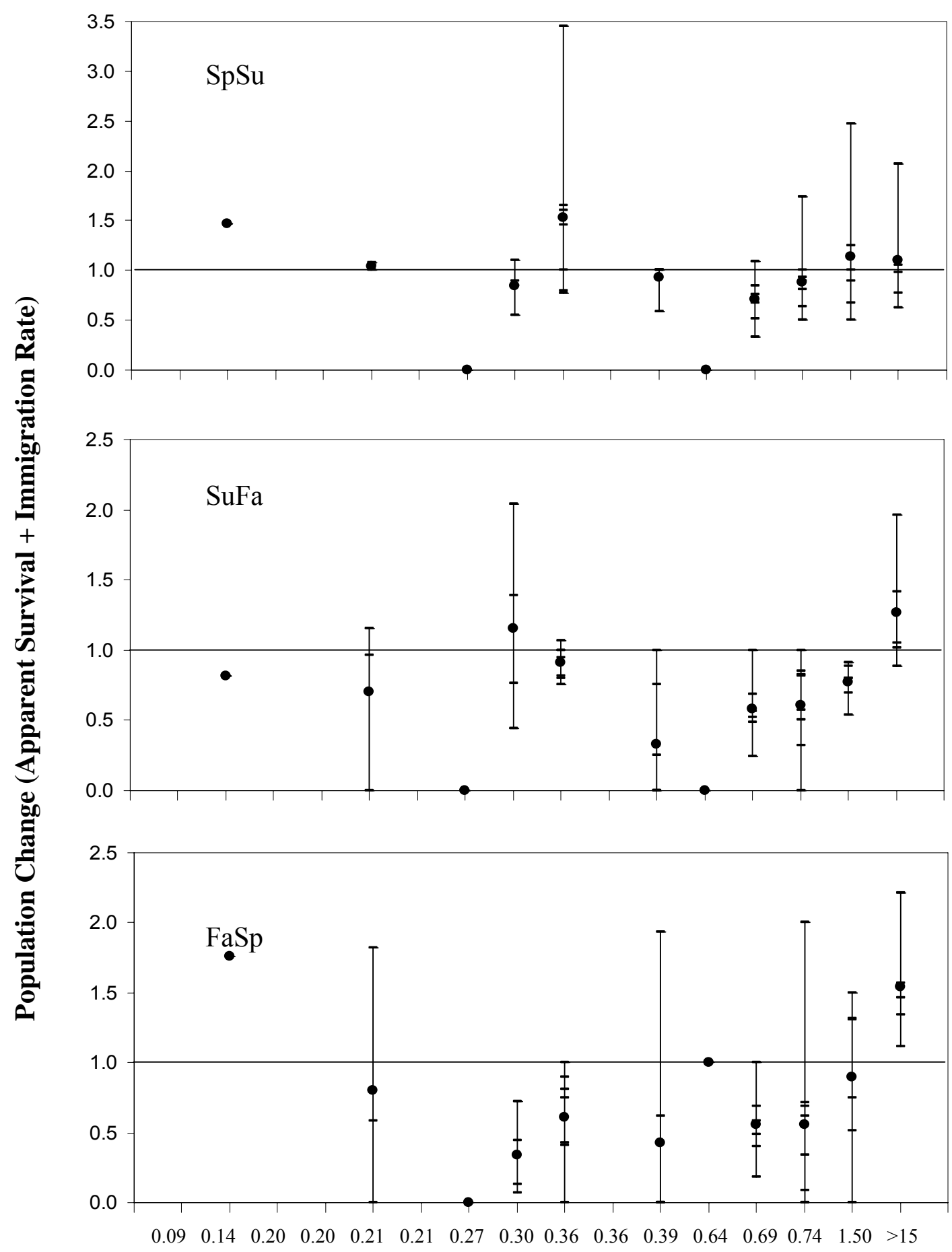

\section{Basin Area $\left(\mathrm{km}^{2}\right)$}

Figure 21. Seasonal reach-to-reach variation in large adult population change within 15 small tributary networks and the main stem. Solid dots represent the mean rate of population change across all reaches within a given tributary network. Hash-marks represent the rate of population change for each reach within a given tributary network. The main stem reaches are represented as $>15 \mathrm{~km}^{2}$. A value of 1 represents no population change. 


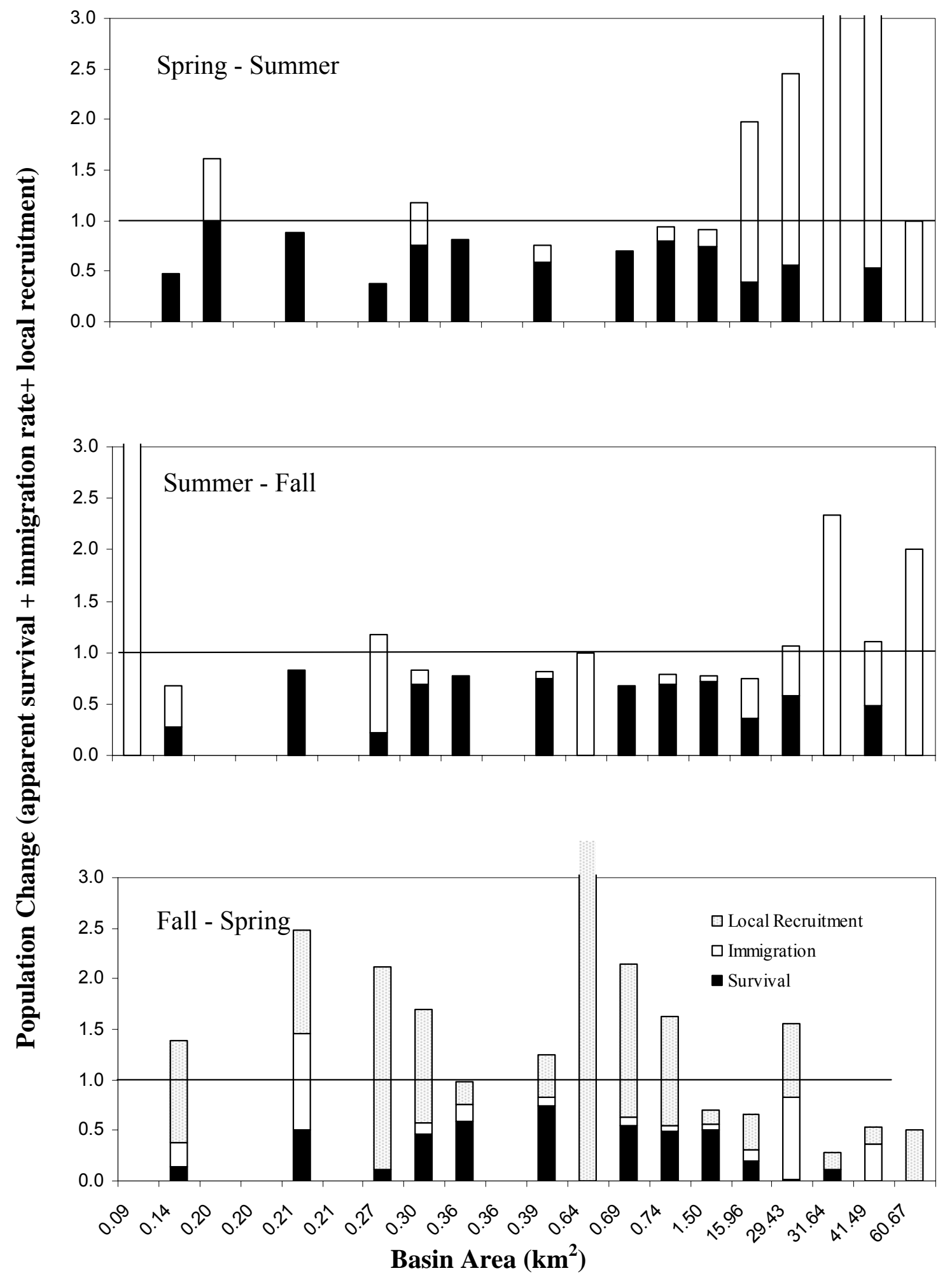

Figure 22. Seasonal small adult brook trout population growth within 15 small basin area watersheds and 5 main stem reaches. A value of 1 represents no population change. 


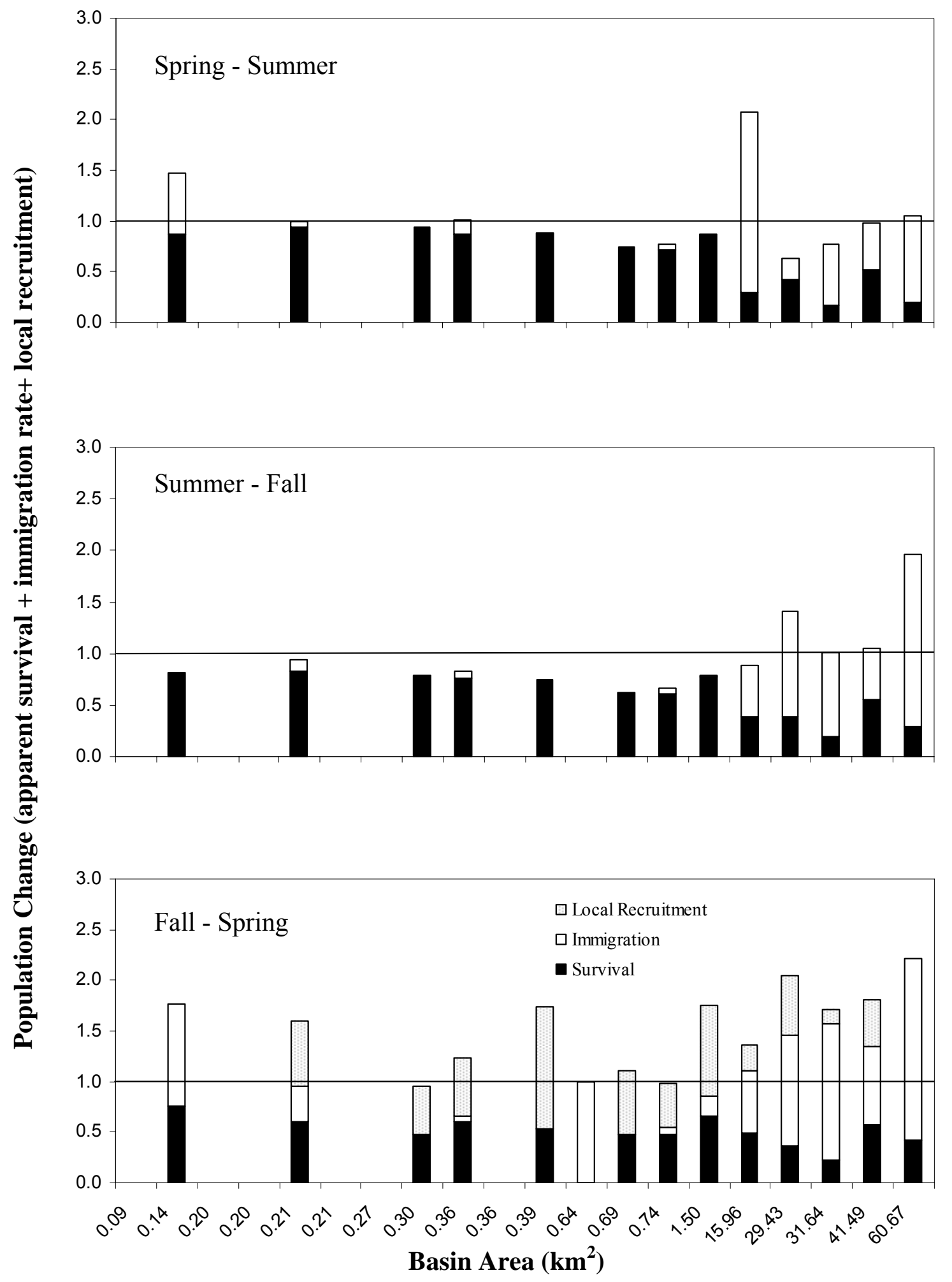

Figure 23. Seasonal large adult brook trout population growth within 15 small basin area watersheds and 5 main stem reaches. A value of 1 represents no population change. 


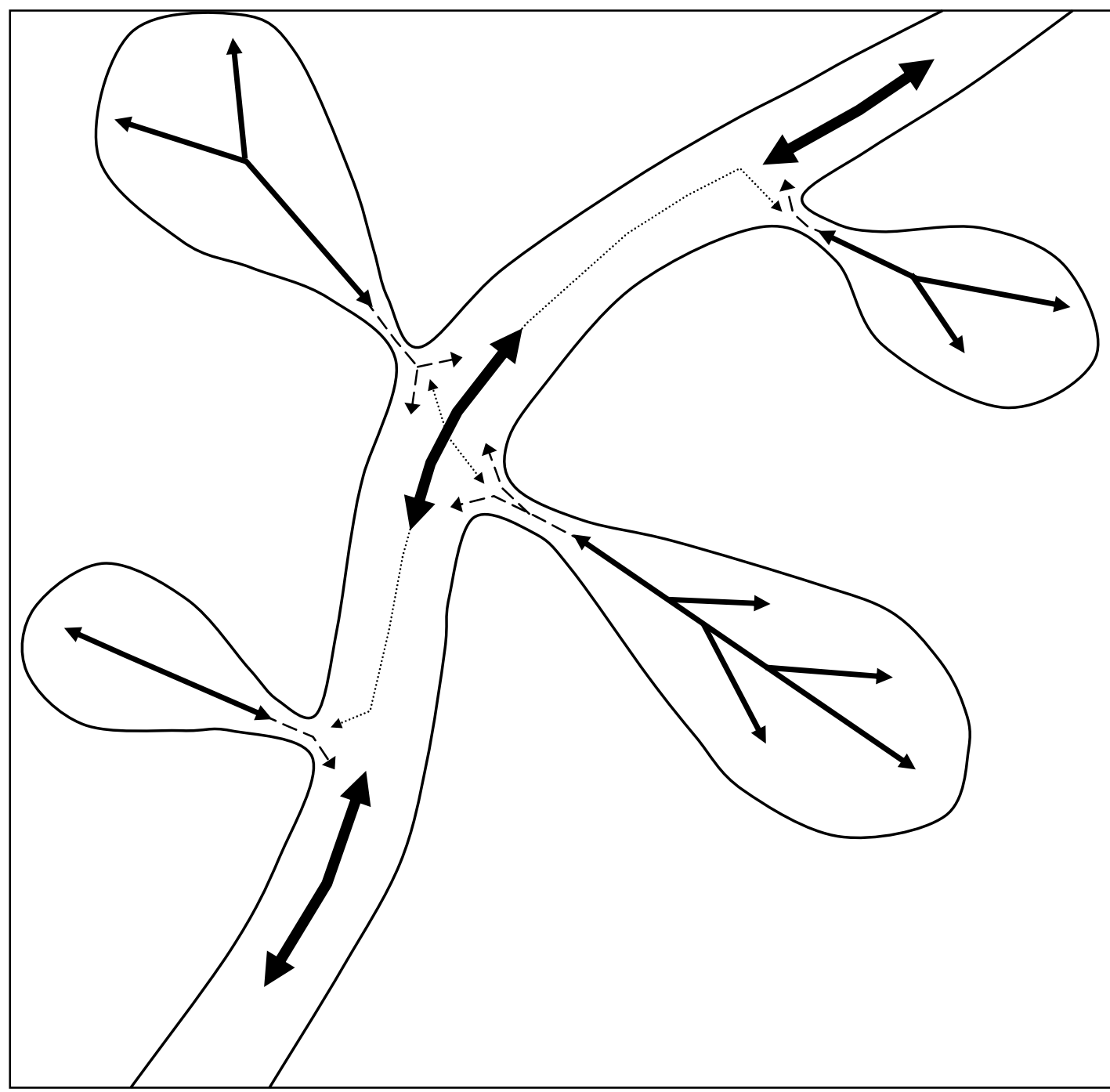

Figure 24. Representation of the degree of connectivity between brook trout habitats within the upper Shavers Fork watershed. Increasing arrow weights represents increasing levels of connectivity. Weights are based on observed patterns of brook trout dispersal, apparent survival, and immigration. Reach-to-reach-scale movements were common throughout small basin area tributaries. Tributary networks acted in aggregate supplying a slow leak of individuals into main stem habitats. Low rates of dispersal were observed between tributary networks. Individuals within mainstem habitat were highly mobile. 
Appendix 1. Site names and northing and easting coordinates (NAD 83, UTM zone 17) for 34 sample sites located within the upper Shavers Fork watershed used to determine the role of physico-chemical habitat parameters on juvenile brook trout recruitment. Site ID numbers correspond to figure 1 and table 1 (chapter 1 of this document).

\begin{tabular}{|c|c|c|c|}
\hline ID \# & Site Name (Unofficial) & Easting & Northing \\
\hline 1 & UNT 2 Below First Fork & 594738.1 & 4271296 \\
\hline 2 & UNT 1 Below First Fork & 594826.6 & 4270550 \\
\hline 3 & Watertank Hollow & 596124.0 & 4269417 \\
\hline 4 & UNT 1 of First Fork & 596494.8 & 4265694 \\
\hline 5 & UNT 3 of First Fork & 595855.4 & 4265101 \\
\hline 6 & UNT 3 Below Black Run & 594685.1 & 4268141 \\
\hline 7 & UNT 2 Below Buck Run & 593177.1 & 4266820 \\
\hline 8 & Buck Run & 592622.8 & 4266286 \\
\hline 9 & Beaver Creek & 591617.5 & 4263595 \\
\hline 10 & UNT of Beaver Creek & 591733.3 & 4263950 \\
\hline 11 & UNT 6 Below Second Fork & 593402.4 & 4264035 \\
\hline 12 & UNT 5 Below Second Fork & 593416.3 & 4263780 \\
\hline 13 & UNT 2 Below Second Fork & 593407.8 & 4262800 \\
\hline 14 & Reggi Run (reach 3) & 593541.0 & 4261741 \\
\hline 15 & Lower UNT of Second Fork & 593018.3 & 4261149 \\
\hline 16 & Upper UNT of Second Fork & 593000.7 & 4261014 \\
\hline 17 & UNT 3 Below Ryans Bend & 591568.5 & 4262022 \\
\hline 18 & Right Fork of UNT 3 of Ryans Bend (reach 1) & 590817.1 & 4261602 \\
\hline 19 & UNT 2 of Ryans Bend & 591085.2 & 4261200 \\
\hline 20 & UNT 1 of Ryans Bend & 591093.9 & 4261153 \\
\hline 21 & UNT of Rocky Run & 590700.4 & 4260317 \\
\hline 22 & UNT 2 Below Twin Tressels & 590747.7 & 4259718 \\
\hline 23 & UNT 2 of Twin Tressels & 591191.2 & 4259437 \\
\hline 24 & UNT 1 of Twin Tressels & 590895.6 & 4259230 \\
\hline
\end{tabular}




\begin{tabular}{lccc}
25 & UNT 2 Below Lamothe Hollow & 590675.0 & 4259281 \\
26 & Thorne Run & 590112.5 & 4258950 \\
27 & Jennifer Hollow & 590461.9 & 4258759 \\
28 & UNT 1 Below Lamothe Hollow & 590934.6 & 4258484 \\
29 & Lamothe Hollow & 591573.9 & 4258380 \\
30 & Powerhouse Run & 590448.4 & 4257350 \\
31 & Oats Run & 591083.8 & 4256874 \\
32 & Little Oats Run & 590959.2 & 4256114 \\
33 & UNT 3 of Black Run & 589730.6 & 4255796 \\
34 & UNT 4 of Black Run & 589229.4 & 4255708 \\
\hline
\end{tabular}




\section{Zachary W. Liller}

\section{Personal Information:}

Full Name: Zachary Wade Liller

Address: P.O. Box 329 Airport Rd. Aniak, AK. 99557

Phone: (304)-685-4841

E-mail: zliller@mix.wvu.edu

\section{Education:}

Master of Science, West Virginia University (February 2006)

- Program: Wildlife and Fisheries Resources

- Thesis topic: Spatial variation in brook trout (Salvelinus fontinalis) population dynamics, and juvenile recruitment potential in an Appalachian watershed

- GPA: $4.0 / 4.0$

Bachelor of Science, West Virginia University (2002)

- Major: Wildlife and Fisheries Resources

- GPA: 3.72/4.0

Minor in Communication Studies, West Virginia University (2002)

High School Diploma, Frankfort High School, Ridgely, WV (1998)

\section{Professional Work Experience:}

Job Title: Graduate Teaching / Research Assistant

Date of Employment: August 2003 - Present

Employer: West Virginia University, Division of Forestry

Supervisor: Dr. J. Todd Petty

Duties and Accomplishments: Served as the project leader for a salmonid population dynamics, movement, and habitat association project; responsible for designing and implementing fish population, aquatic habitat, and water quality monitoring protocols; responsible for leading large field crews into remote areas for extended periods of time; field work regularly required packing heavy equipment (100 lbs) several miles across rough terrain in inclement weather; served as a Shavers Fork watershed outreach liaison; managed large biological datasets; conducted quantitative and qualitative analysis of large biological datasets; prepared and presented technical reports and presentations; served as the West Virginia University Department of Forestry teaching assistant for undergraduate wildlife and fisheries courses. 
Job Title: Research Assistant I

Date of Employment: February 2003 - August 2003

Employer: West Virginia University, Division of Forestry

Supervisor: Dr. J. Todd Petty

Duties and Accomplishments: Assisted with regional assessments of cold and warmwater fish assemblages; conducted aquatic habitat and water quality assessments; collected and processed benthic macroinvertebrate samples; managed large biological datasets; field work regularly required packing heavy equipment (100 lbs) several miles across rough terrain in inclement weather.

Job Title: Fisheries Technician (Field Crew Leader)

Date of Employment: August 2002 - December 2002

Employer: West Virginia University Center for Civic Engagement

Supervisor: Dr. J. Todd Petty

Duties and Accomplishments: Served as the project field crew leader for the Friends of Deckers Creek watershed monitoring program; responsible for designing and implementing cold and warmwater fish population monitoring protocols; collected benthic macroinvertebrates; calculated indexes of biotic integrity (IBI) based on macroinvertebrate and fish community composition as a relative measure of ecosystem health; managed large biological datasets.

Job Title: Fisheries Technician

Date of Employment: May 2002 - August 2002

Employer: West Virginia University, Division of Forestry

Supervisor: Dr. J. Todd Petty

Duties and Accomplishments: Assisted with regional assessments of cold and warmwater fish assemblages; conducted aquatic habitat and water quality assessments; collected and processed benthic macroinvertebrate samples; managed large biological datasets; field work regularly required packing heavy equipment (100 lbs) several miles across rough terrain in inclement weather.

\section{Qualifications, Experiences, and Skills:}

Leadership and organization

- Organization of multiple field crews consisting of 2-14 summer technicians and graduate students

- Organize and repair equipment for extensive hiking / camping in the field

Fish collection and monitoring techniques

- Identification of WV cold and warmwater fishes

- Boat and backpack electrofishing

- Fyke, gill, and seine nets

- Mark recapture (Elastomer and PIT tagging)

- Collection of stomach contents 
- Calculation of fish condition indices

- Calculation of indices of biotic integrity

- Radio telemetry

- Hydroacoustics

Macroinvertebrate collection techniques

- Identification of major invertebrate orders and families

- Hess and serber sampler, D-frame and kick nets

Habitat assessment techniques

- Indices of biotic integrity

- Basin wide visual extrapolation techniques

- Representative Reach extrapolation techniques

- EPA rapid visual habitat assessment form

Water quality monitoring

- Knowledge various $\mathrm{pH}$, alkalinity, conductivity, and dissolved oxygen meters

- Alkalinity and acidity titrations

Computer programs

- Statistical analysis software (SAS, JMP, NTSYSpc)

- Program Mark

- Program Capture

- Spatial analysis software (AcrGIS)

- Microsoft Office (Word, Excel, PowerPoint)

Wetland delineation

- Identification of primary and secondary indicators of hydrophytic vegetation, hydric soils, and hydrology

Professional writing and speaking

- Research proposal writing

- Scientific report writing

- Wildlife and fisheries management plan writing

- Technical presentations

- Teaching

- Limnology

- Principles of Fish Management

- Vertebrate Natural History

- Ecology of Freshwater Invertebrates

- Fundamentals of downhill ski and snowboarding

\section{Relevant Coursework}

Fisheries techniques

Fish management

Forest Hydrology: watershed management

Ecology and management of wetland wildlife

Wildlife management

Applied GIS for environmental management 
Limnology

Advanced ichthyology

Fish physiology

Aquatic toxicology

Advanced population ecology

Statistical methods I \& II

Quantitative ecology

Principles of soil science

Aqueous geochemistry

\section{Manuscripts in Progress:}

Liller, Z. W., and J. T. Petty. In progress. Physico-chemical factors influencing the spatial variation in juvenile brook trout (Salvelinus fontinalis) recruitment in an Appalachian watershed (Working title).

Liller, Z. W., and J. T. Petty. In progress. Spatial variation in brook trout (Salvelinus fontinalis) population dynamics in an Appalachian watershed (Working title).

\section{Technical Presentations:}

Liller, Z. W. 2006. Spatial variation in juvenile brook trout (Salvelinus fontinalis) population dynamics and juvenile recruitment potential in a Appalachian watershed. Thesis defense, Morgantown WV.

Liller, Z. W., and J. T. Petty. 2005. Physico-chemical factors regulating spatial variation in brook trout (Salvelinus fontinalis) young-of-year recruitment in an Appalachian watershed. Presented for: (1) Annual West Virginia University Wildlife and Fisheries Seminar, Morgantown WV, (2) West Virginia Society of American Foresters and American Fisheries Society, Flatwoods, WV, (3) Annual Southeastern Division of the American Fisheries Society, Virginia Beach, VA.

Liller, Z. W., and J. T. Petty. 2004. The upper Shavers Fork watershed: where have we been and where are we going. Annual West Virginia University Wildlife and Fisheries seminar, Morgantown, WV.

\section{Professional Memberships:}

West Virginia University Student Subunit of the American Fisheries Society: member since 2004

West Virginia Chapter of the American Fisheries Society: member since 2004

National Society of the American Fisheries Society: member since 2005 
Certifications:

Adult CPR and First Aid - Current

Defensive Driving - Current

Electrofishing Safety - April 2001

West Virginia Drivers License

\section{Honors:}

B.S. - Graduated Magna Cum Laude (GPA 3.72)

Gamma Sigma Delta - The Honor Society of Agriculture - April 2002

Xi Sigma Pi - The Honor Society of Forestry - March 2002

National Society of Collegiate Scholars - April 1999

Presidential Award for Excellence in Scholarship, (GPA 4.0/4.0) - Spring 2000,

Fall 2001, Spring 2002, Fall 2002 


\section{References of Zachary W. Liller}

J. Todd Petty, Ph.D.

Assistant Professor

West Virginia University

Wildlife \& Fisheries Resources

PO Box 6125

Morgantown WV 26506-6125

Phone: (304)-293-2941 ext. 2417

FAX: (304)-293-2441

E-mail: jtpetty@mail.wvu.edu

Patricia Mazik, Ph.D.

Unit Leader

West Virginia Cooperative Fish and Wildlife Unit

322 Percival Hall

Morgantown, WV 26506-6125

Phone: (304)-293-2941 ext. 2431

FAX: (304)-293-4826

E-mail: pmazik@wvu.edu

Kyle J. Hartman, Ph.D.

Associate Professor and Program Coordinator

West Virginia University

Wildlife \& Fisheries Resources

PO Box 6125

Morgantown, WV 26506-6125

Phone: (304)-293-2941 ext. 2494

E-mail: hartman@wvu.edu

Jennifer Barker Fulton, M.S.

Research Coordinator

West Virginia University

Wildlife \& Fisheries Resources

PO Box 6125

Morgantown, WV 26506-6125

Phone: (304)-293-2941 ext. 2321

E-mail: jebarker@mail.wvu.edu 